\title{
Student-Athletes' Experiences with Racial Microaggressions in Sport: A Foucauldian Discourse Analysis
}

Sae-Mi Lee

Follow this and additional works at: https://researchrepository.wvu.edu/etd

\section{Recommended Citation}

Lee, Sae-Mi, "Student-Athletes' Experiences with Racial Microaggressions in Sport: A Foucauldian Discourse Analysis" (2017). Graduate Theses, Dissertations, and Problem Reports. 7104.

https://researchrepository.wvu.edu/etd/7104

This Dissertation is protected by copyright and/or related rights. It has been brought to you by the The Research Repository @ WVU with permission from the rights-holder(s). You are free to use this Dissertation in any way that is permitted by the copyright and related rights legislation that applies to your use. For other uses you must obtain permission from the rights-holder(s) directly, unless additional rights are indicated by a Creative Commons license in the record and/ or on the work itself. This Dissertation has been accepted for inclusion in WVU Graduate Theses, Dissertations, and Problem Reports collection by an authorized administrator of The Research Repository @ WVU.

For more information, please contact researchrepository@mail.wvu.edu. 
Student-Athletes' Experiences with Racial Microaggressions in Sport:

A Foucauldian Discourse Analysis

Sae-Mi Lee

Dissertation submitted to the

College of Physical Activity and Sport Sciences

at West Virginia University

in partial fulfillment of the requirements for the degree of

Doctor of Philosophy

in

Sport and Exercise Psychology

Edward F. Etzel, Ed.D., Chair

Malayna B. Bernstein, Ph.D.

Samuel J. Zizzi, Ed.D.

Clayton R. Kuklick, Ph.D.

Brian T. Gearity, Ph.D.

Department of Sport Sciences

Morgantown, West Virginia

2017

Keywords: Microaggressions; Foucault; Intercollegiate athletics; Racial subjectivity Copyright 2017 Sae-Mi Lee 


\title{
Abstract \\ Student-athletes' Experiences with Racial Microaggressions in Sport: A Foucauldian Discourse Analysis
}

\begin{abstract}
Sae-Mi Lee
Despite growing research on racial microaggressions as a subtle but prevalent form of racial discrimination, research on microaggressions in sport and their effects on the psychosocial wellbeing of athletes is scarce. Moreover, some researchers question the legitimacy of microaggressions due to their subtle nature and the inconsistency among individuals in how microaggressions are experienced (Lilienfeld, 2017). The purpose of this study was to examine U.S. collegiate student-athletes-of-colors' experiences with racial microaggressions in sport through a new theoretical lens, Foucauldian poststructuralist theory. I theorized microaggressions as an example of the daily panoptic gaze that leads to self-surveillance and the production of normalized individuals (Foucault, 1995). Each of the eight student-athletes-of-color participated in two interviews: a two-person focus group interview followed by an individual interview. The interviews were first analyzed deductively using Sue's (2010) typology of microaggressions. A Foucauldian discourse analysis (Willig, 2013) was also conducted to identify the discourses that student-athletes-ofcolor drew upon to make sense of their microaggression experiences. The various racial microaggressions shared by the participants clearly illustrated how student-athletes-of-colors' experiences and subjectivities were racialized. However, the discourses they drew upon constituted how they made sense of their microaggression experiences. Within sport, the sport transcends race discourse was widely circulated and legitimized through various sporting practices. Within this discursive context, athletes were limited in their ability to perceive and acknowledge race and racial microaggressions. The results of this study shed light on how racial microaggressions manifest in the lives of student-athletes and how the discourses and practices that we take for granted constitute their racial subjectivities.
\end{abstract}




\section{Dedication}

To those who are constantly asked to "prove" that their experiences are real and valid:

This work is for you.

I see you. You matter.

You may not fit, but you belong. 


\section{Acknowledgements}

I would like to first and foremost thank my exceptionally supportive family. I could never have done any of this without you. Thank you for always being there for me and for having the most adorable pets that would "call" to cheer me up whenever times got tough.

I would also like to thank my incredible committee members who guided me through this challenging dissertation process. Dr. Ed, I know I did not make advising me easy! I am so thankful you did not give up on me (!) and were willing to patiently walk with me until the very end. Dr. Malayna Bernstein, I am the scholar that I am today thanks to your brilliant supervision and tireless support. I am so grateful I met you. Dr. Gearity and Dr. Kuklick, thank you so much for sharing your expertise and passion for Foucault with me. Learning Foucault was "fun," thanks to you both. Dr. Sam Zizzi, Zen master, thank you for helping me climb research mountain. The view up here is magnificent.

I am fortunate to have a wonderful support system. Thank you to the West Virginia University faculty, staff, and colleagues who taught me, guided me, and supported me throughout these past five years. I would also like to thank Ithaca College for supporting me as a Dissertation Diversity Fellow during my last year of dissertation writing. A special shout out to Dr. Janaina Fogaça, Aaron Goodson, Dr. Shuang Li, Dr. Anna Marie Jaeschke, Dr. Noora Ronkainen, Anna Kavoura, Dr. Marsha Nicole Horsley, Dr. Kayla Wheeler, Dr. Ashley Hall, and Dr. Justine Vosloo. How incredibly lucky am I to have friends and colleagues like you?

I would also like to express my sincerest gratitude to the participants of my study, who took time out of their very busy schedules to share personal and intimate details about their lives with me. Thank you.

Finally, I would like to thank all the courageous social justice scholars and activists who have worked tirelessly to shed light on, and bring justice to, society's margins. Thank you. I am encouraged and inspired by your work and I humbly follow in your footsteps to further the social justice agenda. 


\section{Table of Contents}

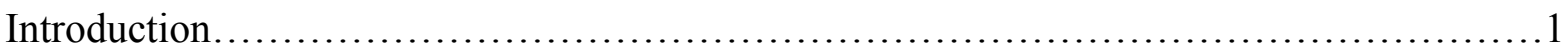

Racial Microaggressions in Everyday Life..........................................2

Racial Microaggressions in Sport...........................................

Foucauldian Poststructuralist Theorizing of Racial Microaggressions.....................6

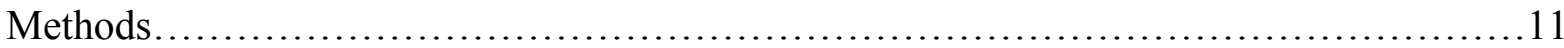

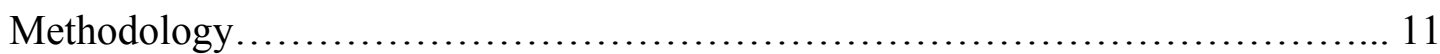

Participants and Recruitment............................................11

Interviews............................................................ 12

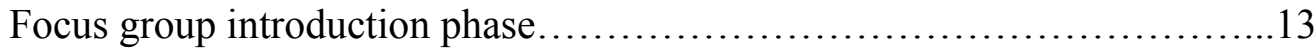

Focus group example phase........................................14

Focus group discussion phase..................................... 14

Individual interviews............................................... 15

Interviewed data.................................................. 16

Data Analysis............................................................... 16

Ensuring Quality in Poststructuralist Research.................................17

Results and Discussion.......................................................... 19

Student-athletes' Experiences with Racial Microaggressions in Sport................19

Microaggressions as reminders of racial subjectivities..................22

Discourses and Subjectivity Negotiations in Sport..............................24

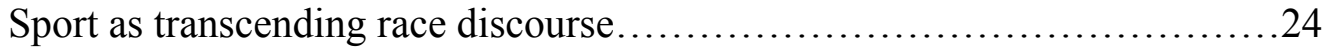

Post-racial society discourse ......................................... 31

Discourse of racism.................................................

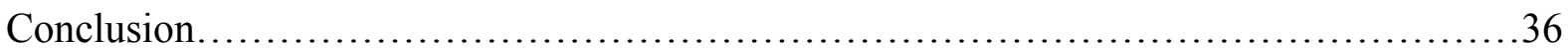

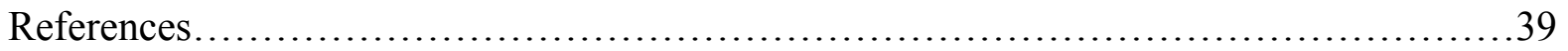

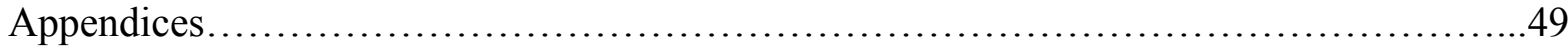


Appendix A: Extended Literature Review .49

Appendix B: Extended Theoretical Framework..................................69

Appendix C: Extended Methodology.........................................84

Appendix D: Focus Group Interview Script.................................94

Appendix E: Focus Group Interview Protocol.................................... 96

Appendix F: Individual Interview Protocol.......................................98

Appendix G: Questions for Foucauldian Discourse Analysis.....................101

Appendix H: Participant Recruitment Email - Student-athlete.....................102

Appendix I: Participant Recruitment Email - Student-athlete development staff.....103

Appendix J: Participant Recruitment Email - Coaching staff..................... 104

Appendix K: Informed Consent Form.......................................105

Appendix L: Resources for Participants.................................. 108

Appendix M: Extended References..................................... 110 


\section{List of Figures}

Figure 1: Categories of and Relationships among Racial Microaggressions.....................3 
Student-athletes' Experiences with Racial Microaggressions in Sport: A Foucauldian

Discourse Analysis

Researchers suggest that racism in the United States has not disappeared, but has become more subtle and insidious (Dovidio \& Gaertner, 2000; Pérez Huber \& Solorzano, 2015). One form of subtle discrimination that contributes to contemporary America's "racism without racists" (Bonilla-Silva, 2006, p. 13) is racial microaggressions. Racial microaggressions are "brief, everyday exchanges that send denigrating messages to certain individuals because of their [racial] group membership" (Sue, 2010, p. 24).

Microaggressions can be expressed verbally or nonverbally, for example, in the form of verbal slights or through dismissals of marginalized groups' experiences (Sue et al., 2007b). Researchers have found that various marginalized groups experience microaggressions and encounter them in diverse contexts such as in school, at the work place, and even in counseling settings (Wong, Derthick, David, Saw, \& Okazaki, 2014). Researchers explained that the effects of microaggressions were comparable to a "death by a thousand cuts" (Sue, 2010, p. 66). Although a single comment or incident can be ignored or overlooked, the constant, cumulative, and omnipresent nature of microaggressions can result in negative physical and mental health outcomes (Sue et al., 2007b) and lead individuals to perceive their surrounding environments as unwelcoming and hostile (Melendez, 2008; Solórzano, Ceja, \& Yosso, 2000).

Despite the growing research on microaggressions, especially racial microaggressions, the concept still remains controversial (Harris, 2008; Thomas, 2008). Critics argued that microaggressions promote a culture of victimhood (Campbell \& Manning, 2014), which produces psychologically weak individuals (Friedersdorf, 2015b) who cannot take a joke. Calling it "macro-nonsense" (Thomas, 2008, p. 274), researchers have also argued that the concept is priming people to become overly sensitive to the behavior of others 
and to adopt a victimhood mentality. Researchers have also pointed to the fact that there is a lack of consistency among individuals' experiences of microaggressions, leading some to question the legitimacy of microaggressions as to whether they really are a manifestation of racial discrimination or simply a misunderstanding (Harris, 2009; Lilienfeld, 2017). Previous research has been limited in being able to clearly theorize why perspectives differ so widely, leading to a critical question: Why might individuals, even those from the same racial minority group, have mixed or contradictory experiences with microaggressions? Moreover, additional theorizing seems warranted to explain why something as subtle as racial microaggressions can bring such significant negative consequences to the victims. Thus, both theoretical and conceptual refinement of microaggression research is warranted.

The purpose of this study was to examine the range of ways a sample of U.S.collegiate student-athletes experienced racial microaggressions through a new theoretical approach, Foucauldian poststructuralist theory. Foucauldian poststructuralist theory provides a way for researchers to understand why people interpret and experience microaggressions differently and why microaggressions, however subtle and seemingly innocuous, can be problematic. In this paper, I theorized that racial microaggressions are a manifestation of the panoptic gaze that leads to self-surveillance and normalized racial bodies. My three specific research questions were: (a) How do student-athletes experience racial microaggressions in sport?, (b) what are the discourses student-athletes draw upon to make sense of racial microaggressions?, and (c) how do student-athletes negotiate their racial identities and realities in sport in relation to this discursive content? In the following sections, I will provide a brief review of literature on racial microaggressions followed by an overview of Foucault's theoretical framework as it relates to better understanding racial microaggressions.

\section{Racial Microaggressions in Everyday Life}


First introduced in 1970 by Chester Pierce, researchers called racial microaggressions a modern day form of racism (Sue et al., 2007b). Also referred to as "microinequities" (Sue, 2010, p. xvi), microaggressions are characterized by their subtlety, which causes the victim as well as the perpetrator to be unaware of its occurrence at times. Although this subtlety makes racial microaggressions particularly complex for researchers to understand, Sue et al. (2007b) outlined three types of microaggressions that can affect interpersonal relationships: (a) microassaults, (b) microinsults, and (c) microinvalidations. All three types of racial microaggressions communicate the message that racial minorities are somehow less worthy and inferior to their White counterparts. The types and themes of racial microaggressions proposed by Sue (2010) are shown below on Figure 1.

\begin{tabular}{|c|c|c|c|}
\hline \multicolumn{4}{|c|}{$\begin{array}{l}\text { Commonplace verbal, behavioral, or environmental indignities, whether intentional or } \\
\text { unintentional, that communicate hostile, derogatory, or negative racial slights and insults to } \\
\text { people of color. }\end{array}$} \\
\hline Verbal Manifestations & \multicolumn{2}{|c|}{ Nonverbal Manifestations } & $\begin{array}{l}\text { Environmental } \\
\text { Manifestations }\end{array}$ \\
\hline $\begin{array}{l}\quad \text { Microinsult } \\
\qquad \text { (often unconscious) } \\
\text { Communications that } \\
\text { convey rudeness and } \\
\text { insensitivity and demean a } \\
\text { person's racial heritage. }\end{array}$ & \multicolumn{2}{|c|}{$\begin{array}{l}\text { Explicit racial derogations } \\
\text { characterized primarily by a } \\
\text { violent verbal, nonverbal, or } \\
\text { environmental attack meant } \\
\text { to hurt the intended victim } \\
\text { through name-calling, } \\
\text { avoidance behavior, or } \\
\text { purposeful discriminatory } \\
\text { actions. }\end{array}$} & $\begin{array}{l}\text { Microinvalidation } \\
\text { (often unconscious) }\end{array}$ \\
\hline \multicolumn{2}{|l|}{ THEMES } & & THEMES \\
\hline \multicolumn{2}{|c|}{$\begin{array}{l}\text { Ascription of Intelligence } \\
\text { Assigning a degree of intelligence to a } \\
\text { person of color based on their race } \\
\text { Second-Class Citizen } \\
\text { Treated as a lesser person or group. } \\
\text { Pathologizing Cultural Values/ } \\
\text { Communication Styles } \\
\text { Notion that the values and } \\
\text { communication styles of people of color } \\
\text { are abnormal. }\end{array}$} & $\begin{array}{l}\text { Belief that } \\
\text { citizens ar } \\
\text { Denial or } \\
\text { does not sc } \\
\text { Statements } \\
\text { minor role } \\
\text { Den } \\
\text { Denial of } \\
\text { its perpetu }\end{array}$ & $\begin{array}{l}\text { Alien in Own Land } \\
\text { isible racial/ethnic minority } \\
\text { foreigners. } \\
\text { Color-Blindness } \\
\text { etense that a White person } \\
\text { color as race. } \\
\text { Iyth of Meritocracy } \\
\text { that assert that race plays a } \\
\text { n life success. } \\
\text { l of Individual Racism } \\
\text { ersonal racism or one's role in } \\
\text { tion. }\end{array}$ \\
\hline
\end{tabular}

Figure 1. Categories of and Relationships among Racial Microaggressions (Sue, 2010, p. 29) 
Despite their subtle manifestation, researchers found that the stress resulting from chronic racial microaggression experiences can lead to negative biological, cognitive, emotional, and behavioral consequences (Sue, 2010). Microaggressions, as a chronic stressor, can lead to lower functioning of the immune system (Sue, 2010), negatively impact physical health outcomes (Wong et al., 2014), and increase mood disorders such as depression and anxiety (Donovan, Galban, Grace, Bennett, \& Felicie, 2013; Gomez, Khurshid, Freitag, \& Lachuk, 2011). Additionally, Salvatore and Shelton (2007) found that racial minorities showed a greater decrease in cognitive functioning when exposed to subtle microaggressions compared to overt forms of racial discrimination. This is because subtle forms of racism potentially require more "guesswork" (Sue, 2010, p. 101) on the part of the victim compared to overt discrimination, and that "guesswork" makes it more cognitively burdensome. Furthermore, microaggressions lead racial minorities to perceive their surrounding climate as hostile and unsafe (Grier-Reed, 2010; Melendez, 2008), which can lead to "hypervigilance and skepticism" (Sue, 2010, p. 103) or internalized racism as a way for racial minorities to cope with the status quo of White supremacy (Sue, 2010). Given the various negative consequences that can adversely impact individuals, it is a timely task for sport psychology researchers to examine how racial microaggressions manifest and impact those in sporting contexts.

\section{Racial Microaggressions in Sport}

Three studies have been conducted on the microaggression experiences of athletes. Jordan (2010) examined the racial microaggression experiences of Black college studentathletes and found that a unique microaggression that Black athletes experienced was having their athleticism attributed to their race (Jordan, 2010). Burdsey (2011) also found that British Asian male cricket players experienced racial microaggressions from a wide variety of sources such as teammates, fans, and even referees. Interestingly, the players expressed a 
tendency to minimize and trivialize their experiences despite recalling specific microaggression examples. Burdsey explained the athletes' (non)responses to the fact that the athletes were entrenched in a color-blind ideology, but further explanations are warranted as to why athletes would adhere to an oppressive ideology that does not directly benefit them. Comeaux (2012) also examined the microaggressions college student-athletes experienced due to their status of being a student-athlete such as verbal slights related to their intelligence or academic motivation. However, Comeaux did not look at racial differences and many of the participants surveyed reported no experiences with microaggressions.

Although these results suggest that athletes, especially athletes-of-color, may not be immune from subtle and overt forms of discrimination, some questions remain concerning understanding microaggressions. Researchers have not clearly articulated why there is such a wide range in the way racial microaggressions are understood. Not only did participants minimize the effects of microaggressions (Burdsey, 2011), but some did not even perceive microaggressions (Comeaux, 2012). Even more, Allen (2010) found that racial microaggressions were perpetrated, not only by White people, but also by racial minorities. Why are there such inconsistencies in experiences with microaggressions? Why do some people perceive them while others do not? Moreover, why do even people of color perpetrate microaggressions and violence against each other (Pérez Huber \& Solorzano, 2015)? It is timely that researchers consider a larger body of theory to understand the ambiguous, subconscious, and contradictory experiences related to microaggressions.

In this paper, I theorize racial microaggression through the lens of Foucauldian poststructuralist theory. There are two studies to date that applied Foucauldian poststructuralist theory to microaggressions. Murray (2013) theorized microaggressions as Foucauldian subjectivism to explain how students, especially students-of-color, are surveyed and corrected to fit the education system that centers on "white, middle-class value 
system[s]" (p. 62). Gearity and Metzger (2017) also applied a Foucauldian poststructuralist perspective to theorize how intersectional microaggressions manifest as a form of disciplinary power in sport coaching to produce normalized athletes. Although these studies offer initial theoretical insights and conceptual tools for analyzing disciplinary power that is fluid and omnipresent, additional studies examining how individuals negotiate their subjectivities in response to microaggressions are warranted. In the following section, I will outline the main principles of a Foucauldian poststructuralist approach and how it can be applied to theorizing racial microaggressions.

\section{Foucauldian Poststructuralist Theorizing of Racial Microaggressions}

Some researchers have criticized microaggressions as an empirical construct due to the inconsistent nature of peoples' experiences with them (Lilienfeld, 2017). Researchers found that not only are the effects of microaggressions dependent on the situation and context (Sue et al., 2007b; Wong et al., 2014), but some racial minorities also reported a tendency to minimize their effects (Burdsey, 2011). Due to the variability in how individuals make sense of them, it has been difficult for researchers to understand what is and is not a microaggression (Lilienfeld, 2017; Wong et al., 2014). When applying the lens of Foucauldian poststructuralist theory to microaggressions, however, the multiple, often contradictory, experiences related to microaggressions can be explained.

Poststructuralist theorists adhere to a relativist ontological assumption that there are multiple realities and that these realities are all partial, fragmented, incomplete, incoherent, and often even contradictory (Markula \& Silk, 2011). Moreover, although poststructuralists acknowledge a material reality outside of language, they posit that it is through language that physical reality acquires meaning (Weedon, 1997). Poststructuralists explain that we enter a world that is already interpreted and learn to make sense of the world, our experiences, and ourselves in particular ways through discourse (Crotty, 1998). Thus, rather than reflecting our 
reality, Foucauldian poststructuralist theorists posit that language and discourse, "ways of knowing" (Markula \& Silk, 2011, p. 49), constitute our reality. In other words, we see the world and ourselves based on socially constructed ways of knowing (i.e., through discourse). We see what we see not because it is the universal truth, but because it is what we know to see and look for.

From Foucauldian poststructuralist theory, then, the fact that there are multiple and often contradictory ways of understanding microaggressions does not delegitimize the concept; there will always be multiple interpretations. Rather, by focusing on examining the discourse used to construct particular ways of knowing and being, Foucauldian poststructuralist theory can help researchers examine the variability and how individuals come to their different interpretations.

Examining the discursive resources available to make sense of microaggressions is important because discourses not only constitute one's reality but also one's sense of self (Kavoura, Ryba, \& Chroni, 2015; Mcgannon \& Busanich, 2010). Although we often think of one's identity as inherent and fixed, Foucault considered identities, or what he called subjectivities, as something that is constantly changing and being (re)negotiated based on the discourses we have available to us. Subjectivity is "the conscious and unconscious thoughts and emotions of the individual, her sense of herself and her ways of understanding her relation to the world" (Weedon, 1997. p. 32). Foucault made a conscious and intentional terminology shift from using identity to subjectivity to reflect his theorizing of identity as socially and discursively constructed (Markula \& Silk, 2011) rather than inherent and fixed. These assumptions decenter humans as rational and conscious beings and, instead, theorize humans as "the product of the society and culture within which we live" (Weedon, 1997, p. 32). 
Although Foucault's theorizing of subjectivity sounds deterministic, as he saw discourse as constituting our subjectivities, Foucault also discussed how we, as subjects, have agency to negotiate between multiple discourses (Gutting, 2005). This is because, within discourse, subjects are offered a subject position, which is "a location for people in relation to dominant discourses, associated with specific rights, limitations and ways of feeling, thinking and behaving" (Weedon, 1996, p. 3). Because there are always multiple, often competing, discourses, individuals constantly negotiate to take up or resist the subject positions offered within discourses to negotiate their subjectivities.

As discourse constitutes the way one sees and understands the world as well as one's self (i.e., subjectivity), it has implications for power (Willig, 2013). Despite adhering to a relativist ontological assumption that truths are multiple, this does not mean all are considered equal and legitimate (Weedon, 2008). Some discourses become more dominant and widely used than others as discourse(s) "legitimate and reinforce existing social and institutional structures, [while] these structures in turn also support and validate the discourses" (Willig, 2013, p. 130). Eventually, some discourses become so dominant that they become taken-for-granted notions of truth; they appear to be common sense ways of understanding so they appear to be difficult to challenge or change (Weedon, 2008). These socially legitimized discourses 'determine what is considered 'normal' in a setting, who belongs, who is allowed to participate and who is not" (Dortants \& Knoppers, 2012 p. 537).

Foucault (1995) theorized that this is how power worked in modern society. Rather than a powerful other (e.g., monarchy) punishing and torturing people for their socially determined deviance, Foucault theorized that some socially determined ways of being and knowing become more dominant than others and, in turn, these dominant discourses produce legitimate ways of being and knowing in the world. When power is no longer centralized but dispersed, not through force, but through discourse; Foucault (1995) called this discursive 
power. From the lens of Foucauldian poststructuralist theory, systems of inequality such as racism are not only upheld by the conscious and intentional harm caused by powerful other, but through our everyday language and normalized ideas (Foucault, 1995).

Discursive power is an efficient way of exercising power because it is subtle and omnipresent, but productive (Foucault, 1995). Foucault theorized that Jeremy Bentham's architectural design of a prison system, the "Panopticon" (Foucault, 1995, p. 200), represents such a disciplinary society that produces, within individuals, the effect of being exposed to a subtle, but pervasive and omnipresent gaze. The panoptic gaze leads individuals to (sub)consciously internalize societal norms and disciplinary practices. Subsequently, society can produce "normalized citizens" (Wilchins, 2004, p. 960, emphasis in original), who work to achieve normality out of fear of appearing abnormal. Through the presence of the panoptic gaze, discursive power is exercised with a "problematic efficiency" (Markula \& Pringle, 2006, p. 43), as it leads to the automatic functioning of disciplinary power where individuals self-survey and correct their own deviance, even in the absence of powerful others. Because disciplinary power is productive, difference can be prevented, rather than punished, "not by authorities, but by individuals themselves, and not just intermittently when in public, but continuously, in private as well” (Wilchins, 2004, p. 994).

Consistent with Foucauldian poststructuralist theory, examining everyday language such as microaggressions becomes essential because language is neither innocent nor neutral. Normalized language such as microaggressions not only reflect dominant racial discourses, but also (re)produce them, which constitutes who and what we consider 'normal' in society. In this study, I theorize that microaggressions are an example of the panoptic gaze that reminds the individual of their deviance from societal norms. By subtly penetrating to the minutest avenues in society and reminding individuals of their racialized deviance even in their most private or random spaces, microaggressions can contribute to producing, what 
Foucault (1995) called, obedient and useful "docile bodies" (p. 135). Such theorizing of microaggressions provides an alternative explanation for why people of color may subconsciously participate in their own subjugation as to avoid "the range of micro-penalties associated to deviations from the 'norm'” (Markula \& Pringle, 2006, p. 44).

As discursive power is everywhere and nowhere and (re)produced through everyday speech, microaggressions cannot or, rather, should not be brushed off (Weedon, 1997). Rather, I theorize that microaggressions are an instructive way to examine and problematize our normalized ways of talking and thinking about race. "For Foucault, it was the processes of ongoing critical thought - problematizing - that would enable researchers to find more instructive ways of seeing the 'things' that society often assumes to be self-evident" (Mills, 2014, p. 39). The goal of a Foucauldian poststructuralist theorizing of microaggressions, then, is not to make clear categorical distinctions between what constitutes an overt discrimination versus a microaggression versus an innocent joke (e.g., asking what is and is not a microaggression). Rather, researchers can move beyond the question of what is and is not a microaggression to examining "whom does discourse serve" (Markula \& Pringle, 2006, p. 48) when everyday language surrounding race such as racial microaggressions is normalized.

In summary, racial microaggressions have emerged as a way of understanding how racism manifests in everyday life (Sue et al., 2007b), but have scarcely been examined in sport settings. Moreover, despite growing research on microaggressions, they remain misunderstood due to their subtle manifestation and the inconsistent experiences people have with them. Theoretical refinements to the construct of microaggressions could help us explain and understand the contradictions surrounding what microaggressions are and why they are worthy of study. In this study, I apply Foucauldian poststructuralist theory to theorize racial microaggressions. Although there are multiple Foucauldian concepts that help explain how discursive power is exercised and resisted such as technologies of discipline (Gearity \& 
Mills, 2012; Jones \& Toner, 2016) or technologies of self (Crocket, 2017; Markula, 2003), the focus of this paper was to examine the panoptic effects of dominant discourses to studentathletes' subjectivities. Thus, I examined the discourses student-athletes drew upon to make sense of racial microaggressions and examined how student-athletes' negotiated their subjectivities within the discursive context of U.S. collegiate sport.

\section{Methods}

\section{Methodology}

The methodological approach for this study, informed by a social constructionist paradigm and Foucauldian poststructuralist theory, is Foucauldian discourse analysis (FDA). Adhering to a constructionist epistemology, I theorized that we see what we know and how we see the world is produced as well as limited by the cultural meanings and interpretations available to us. Thus, knowledge construction has power implications because those cultural meanings and interpretations are constructed and circulated through language and discourse produce particular realities and subjectivities. Thus, I focused on discourse as a way to access meaning(s) and truth(s) that inform participants' experiences with microaggressions. Using a Foucauldian approach to discourse analysis, I examined how power operates within and via language and how power and language constitute participants' reality and sense of self relative to racial microaggressions in intercollegiate athletics.

\section{Participants and Recruitment}

Eight student-athletes were recruited for this study. The number of participants offered variability in the range of ways student-athletes negotiate and make sense of their microaggression experiences, but also made the data feasible for an in-depth analysis (Markula \& Silk, 2011). Participants were selected for this study using purposeful criterion sampling. The minimum criteria for participation was: to be a student-athlete representing a National Collegiate Athletic Association (NCAA) Division I sports team, and to have trained 
for at least one semester with their team. These criteria were established so the student-athlete would be familiar with their sport/team culture and have experience navigating both school and intercollegiate sport. Moreover, student-athletes who self-identified as belonging to a racial minority group were recruited to examine the range of ways student-athletes can experience racial microaggressions. After approval from the Institutional Review Board, I identified 129 student-athletes who could potentially identify as a racial minority from the picture roster of a NCAA Division I mid-Atlantic land grant institution's website. Studentathletes were invited to participate in this study via email and various members of the athletic team staff were also contacted asking for their cooperation in participant recruitment. The recruitment email (see Appendix H - J) was sent out three separate times one to two weeks apart. Once there were enough participants to arrange a focus group interview, I emailed the student-athletes and chose a time that best worked for them. Participants were informed that the focus group interviews served an informational purpose and would help them with their individual interviews. At the end of the focus group, I scheduled a follow up interview with each participant.

Two athletes identified as bi-racial (e.g., Black, Asian, Hispanic), four athletes identified as Black/African American, and two athletes identified as Asian/Asian American. Three participants were international students representing each of the following three continents: Asia, Europe, and North America. The other five participants were from the U.S.A. Seven participants were female athletes and one participant was a male athlete. Each participant played a sport - either soccer, golf, gymnastics, or volleyball. The age range of the participants was 18 to 20 years old.

\section{Interviews}

Participants participated in two separate interviews: (a) a focus group interview and (b) an individual interview (the interview protocols can be found in Appendix E \& F). 
Because I was focused on accessing the discourses participants drew upon to make sense of their racial microaggression experiences, I had to elicit participants' talk surrounding race and racial microaggressions. Thus, I used semi-structured interviews with open-ended questions about their experiences in sport and their thoughts about, experiences with, and responses to microaggressions. Markula and Pringle (2006) suggested that those who apply poststructuralist analysis remain flexible in their questioning to accommodate new or unexpected information or situations.

The purpose of starting with a focus group interview was to introduce participants to the concept of microaggressions and provide space for participants to reflect on their understanding and experiences with them. This was because participants may not have had the language to either make sense of or describe microaggression experiences due to the newness as well as subtlety of the concept. Moreover, some researchers have suggested that focus groups are ideal for critical research because focus groups disrupt the power between the researcher and the researched (Liamputtong, 2006; Madriz, 2000; Wilkinson, 1999). Although the researcher inevitably has the power to focus the content of the interview, the researcher has less control of the conversation in focus group settings compared to individual interviews (Madriz, 2000). Although the goal was to have four participants per focus group, I conducted two-person focus groups due to scheduling conflicts of the participants. The focus group interviews were organized into three phases: (a) an introduction phase, (b) an example phase, and (c) a discussion phase.

Focus group introduction phase. The purpose of phase one was to introduce the participants to each other and create a comfortable environment. I purposely used broad and open-ended questions about the participants' identity and experiences as a student-athlete so that each participant could choose what to discuss and emphasize. I sequentially asked the 
participants to describe who they were, what it was like to be a student-athlete, and what it was like to be a student-athlete-of-color.

Focus group example phase. The purpose of phase two of this investigation was to focus the interview on racial microaggressions. Because microaggressions are still a novel concept, I first provided brief examples of microaggressions that have been documented in real life. Participants viewed a collection of photos from the I, too, am Harvard/Princeton/ Oxford campaigns, which is a collection of photos from racial minority students expressing their personal experiences of being different/treated differently due to their race (e.g., https://itooamharvard.tumblr.com). I purposely chose a collection of photos that included various genders and races. Although I selected photos that I believed exemplified the construct of microaggressions, I did not label them as microaggressions during the interview. Rather, I referred to them as examples of experiences of racial minority students. Participants had the opportunity to ask clarifying questions about the examples.

Focus group discussion phase. The purpose of phase three was to elicit participants' talk surrounding microaggressions by reflecting on the photo examples of microaggressions. Participants were asked to discuss their thoughts and reactions related to the photo examples described above. Participants were also asked to share their own experiences that appeared similar or related to the photo examples. Participants were asked how these experiences may have affected them in the past and in the present.

Although I provided photo examples of racial microaggressions, the participants were exposed to additional examples and ideas by listening to fellow participants, in addition to the researcher (Madriz, 2000). Discussing microaggression experiences in a group setting helped participants gained exposure to various ways of talking and thinking about microaggressions. Previous research supports the use of focus groups to discuss subtle discrimination experiences; studies found that hearing others' experiences helped participants recall their 
own experiences with subtle forms of discrimination (Cooper, 2015; Melendez, 2008;

Solórzano et al., 2000). The variety of examples also allowed me to inquire about the complexities regarding microaggressions; I could note and probe further on each participant's experiences. For this phase, however, I also informed participants that, since there are limits to confidentiality in focus groups, they could choose to be silent if they preferred.

Individual interviews. The purpose of the follow up interview was to allow participants to speak in more depth about their microaggression experiences. Open-ended semi-structured interviews were conducted one week after the focus group interview. The week between was intentionally designed to offer participants enough time to further reflect on their experiences, but not too much time that they forgot what was discussed in the focus group interview. At the beginning of each individual interview, the participant received a one-page summary of the focus group discussion. The participant was invited to read through it and comment on, correct, change, or add to my summary of the focus group. This form of member checking lessened the burden on the participants to read through an entire transcript, but still allowed them to see how I as the researcher was organizing the focus group interview and documenting their input. The summary also prompted participants to remember the focus group and allowed me to follow up on participants' focus group experience, inviting them to share thoughts that they were unable or unwilling to share, or to discuss additional insights they have had since participating in the focus group. Participants were subsequently asked about their experiences in sport and microaggressions in more depth, by asking them about how microaggressions affected them. Specifically, I asked about how they felt, what they were thinking, and how they behaved in response to microaggressions to examine the discourses that were informing participant's understanding of their microaggression experiences and the subsequent effect of those discourses on participants' understanding of themselves. 
Interviewed data. All interviews were audio recorded using a digital recorder. Participants chose pseudonyms to help ensure confidentiality in the tape recordings. Both types of interviews were conducted in a private classroom at the university to ensure easy access for participants. The focus groups took approximately 60 minutes. The individual interviews ranged from approximately 60 to 120 minutes. The interviews were transcribed verbatim to capture, at times, the incoherent and choppy nature of discourse and speech (Markula \& Silk, 2011). I also took analytic memos throughout data collection, transcription, and analysis to facilitate researcher reflexivity, which is an important step for ensuring quality in poststructuralist studies (Avner, 2014; Mills, 2014). Once all the interviews had been completed, I transcribed half of the interviews and a transcription agency transcribed the other of the interviews to be efficient with time.

\section{Data Analysis}

First, I identified all the ways participants explicitly and implicitly referenced racial microaggressions. Because "the fact that a text does not contain a direct reference to the discursive object can tell us a lot about the way in which the object is constructed" (Willig, 2013, p. 131), I went beyond a keyword search of the term microaggressions to identifying all texts referencing race in the widest sense. Then, I used Sue et al.'s (2007b) typology of microaggressions (i.e., microassaults, microinsults, microinvalidations) as codes to deductively analyze the data. When some microaggressions did not fit into Sue's typology, I analyzed the data inductively to identify commonalities between these microaggressions to create a new microaggression theme.

I also applied Foucauldian discourse analysis (FDA) to examine the effects of discourse and power on participants' understanding of racial microaggressions and themselves. This analytic approach was consistent with the theoretical lens of this study because I theorized that "power is actually produced by discourse... [because] the way in 
which we talk about things has implications for the ways in which we experience the world, both physically and psychologically" (Willig, 2013, p. 138).

Willig's approach to FDA was instructive for the purposes of this study because it offered theoretical constructs that helped me identify the relationship between discourse and their implications to subjectivities. Willig's approach to FDA focuses researchers' attention to the following six theoretical constructs: (a) discursive constructions, (b) discourses, (c) action orientation, (d) positionings, (e) practice, and (f) subjectivity. Although I looked for each of these constructs within my data, I modified the order of Willig's approach because I had considerable data about participants' positioning and subjectivity within my data, due to the purposeful questioning during data collection. Moreover, I looked at the constructs of positions, practice, and subjectivity concurrently rather than sequentially because these constructs were interconnected rather than mutually exclusive. Once I identified participants' discursive constructions of both microaggressions and their subjectivities, I identified the wider societal discourses and the institutional context they were situated in.

\section{Ensuring Quality in Poststructuralist Research}

As a poststructuralist researcher, I adhered to a constructionist epistemological and relativist ontological view of knowledge and reality. This means poststructuralists follow a different process of research validation from traditional validation procedures of positivism/postpositivism, such as bracketing or triangulation to verify representative truths (Markula \& Silk, 2011). Rather, Markula and Silk (2011) suggested poststructuralist researchers "place less significance on detailed, 'procedural' judgement criteria and call for a more in-depth, theoretically driven, yet practically applicable, socially situated knowledge production process" (p. 220).

To socially situate knowledge production, poststructruliasts researchers engage in self-reflexivity of how they are co-constructing knowledge, as poststructuralists assume that 
knowledge is co-constructed by the researcher's consciousness (Mcgannon \& Busanich, 2010; Mills, 2014). Researcher reflexivity means “carefully writing oneself into one’s research" (Avner, 2014, p. 79) and acknowledging and reflecting on the ways one's own knowledge and experiences shape their research questions, processes, analyses, and presentation. In poststructuralist research, researcher co-construction is not seen as a limitation, but an inevitable part of knowledge construction. The goal of researcher reflexivity, then, is not to try to legitimize the researcher's analysis as more truthful or objective. Rather, the goal is to document and contextualize the research process by informing the reader of the researcher's lens, which, in the case of this study was designed to align with a Foucauldian poststructuralist theoretical approach. Viewing the phenomenon and data from multiple angles and perspectives offers a crystallized (Ellingson, 2008; Mills, 2014; Richardson, 2000) understanding of microaggressions, which is more consistent with the philosophical assumptions of poststructuralism.

The analytic memos that were taken during data collection and analysis served as a tool to facilitate research reflexivity. I engaged in a cycle of "going back to the data, Foucault's theories and my emerging analysis" (Mills, 2014, p. 84) in order to understand my analysis in various ways. I attempted to make sense of how I was collecting and interpreting the data by asking, 'how do I know what I know/see?' by going back and forth from Foucault's theoretical concepts to the data and going back and forth from my analytic memos to be critically reflective of why I did what I did and how. Ellingson (2008) argued that self reflexivity of the researchers' role within the research process provides "far more rigor than pretending my subjectivity does not exist or has been somehow eliminated from the process of my research" (pp. 183-184, emphasis in original).

Ann Oakley famously said, "a way of seeing is also a way of not seeing" (Crotty, 1998, p. 55). There will always be additional and alternative ways of seeing and knowing, but 
the following results and discussion provide one particular theoretical understanding of student-athletes' experiences with racial microaggressions in sport. Given the novelty of the topic and theoretical approach of this study, the purpose of this study was to be exploratory.

\section{Results and Discussion}

The purpose of this study was to examine the range of ways U.S. collegiate studentathletes experienced racial microaggressions. In the following section, I first discuss the racial microaggressions student-athletes-of-color shared. Although I tried to focus the interviews, especially the follow up individual interview, on how race entered sporting contexts, the participants reported experiencing various forms of microaggression in all the contexts they navigated including in school, the community, online, as well as in their sport. In this paper, I only described the data related to the racial microaggressions student-athletes experienced in athletics.

\section{Student-athletes' Experiences with Racial Microaggressions in Sport}

Even before I shared examples of microaggressions during the focus group, some participants described experiences that could be characterized as microaggressions as defined by Sue et al. (2007b). For example, Jade described her experiences as "it's little things that like a Black person might notice more than a White person because they wouldn't realize or think about that." Although none of the participants had heard of the term racial microaggression before, all the participants in this study reported various verbal and nonverbal communications that could be characterized as racial microaggressions. Once exposed to different microaggression examples, all the participants reported that they were relatable experiences that were present throughout their lives.

Consistent with previous microaggression research, there were racial differences in the types of microaggressions the participants experienced (Constantine \& Sue, 2007; Johnston \& Nadal, 2010; Nadal, Wong, Sriken, Griffin, \& Fujii-Doe, 2015). For the 
Asian/Asian-American student-athletes, others frequently assumed they were academically oriented. Moreover, their academic achievements were attributed to their race rather than their effort. Henry, an Asian athlete, observed that his classmates would try to sit around him in math and science classes, even when he was the one who missed classes due to competitions. When he did not perform well, sport staff such as academic advisors had made comments such as, "we recruited you because you are good at sport and you are good academically. Are you partying a lot? Because [school name removed] is a party school?" Lucy, an Asian American athlete, also noted that teammates frequently requested her help during study hour. She noted receiving comments from teammates, "Oh Lucy will help us meet our team GPA. She can get us that. We're good." These microaggressions could be categorized as microinsults, as they are attributing one's intelligence to one's race (Sue, 2010). Whether the participants perceived these examples as microaggressions, however, was dependent on the discourses they drew upon to make sense of their experiences, which will be described later in the document.

In addition to race-based assumption about their intelligence, participants in this study experienced race-based assumptions about their physical and athletic abilities. Asian/AsianAmerican athletes faced negative racial stereotypes related to their physical and athletic abilities. Henry, the only male athlete in this study, shared experiences that could be characterized as microassaults, which are more overt forms of microaggressions (Sue et al., 2007b). For example, the strength coach would comment, "my 2-year-old daughter could lift more than you, you little Asian!" as a way to motivate him during his lifting sessions. Lucy, an Asian American athlete, reported that she heard peers comment that "she's just good [at basketball] because her dad is Black" even though Lucy was monoracial. Although not about physical ability, a microassault that Henry experienced was being called a "yellow monkey" by a teammate and opponents. 
Most microaggressions about athletic and physical abilities were more likely to be delivered in the form of a microinsult. Sarah's coaches also commented that "she can't jump that high" because she was shorter and, at times, advised her to be more technical than physical in her playing style. As Sarah was biracial, she noted her coaches also encouraged her to "be more Latin American" when they wanted her to be more physical and aggressive. These comments could be characterized as microinsults since they are based on racial stereotypes that Asians are docile and Latina/os are emotional and aggressive (Sue, 2010). Henry also observed that strangers who would approach him on the field sometimes asked whether his team had to order special shirts for him because he was Asian, even though he was similar in size with most of his White teammates.

Black/African-American athletes also navigated expectations related to their athletic abilities. These findings were consistent with previous research findings on stereotypes and micraggresson experiences of Black athletes (Cooper, 2015; Hackett, 2013; Jordan, 2010). All the Black/African-American athletes in this study reported hearing variations of comments such as "Of course you're fast. You're Black!” or "When Black people lift, they gain muscles so much faster." Their athletic abilities were often attributed to biology; Katy was taught that "Black people have like more muscles like mass" in high school and one of her trainers expected her to recover more quickly from an injury due to this fact. Their dancing abilities were also attributed to their race.

Moreover, all the Black/African American athletes reported taking safety into consideration when navigating different spaces. For example, all female athletes checked whether there were other athletes-of-color on their teams before committing to the university, which served as an indicator of whether they would be safe and welcomed. Kiya and MJ also explained how they would be cautious of the locations their team bus stopped at during team 
travels, but their White teammates were unaware and would ask them to go in stores or gas stations with them.

The Asian/Asian-American athletes, consistent with previous research on Asian Americans (Sue, Bucceri, Lin, Nadal, \& Torino, 2007a), frequently had to respond to variations of the question, "Where are you really from?," which Sue et al. (2007a) described as a microinsult. Sally described how people often asked, "are you Chinese?" rather than asking her ethnicity. Sarah also reported being referred to as Chinese or other ethnicities by acquaintances and even teammates even though she had explained her ethnicity multiple times. Henry was often asked, by sport staff and opponents, whether he was in the country legally or illegally. When people learned that Sarah, who was from Canada, was an international student, they often assumed or joked that she was from Mexico and had "hopped the fence," not from Canada.

The participants in this study described that most sport-related microaggressions occurred during off-the-field settings such as during team dinners or during trainings. Sally reported that her teammates made jokes based on racial stereotypes during team dinners such "We saved you some watermelon/fried chicken. We know you love watermelon/fried chicken.” MJ, who was biracial, also described how, growing up, her peers or teammates would not know she was biracial and, when they did not see two Black parents, her teammates and peers assumed that her parents were unsupportive of her. Jade also heard teammates make comments about her hair such as "Whew! Like I'm so glad my hair is just straight." These could be characterized as microinsults as they are pathologizing the athletes' racial and/or cultural backgrounds.

Microaggressions as reminders of racial identities. The participants in this study reported a type of microaggression that could not be characterized using Sue's typology of microaggressions. Although racial microaggressions have been described as (in)directly 
communicating a message that people of color are inferior to White people (Sue, 2010), participants in this study constructed a type of microaggressions that was more subtle and nuanced and could not neatly be characterized within Sue's typology, as they were not (in)directly insulting or invalidating.

Some athletes constructed microaggressions as events that served as a reminder of their racial identity. These athletes reported perceiving incidents as microaggressions when people "made it about race" when it did not have anything to do with race. For example, Jade observed that people would frequently comment that they knew of Gabby Douglas when she shared that she was a gymnast. She described how it was annoying because she not only hears it frequently, but because she felt that "they are just trying to group people together." Reference to Gabby Douglas was a reminder to Jade that, when others saw her, they saw not just a gymnast, but a Black gymnast. Henry also noted that he was often referred to as "hey Asian" by his strength and condition coach and peers. He reported that while he did not feel that it was offensive, he wanted to be called by his name rather than his race like all his other teammates. Sally also described that, although race was not at the forefront of her awareness in sport, occasionally, she said she would hear a comment and that could "bring me back to reality or something."

In summary, participants from this study reported experiencing racial microaggressions on their sport, in classrooms, online, and in their community. These results were consistent with previous research findings that students-of-color had to learn to navigate the multiple spaces they encountered (Solórzano et al., 2000; Yosso, Smith, Ceja, \& Solórzando, 2009), but added additional dimensions of online and sporting contexts. Although these examples clearly demonstrate how student-athletes' experiences, in and out of sport are racialized, the participants did not always perceive the above examples as microaggressions, especially in sport. 


\section{Discourses and Subjectivity Negotiations in Sport}

Through a Foucauldian approach to discourse analysis, I identified three discourses that student-athletes drew upon to make sense of their racial microaggression experiences: sport transcends race discourse, post-racial society discourse, and discourse of racism. The multiple, competing, and contradictory discourses offered various subject positions that participants took up or resisted to negotiate their subjectivities.

Sport as transcending race discourse. Within sport as transcending race discourse, the idea that sport is a meritocratic space where athletes can participate, experience, and succeed irrespective of their race was circulated. Although the participants in this study acknowledged various ways their experiences were racialized both in society and in sport, they heavily drew upon the sport as transcending race discourse to make sense of their racebased experiences in sport. MJ pointed to the presence of various races in sport as evidence that identities do not matter in sport:

I feel like sports is the great equalizer with that [race]... even now, we have boys on the team that are mixed and African-American, and they fit in well, and people support them. So, I feel it's no longer about what I look like, what I. It's all about what jersey I'm wearing, what team I'm on, and like where you're going.

MJ also described how being a team leads you to embrace your teammates regardless of their identities:

The love we have for each other as a team, as a support, and I think the love, the connection you feel for your teammates outweighs any racial, LGBT, any of that.

Like, because at the end of the day, I know you have my back on the court, and I have yours, and that's all that really matters.

Sally, despite explaining earlier in her interview that she would never "act like a Black person in front of White people" or approach a White person she did not know, also 
explained how sport was an exceptional space where race did not matter:

It was different because like, they [teammates] all like me because we're a team now, and they know I'm going to be here for four years and you have to like me or like, you know, we're going be playing with each other. We got to have a connection. So, you have to be my friend. You know?... You want to like jump in and like love your teammates, or just have a connection with them, so you guys then have that same connection on the field or on the court or something.

The sport as transcending race discourse was emphasized by the coaching staff as well as the university athletic department as necessary to perform well. The participants observed their coaches describe that they "don't see color" and expected the athletes to unite as a team regardless of race, nationality, personality etc. Sally described how this message was communicated:

Our coach like stresses the fact that this team is a family, so like we have like everyone else is back home, wherever you live, so these are the people you need to talk to if you need help, and you need to talk to our coach because she's like our mom. You know?... And she [coach] like stresses like family and stuff because this is the, your home away from it. You need to like, like it and accept all these people on your team, because they're not going anywhere.

Not only did the coaches and administration reiterate this message, but they also reinforced this discourse of transcending race through various techniques of discipline (Foucault, 1995). For example, the coach/athletic staff determined the athletes' living spaces and schedules, engaged in various team building activities to build cohesion, and used team punishments for individual mistakes. Kiya noted how the team was encouraged to see beyond race to identify as a team first by the coaches and administration: 
Especially, because they [coaches] kind of make it that way... like when you see them all the time, like have fall with them, spring with them, [laughs] summer with them. So, it's kind of like you can't get away from them type of thing. And so, um, and then you pretty much, you have like schedule, like pretty much all your scheduling is done by the coaches, and then you have mandatory like team time where you have like a team dinner, and then you have like team activities, where you like do stuff outside of volleyball to kind of help with the chemistry and stuff.

As a result, all of the participants discussed how this set up of intercollegiate sport led them to perceive their athletic and personal lives as indistinguishable. MJ explained:

You live with them and everything. So your life changes. I feel like college is such a life changing thing, and you change with the same people. So, you like. We room together and stuff like that. And you so come in with the people, and you leave with the same people. So it's just kind of like, it's, it's one because then you have, you really don't have a choice, but to like, they become your family. And that's like kind of how college sports is. And then so there really is no separation. Well, at least in that aspect, pertaining like your personal life and your athletic life. They [coaches] put, it's required because they make, they make it. So, um, like they talk to whoever runs the dorms and stuff, and like they set you with a roommate that's on the team. The participants also explained how the goal of sport, winning, superseded everything else including race. They explained, "fans will cheer for you regardless of your race" and that "coaches will recruit the best players regardless of race as long as they help them win," which they perceived as evidence that racial microaggressions or other forms of racial discrimination did not occur in sport. In other words, harboring negative attitudes or beliefs based on race was seen by the participants as incompatible with the goals of winning. These findings were consistent with Brown et al.'s (2003) explanation for how the emphasis of 
winning in sport contributes to creating a true homogenous in-group in sport where the goal of winning was perceived as transcending all other matters. Kiya explained how the goal of sport, winning, supersedes race:

So, like I've never really experienced that [racial discrimination] either 'cause I mean everyone, when you start playing sports, the color doesn't matter. Because I mean, if you think about it, football, all football teams, all basketball teams, a majority are Black. [Laughs] And so, I mean, at that point, I feel like that's the only time that race doesn't matter because they want their team to win, and they don't really care who, who, who is doing whatever, as long as they're winning games... It's how good are you at your sport? Are you a good athlete? How are you going to win games?

The sport as transcending race discourse had several implications to student-athletes' understanding of microaggressions and themselves. Within this discourse, participants were offered the subject position of an athlete who transcends race. From this subject position, participants did not have access to language to make sense of their microaggression experiences or racial subjectivities because they had to transcend race in order to take up the subject position. Within this discourse, race, let alone racial microaggressions, were considered absent in sporting contexts. Participants in this study generally were most able and willing to recall microaggression examples from the distant past or from non-sport settings compared to sport settings.

Moreover, despite researchers finding that people of color rarely minimize the effects of racial discrimination (Bonilla-Silva, 2006; Sue, 2010), even when the participants acknowledged various race-based incidents in sport, the participants largely minimized their racial microaggression experiences. From a Foucauldian poststructuralist perspective, the participants' adherence to dominant discourse and minimizing racial microaggressions are explained, not because victims felt powerless to resist or challenge the dominant ideology, 
but because discursive power is productive. Participants in this study negotiated their subjectivities to what is normative within the discursive context of sport, which was to identify as an athlete first and transcend other subject positions such as race.

Drawing from the sport as transcending race discourse, seeing the influences of race in sport was seen as a personal problem of being a bad athlete who did not put the success of the team and sport first. This led participants to self-survey themselves to transcend race in sporting contexts. For example, Kiya and MJ described how the White teammates had noticed that the athletes were often sitting in their own racial groups during team meal times. Because their team's racial demographic was almost split in half between White athletes and athletes-of-color, Kiya and MJ explained it was more noticeable. In response, the participants described how the athletes-of-color apologized and committed to "fixing the issue" of the Black athletes sitting together. This was somewhat contradictory with what Kiya and MJ were saying earlier in the interview about how they enjoyed socializing with other athletesof-color because they felt a sense of connection and community. Although the participants did not perceive the White teammates comments of, "do you guys realize you are all sitting together?" as a microaggression, it acted as a panoptic gaze to remind the athletes-of-color of their deviance from the sport norm, which was to transcend race and be an athlete first. Within the sport as transcending race discourse, Kiya and MJ took on the subject position of a race-less athlete, which subsequently shaped as well as limited their ability to see race including issues of racial discrimination and microaggressions.

Jade and Kiya constantly negotiated between taking on or resisting the subject positon of a race-less athlete. By drawing on a competing discourse of racism, which will be discussed later in this paper, Jade explained how she learned to embrace her natural Black hair or feel proud of her race. She, however, contradicted herself later in the interview by noting how some of her teammates who were "pro-Black," sometimes took it too far. She 
perceived verbal and nonverbal expressions from her White teammates were communicating, “Ok. That's enough" when they were being "too Black.” Although Jade could draw upon competing discourses to negotiate her subjectivity as racialized, you had to negotiate your "Blackness" in sport.

Kiya also negotiated the boundaries of her racial subjectivity. Throughout her interview, drawing on the discourse of racism, she spoke passionately and extensively about her subjectivity as an African American woman. She was also very knowledgeable about the current and historical racial inequalities faced by African Americans and suggested that "not taking about race makes racism worse." When discussing her experiences in sport, however, she struggled to negotiate the contradicting discourses of sport as transcending race and the discourse of racism. Within the discursive context of sport, she had to negotiate her subjectivity between being Black or an athlete. She could not, however, be both at the same time. In the following quote, Kiya describes the consequences of going against the norm of transcending race:

Um, I don't typically. Unless. Um. For me, they don't necessarily really, I try not to combine them [race and sport]. Because there's really no need [laughs]. There's really no need. To do that. I mean. Unless like someone else comes and brings some outside stuff then I don't - worry about it. Because the fact that, it's, it's just a nasty situation. And people get really emotional about it [race] and I know I will get emotional about it and. Be all up in someone's face and I don't have time for that... And so, really like, as a team, in order to function with, because we have like half of our team almost is Black. And other half is White that, they, you can't have that type of animosity or, any of that because, that's the type of stuff that ruins teams. And that people want to quit and you get into fights and like. It just wouldn't work. And so that's why. You can't have it like that. 
If Kiya were to reject the subject position of a race-less athlete and talk about race, she would be positioned as the athlete who ruins the teams' chemistry and subsequent performance by bringing race into "the family." The sport as transcending race discourse was legitimized by and consequently served the institution of sport.

Although these findings are consistent with Burdsey's (2011) findings that the entrenched color-blind ideology in sport influences participants' (non)responses to microaggressions, this is a contrasting view to critical humanist theorists who assumed power as binary, hierarchical, and oppressive (Markula \& Silk, 2011). From a Foucauldian perspective, athletes adhered to the sport as transcending race discourse because that was what was legitimized as normal. Moreover, they received micropunishments in the form of microaggressions when they deviated from the norm of being a race-less athlete. If a participant was to recognize something as a racial microaggression, then the participants would be positioned as the ones unable to transcend issues of race and to be a "team player."

Although this discourse can contribute to athletes overcoming racial barriers and stereotypes to work together as a team, as can be seen from the results of this study, the discourse ignores and invalidates the racialized realities of student-athletes-of-color. The myriad of racial microaggressions listed in the first part of my results and discussion section demonstrate that student-athletes-of-colors' subjectivities and lives are already racialized, whether they are conscious of it or not. Moreover, MJ explained that the sport as transcending race discourse had limits:

But the second [sport name removed] is done, it [race] still becomes an issue. Like the second I walk out of the gym, it's still an issue. The jersey comes off, it's still an issue. So, I think sports is almost a release from the issue, but it doesn't. Like it doesn't make it go away, but it's a release for a little bit of time. 
MJ's quote illustrates Fisher and colleagues' (2003) argument that athletes are more than athletes; they possess intersecting subjectivities. Even if sport were truly a unique space where participants could transcend their race, as MJ points out, "the jersey comes off" and athletes are re-positioned as racial subjects in different discursive contexts.

Even though the previous section of this study demonstrated how racial microaggressions acted as examples of other people, often White people, bringing race into the conversation, the sport transcends race discourse limited participants' ability to perceive and describe them as racial issues. Foucault (1995) described how dominant discourses not only become internalized by individuals, but that individuals engage in self surveillance to prevent their deviance from the norm out of a fear of being abnormal. Student-athletes' selfsurveillance to fit the discursively constructed subject position of an athlete was also evident in this study. This, according to Foucault (1995) is a more subtle, subconscious, and effective way of exercising power.

Post-racial society discourse. Another discourse that the participants heavily drew upon to make sense of their microaggression experiences was the post-racial society discourse, which is the belief that racism is limited to overt acts of racism by overt racists. Participants explained how their experiences were different from their parents' experiences or "back in the day" when people of color faced "real racial discrimination." This implied that racism is only upheld by overt acts of discrimination and that we live in a society where overt racists are scarce.

Within the post-racial society discourse, racial microaggressions were constructed as unintentional bias, innocent mistakes, or jokes rather than as acts that are discriminatory. Unlike their parents' generations, within this discourse, the subject position of a victim or perpetrator were no longer offered. Rather, perpetrators of microaggressions were positioned as clueless or curious people who had no intent to harm. Because microaggressions were 
constructed as harmless due to the lack of an overt intent to harm, in response, the participants were positioned as subjects who could not be harmed. In other words, if there was no intent to harm, they could not experience harm. Lucy explained that, "I guess, um, unless it's like, really, really bad then you should just let it go. Like, most things are really minor, like, you shouldn't let it bother you that much. Unless it's like something really, really, really bad."

Although some of the participants recognized that some perpetrators may have harbored racial bias or prejudicial attitudes, drawing upon this discourse, the perpetrators were positioned as being clueless rather than being racially motivated. Sarah explained, “some people can't help themselves. They are just really sheltered." Henry often explained away his microaggressions as, “They [offenders] just don’t know. They’ve never met someone like me. Some people never even left [state name removed]" implying that it was normal and almost inevitable that he would encounter racial microaggressions.

In response to the clueless perpetrator, participants were offered the subject position of the understanding victim, which had consequences to how participants could think, feel, and act. For example, even when some participants described that they were frustrated when they heard comments such as "Whew, your [Black] hair is a lot" or "Run faster little Asian!" they explained that they cannot be upset for long because the perpetrators did not intend to insult them. At times, Jade shared that she could not brush off comments as easily, but, by taking up the position of the understanding victim, Jade blamed herself for her negative responses by explaining that, "sometimes I just overthink things."

Participants were engaging in what Sue (2010) called, "rescuing offenders" (p.76) by acknowledging offenders of microaggressions as products of their environment. Participants explained that, "I know they didn't mean it that way" or say "People sometimes just don't know what they are saying" and minimized the negative responses they had with 
microaggression. This is because, within the post-racial society discourse, perceiving microaggressions as harmful was not a compatible or privileged position. Although participants do have the agency to resist the subject position of the unharmed subject, there are social consequences to resisting dominant discourses such as being considered overly sensitive and petty (Thomas, 2008).

Discourse of racism. Discourse of racism is the acknowledgement that people have historically been and continue to be socially stratified based on one's skin color. Within this discourse, more subject positions were available to the participants such as being a racial subject, as well as a victim of racism. Microaggressions could be constructed as problematic in that they reflected racial bias or perpetrated harmful racial stereotypes because subject positions of a racial subject such as being the victim and perpetrator were available. Within the subject position of a racial subject, participants could perceive and acknowledge microaggressions as racially-based stereotypes. Their feelings of annoyance or frustration by the microaggressions were also legitimized as microaggressions were constructed as reflecting racial bias. For example, Lucy felt angry when her peers attributed her athletic abilities to her being half-Black (she was not). Even though the perpetrator responded that they "didn't mean it that way," drawing from the discourse of racism, Lucy could legitimize her position to feel offended and confront them by saying, "I'm not Black. I'm fully Asian." Even when microaggressions were delivered in the form of a joke or a sincere question, when drawing from the discourse and understanding that racism still exists in our society, participants were positioned to recognize microaggressions as rude and harmful. For example, when Sarah's guy friends joked about her hopping the fence as a Mexican or when people asked Lucy if she was Chinese, they felt that these comments were inappropriate. Lucy explained, “It's just mean, like rude, like you're just making fun of someone just because of who they are." Many of the participants recognized that they themselves also held 
racial biases towards races different from their own. When acknowledging that racism was still a societal problem, however, they perceived that microaggressions were problematic regardless of the perpetrators' intent.

Drawing from the discourse of racism, participants could justify their sensitivity towards subtle slights such as microaggressions. In fact, an action did not have to actually occur for some participants to recognize themselves as racial subjects. For example, Jade explained that she would think, "I hope the judges like me" during meets because she perceived that "Judges really can just look at me and be like, oh she's Black. Like maybe we'll just judge her harder like.. just stuff like that that no one could know." When we acknowledge that racism still exists, especially in forms that are not directly observable such as institutional racism (Pérez Huber \& Solorzano, 2015), aversive racism (Dovidio \& Gaertner, 2000), or color-blind racism (Bimper, 2015), Jade's thoughts can be understood as "healthy paranoia or cultural mistrust" (Sue, 2010, p. 73) to survive in the dominant culture. Similarly, Kiya and MJ concerns for their safety when traveling to rural areas, even when they are with the team, could be justified when drawing from the discourse that racism exists. Outside of this discursive understanding, however, the participants' proactive concerns, thoughts, and feelings would most likely be understood as being overly sensitive, crazy, or paranoid (Friedersdorf, 2015a, 2015b; Thomas, 2008).

Drawing from the discourse of racism, all the participants in this study explained how connecting with other people of color helped them validate their racial realities. Jade explained how she was able to learn to love her hair by watching Youtube videos or Pinterest posts about natural Black hair. All the participants in this study also reported that they spoke with their parents or their friends who are also people of color, which helped them recognize that their responses to microaggressions were valid. Moreover, all the participants in this 
study described how they felt it was easier to connect with other people of color because they shared similar experiences including those related to racial injustices. Kiya described it as:

So, it's just like trying to find other people who look like you to have at least like one person you can relate to, who like. If like stuff happens on the news, I can feel comfortable talking to you about it. 'Cause, like, even though like, even though like if you're Caucasian and you're my friend, like you don't necessarily understand like what I'm saying, personally.

This is how sport could be perceived as a positive space for student-athletes-of-color. All the female participants in this study, for example, participated in teams that had an exceptionally high proportion of athletes-of-color on their teams. Many participants described how it was comforting and validating to have other athletes-of-color on the team they could share their experiences; this was different from other contexts participants had to navigate such as the classroom in which they were often the numerical minority.

Drawing upon the discourse of racism, participants were better positioned to brush off microaggressions because they perceived the perpetrators' ignorance to be the problem, not themselves. As racial microaggressions were an everyday experience for them, the participants often did not respond to the microaggressions by saying "some people are ignorant and there is nothing you can do about it" or "Those things don't bother me anymore because I know who I am and what I bring to the table.” Lucy explained:

Um, you don't have to be what people say you are. You can be whatever you want to be. So, just don't let what people say affect you. So, you know, who you are, so nothing anyone says can change who you are unless you let it....You just, like, find out you're happier when you don't, like, you aren't living for other people, just live for yourself. 
Although this was an empowering discourse that allowed participants to cope with racial microaggressions, the participants were not necessarily positioned to challenge racism, but use "situation-specific strategies and tactics to cope with inequality" (Kavoura et al., 2015, p. 8). The onus of dealing with and overcoming racism was still placed on the people of color. For example, all the American participants described how they were bothered by such comments when they were younger, but that they learned to become more confident and secure of themselves overtime. Jade and Kiya shared that, because they were taught by their parents from an early age that they had to be ten times better than their White peers to be considered equal, they worked harder to be and perform better than their White counterparts. However, if you continued to be bothered by microaggressions, does that mean you are not a confident and secure person? Within this discourse, the ways in which participants could construct subjectivities were still limited.

\section{Conclusion}

While cultural sport psychology scholars have called researchers to centralize the influences of culture in sport psychology research (McGannon \& Smith, 2015; Ryba et al., 2013; Schinke et al., 2015), few studies have examined the marginalized experiences related to race in sport (Kamphoff et al., 2010; Ram et al., 2004). The purpose of this study was to examine racial microaggressions in a new context of sport and through a new theoretical approach, Foucauldian poststructuralist theory.

The racial microaggression examples shared in this study clearly demonstrated that, for the participants in this study, whether they were conscious of it or not, their experiences were racialized. Moreover, using Foucauldian poststructuralist theory, I was able to explain the contradictory experiences of student-athletes by examining how they negotiated multiple discourses to make sense of their experiences. Within sport, the sport transcends race discourse was widely circulated and legitimized through various sporting practices. Within 
this discourse, an athlete was constructed as one who transcends race to contribute to the team and win, which led participants to be blind to or minimize their experiences with race. Moreover, the microaggressions acted as a panoptic gaze that reminded participants of their deviance from the norm of being a race-less athlete, which led them to self-survey and correct such deviance of being conscious of race. In other words, there was little room within the sport as transcending race discourse for student-athletes-of-color to recognize and acknowledge the influences of race to their subjectivities and their sporting realities.

These findings have several implications for sport psychology professionals (SPP). First, the study findings illustrate the importance for SPPs to better understand the influences of race and racism. As demonstrated in this study, it is important to problematize everyday talk such as microaggressions as language not only reflects, but further produce our realities. Learning about racial microaggressions could be a way SPPs reflect on how racial inequities are (sub)consciously (re)produced through our taken-for-granted language and practices. Additionally, given that the presence of microaggressions can lead to negative mental health consequences and lead one to perceive the climate as hostile (Melendez, 2008; Solórzano et al., 2000), SPPs should educate clients and teams about racial microaggressions to create a safe and cohesive environment for everyone. By using Foucauldian poststructuralist theory, SPPs can not only discuss what microaggressions are, but also facilitate critical reflections on why certain language can be problematic.

Despite a rigorous study design, however, there were limitations to this study. Poststructuralist researchers posit that researchers co-construct knowledge and alternative interpretations will always be available regardless of the validation procedure that was followed in conducting this study. Moreover, Crocket (2017) recently critiqued sport sociology researchers' overreliance on interviews as a methodological tool when applying Foucauldian theory. He suggested researchers employ alternative methodological tools (e.g., 
fieldwork) to consider the effects of "affect, emotions, and embodiment" (p. 22) to participants' subjective experiences.

Although the purposes of this study were unrelated to generalizability, given that the findings from this study are exploratory, additional studies are needed to gain a crystallized (Ellingson, 2008; Richardson, 2000) understanding of microaggressions. Future studies could further employ various Foucauldian concepts such as technologies of discipline (Foucault, 1995) or technologies of self (Foucault, 1990; Markula, 2003) to further examine how discursive power is exercised, negotiated, and resisted in sport. This would help researchers better understand how racial inequities are (re)produced even when we do not have personal intentions to be discriminatory. Moreover, researchers should examine the influences of microaggressions to intersecting subjectivities beyond that of race. Theorizing microaggressions through Foucauldian poststructuralist theory opens up possibilities for researchers to look beyond identity-based microaggressions as subjectivities are considered to be multiple and constantly negotiated (i.e., subjectivities) rather than fixed and inherent. 


\section{References}

Allen, Q. (2010). Racial microaggressions: The schooling experiences of Black middleclass males in Arizona's secondary schools. Journal of African American Males in Education, 1(2), 125-143. Retrieved from http://digitalcommons.chapman.edu/education_articles/24/?utm_source=digitalcomm ons.chapman.edu\%2Feducation_articles\%2F24\&utm_medium=PDF\&utm_campaign $=$ PDFCoverPages

Avner, Z. (2014). What can Foucault tell us about fun in sport? A Foucauldian critical examination of the discursive production and deployment of fun within varsity coaching contexts. (Doctoral dissertation, University of Alberta, Alberta, Canada). Retrieved from https://era.library.ualberta.ca/files/rb68xc09k/Avner_Zoe_201407_PhD.pdf

Bimper, A. Y. (2015). Lifting the veil: Exploring colorblind racism in black student athlete experiences. Journal of Sport and Social Issues, 39(3), 225-243. doi: $10.1177 / 0193723513520013$

Bonilla-Silva, E. (2006). Racism without racists: Color-blind racism and the persistence of racial inequality in the United States (2nd ed.). Lanham, MD: Rowman \& Littlefield Publishers.

Brown, T. N., Jackson, J. S., Brown, K. T., Sellers, R. M., Keiper, S., \& Manuel, W. J. (2003). "There's no race on the playing field" Perceptions of racial discrimination among White and Black athletes. Journal of Sport \& Social Issues, 27(2), 162-183. doi: $10.1177 / 0193732502250715$

Burdsey, D. (2011). That joke isn't funny anymore: Racial microaggressions, color-blind ideology and the mitigation of racism in English men's first-class cricket. Sociology of Sport Journal, 28(3), 261-283. Retrieved from 
http://web.b.ebscohost.com/ehost/detail/detail?sid=46fa0661-95d3-46de-93cfa175f7e 5e4b6\%40sessionmgr101\&vid=0\&hid=123\&bdata=JnNpdGU9ZWhvc3QtbG 12ZSZzY29wZT1zaXRl\#db=s3h\&AN=66736158

Butryn, T. M. (2002). Critically examining white racial identity and privilege in sport psychology consulting. The Sport Psychologist, 16(3), 316-336. Retrieved from http://www.fitnessforlife.org/AcuCustom/Sitename/Documents/DocumentItem/2790. pdf

Butryn, T. M. (2009). (Re)examining whiteness in sport psychology through autonarrative excavation. International Journal of Sport and Exercise Psychology, 7(3), 323-341. Retrieved from https://www.researchgate.net/profile/Ted_Butryn/publication/254300977_Reexamini ng_whiteness_in_sport_psychology_through_autonarrative_excavation/links/573ce24 408aea45ee841a1fc.pdf

Campbell, B., \& Manning, J. (2014). Microaggression and moral cultures. Comparative Sociology, 13(6), 692-726. https://doi.org/10.1163/15691330-12341332

Comeaux, E. (2012). Unmasking athlete microaggressions: Division I student-athletes' engagement with members of the campus community. Journal of Intercollegiate Sport, 5(2), 189-198. http://dx.doi.org/10.1123/jis.5.2.189

Constantine, M. G., \& Sue, D. W. (2007). Perceptions of racial microaggressions among black supervisees in cross-racial dyads. Journal of Counseling Psychology, 54(2), 142-153. doi: 10.1037/0022-0167.54.2.142

Cooper, J. N. (2015). The value of qualitative approaches in the examination of Black male student athletes. Qualitative Research in Sport, Exercise and Health, 7(3), 361-376. https://doi.org/10.1080/2159676X.2014.888586

Crocket, H. (2017). Problematizing Foucauldian ethics: A review of technologies of the 
self in sociology of sport since 2003. Journal of Sport and Social Issues, 41(1), 2141. https://doi.org/10.1177/0193723516677617

Crotty, M. J. (1998). The foundations of social research: Meaning and perspective in the research process. Thousand Oaks, CA: SAGE Publications.

Donovan, R. A., Galban, D. J., Grace, R. K., Bennett, J. K., \& Felicie, S. Z. (2013). Impact of racial macro- and microaggressions in Black women's lives: A preliminary analysis. Journal of Black Psychology, 39(2), 185-196.

https://doi.org/10.1177/0095798412443259

Dortants, M., \& Knoppers, A. (2013). Regulation of diversity through discipline: Practices of inclusion and exclusion in boxing. International Review for the Sociology of Sport, $48(5), 535-549$.

Dovidio, J. F., \& Gaertner, S. L. (2000). Aversive racism and selection decisions: 1989 and 1999. Psychological Science, 11(4), 315-319. https://doi.org/10.1111/14679280.00262

Ellingson, L. L. (2008). Engaging crystallization in qualitative research: An introduction. Thousand Oaks, CA: SAGE Publications.

Fisher, L. A., Butryn, T. M., \& Roper, E. A. (2003). Diversifying (and politicizing) sport psychology through cultural studies: A promising perspective. The Sport Psychologist, 17(4), 391-405.

Foucault, M. (1995). Discipline and punish: The birth of the prison (2 ed.). New York, NY: Vintage Books.

Friedersdorf, C. (2015a, September 11). The rise of victimhood culture. The Atlantic. Retrieved from http://www.theatlantic.com/politics/archive/2015/09/the-rise-ofvictimhood-culture/404794/ 
Friedersdorf, C. (2015b, September 14). Why critics of the "microaggressions" framework are skeptical. The Atlantic. Retrieved from http://www.theatlantic.com/politics/archive/2015/09/why-critics-of-themicroaggressions-framework-are-skeptical/405106/

Gearity, B. T., \& Mills, J. P. (2012). Discipline and punish in the weight room. Sport Coaching Review, 1(2), 124-134. https://doi.org/http://dx.doi.org/10.1080/21640629.2012.746049

Gearity, B. T., \& Metzger, L. H. (2017). Intersectionality, microaggressions, and microaffirmations: Towards a cultural praxis of sport coaching. Sociology of Sport Journal, Advance online publication. 1-41. http://dx.doi.org/10.1123/ssj.2016-0113

Gill, D. L. (2001). Feminist sport psychology: A guide for our journey. The Sport Psychologist, 15(4), 363-372.

Gomez, M. L., Khurshid, A., Freitag, M. B., \& Lachuk, A. J. (2011). Microaggressions in graduate students' lives: How they are encountered and their consequences. Teaching and Teacher Education, 27(8), 1189-1199. https://doi.org/10.1016/j.tate.2011.06.003

Grier-Reed, T. L. (2010). The African American student network: Creating sanctuaries and counterspaces for coping with racial microaggressions in higher education settings. The Journal of Humanistic Counseling, Education and Development, 49(2), 181-188. https://doi.org/10.1002/j.2161-1939.2010.tb00096.x

Gutting, G. (2005). Foucault: A Very Short Introduction. Oxford, UK: Oxford University Press.

Hackett, C. D. (2013). Constructing an understanding of Black student athletes' achievement concerns at a private Hispanic serving institution. Journal of African American Males in Education, 4(1), 62-77. 
Harris, R. S. (2009). Racial microaggression? How do you know?-Revisited. American Psychologist, 64(3), 220-220. https://doi.org/10.1037/a0014749

Johnston, M. P., \& Nadal, K. L. (2010). Multiracial microaggressions: Exposing monoracism in everyday life and clinical practice. In D. W. Sue (Ed.), Microaggressions and marginality: Manifestation, dynamics, and impact (pp. 123-144). Retrieved from http://works.bepress.com/marc_johnston/3/

Jones, L., \& Toner, J. (2016). Surveillance technologies as instruments of discipline in the elite sports coaching context: A cautionary post-structural commentary. Sensoria: A Journal of Mind, Brain \& Culture, 12(2), 13-21. Retrieved from http://sensoria.swinburne.edu.au/index.php/sensoria/article/view/439

Jordan, T. A. (2010). The impact of racial microaggressions on Black athletes: Implications for counseling and sport psychology (Master's thesis, Georgia Southern University). Retrieved from http://digitalcommons.georgiasouthern.edu/cgi/viewcontent.cgi?article=1110\&context $=$ etd

Kamphoff, C. S., Gill, D. L., Araki, K., \& Hammond, C. C. (2010). A content analysis of cultural diversity in the Association for Applied Sport Psychology's conference programs. Journal of Applied Sport Psychology, 22(2), 231-245.

Kavoura, A., Ryba, T. V., \& Chroni, S. (2015). Negotiating female judoka identities in Greece: A Foucauldian discourse analysis. Psychology of Sport and Exercise, 17, 8898. https://doi.org/10.1016/j.psychsport.2014.09.011

Krane, V., \& Barber, H. (2005). Identity tensions in lesbian intercollegiate coaches. Research Quarterly for Exercise and Sport, 76(1), 67-81. https://doi.org/10.1080/02701367.2005.10599263 
Liamputtong, P. (2006). Researching the vulnerable: A guide to sensitive research methods. Thousand Oaks, CA: SAGE Publications.

Lilienfeld, S. O. (2017). Microaggressions: Strong claims, inadequate evidence. Perspectives on Psychological Science, 12(1), 138-169.

Madriz, E. (2000). Focus groups in feminist research. In N. K. Denzin \& Y. S. Lincoln (Eds.), The handbook of qualitative research ( $2^{\text {nd }}$ ed. , pp. 835-850). Thousand Oaks, CA: SAGE Publications.

Markula, P. (2003). The technologies of the self: Sport, feminism, and Foucault. Sociology of Sport Journal, 20(2), 87-107.

Markula, P., \& Silk, M. (2011). Qualitative research for physical culture. London, UK: Palgrave Macmillan. doi: 10.1057/9780230305632

Markula, P., \& Pringle, R. (2006). Foucault, sport and exercise: Power, knowledge and transforming the self. New York, NY: Routledge.

McDonald, M. G. (2012). Thinking through sport, analyzing whiteness. Journal of Multicultural Discourses, 7(3), 235-241. https://doi.org/10.1080/17447143.2012.699530

Mcgannon, K. R., \& Busanich, R. (2010). Rethinking subjectivity in sport and exercise psychology: A feminist post-structuralist perspective on women's embodied physical activity. In T. V. Ryba, R. J. Schinke, \& G. Tenenbaum (Eds.), The cultural turn in sport psychology (pp. 203-229). Morgantown, WV: Fitness Information Technology. Retrieved from https://www.researchgate.net/publication/257959295_Rethinking_subjectivity_in_spo rt_and_exercise_psychology_A_feminist_poststructuralist_perspective_on_women's_embodied_physical_activity 
McGannon, K. R., \& Smith, B. (2015). Centralizing culture in cultural sport psychology research: The potential of narrative inquiry and discursive psychology. Psychology of Sport and Exercise, 17(0), 79-87.

Melendez, M. C. (2008). Black football players on a predominantly White college campus: Psychosocial and emotional realities of the Black college athlete experience. Journal of Black Psychology, 34(4), 423-451. https://doi.org/10.1177/0095798408319874

Mills, J. P. (2014). Soldiers, animals and machines: A Foucauldian analysis of the making of the contemporary endurance running body. (Doctoral dissertation, University of Alberta, Alberta, Canada). Retrieved from https://era.library.ualberta.ca/downloads/d791sg391

Murray, K. (2013). Microaggression as Foucaultian subjectivism: A critical race analysis of the classroom dynamic. Journal of Philosophy \& History of Education, 63(1), 59-68.

Nadal, K. L., Wong, Y., Sriken, J., Griffin, K., \& Fujii-Doe, W. (2015). Racial microaggressions and Asian Americans: An exploratory study on within-group differences and mental health. Asian American Journal of Psychology, 6(2), 136-144. https://doi.org/10.1037/a0038058

Patton, M. Q. (2014). Qualitative research \& evaluation methods: Integrating theory and practice (4 ed.). Thousand Oaks, CA: SAGE Publications.

Pérez Huber, L., \& Solorzano, D. G. (2015). Racial microaggressions as a tool for critical race research. Race Ethnicity and Education, 18(3), 297-320. https://doi.org/10.1080/13613324.2014.994173

Pierce, C. M., Carew, J. V., Pierce-Gonzalez, D., \& Wills, D. (1977). An experiment in racism TV commercials. Education and Urban Society, 10(1), 61-87.

Rainey, D. W. (2012). Sport's officials' reports of hearing trash talk and their responses to trash talk. Journal of Sport Behavior, 35(1), 78-93. 
Rainey, D. W., \& Granito, V. (2010). Normative rules for trash talk among college athletes: An exploratory study. Journal of Sport Behavior, 33(3), 276-294.

Ram, N., Starek, J., \& Johnson, J. (2004). Race, ethnicity, and sexual orientation: Still a void in sport and exercise psychology? Journal of Sport and Exercise Psychology, 26(2), 250-268. https://doi.org/10.1123/jsep.26.2.250

Richardson, L. (2000). Writing: A method of inquiry. In N. K. Denzin \& Y. S. Lincoln (Eds.), The handbook of qualitative research ( $2^{\text {nd }}$ ed., pp. 923-948). Thousand Oaks, CA: SAGE Publications.

Ryba, T. V., Stambulova, N. B., Si, G., \& Schinke, R. J. (2013). ISSP position stand: Culturally competent research and practice in sport and exercise psychology. International Journal of Sport and Exercise Psychology, 11(2), 123-142.

Sage, G. H., \& Eitzen, D. S. (2015). Sociology of North American sport (10 ed.). New York, NY: Oxford University Press.

Salvatore, J., \& Shelton, J. N. (2007). Cognitive costs of exposure to racial prejudice. Psychological Science, 18(9), 810-815.

Solórzano, D., Ceja, M., \& Yosso, T. (2000). Critical race theory, racial microaggressions, and campus racial climate: The experiences of African American college students. The Journal of Negro Education, 69(1), 60-73. https://doi.org/10.1080/095183998236926

Sue, D. W., Bucceri, J., Lin, A. I., Nadal, K. L., \& Torino, G. C. (2007a). Racial microaggressions and the Asian American experience. Cultural Diversity and Ethnic Minority Psychology, 13(1), 72-81. https://doi.org/10.1037/1099-9809.13.1.72

Sue, D. W., Capodilupo, C. M., Torino, G. C., Bucceri, J. M., Holder, A. M. B., Nadal, K. L., \& Esquilin, M. (2007b). Racial microaggressions in everyday life: Implications for 
clinical practice. American Psychologist, 62(4), 271-286.

https://doi.org/10.1037/0003-066X.62.4.271

Sue, D. W. (2010). Microaggressions in everyday life: Race, gender, and sexual orientation. Hoboken, N.J: Wiley.

Thomas, K. R. (2008). Macrononsense in multiculturalism. American Psychologist, 63(4), 274-275. https://doi.org/10.1037/0003-066X.63.4.274

Weedon, C. (1997). Feminist practice and poststructuralist theory (2 ed.). Hoboken, N.J: Wiley-Blackwell.

Whaley, D. E., \& Krane, V. (2012). Resilient excellence: Challenges faced by trailblazing women in U.S. sport psychology. Research Quarterly for Exercise and Sport, 83(1), 65-76. https://doi.org/10.1080/02701367.2012.10599826

Wilchins, R. (2004). Queer theory, gender theory: An instant primer. Bronx, NY: Magnus Books.

Wilkinson, S. (1999). Focus groups: A feminist method. Psychology of Women Quarterly, 23(2), 221-244. https://doi.org/10.1111/j.1471-6402.1999.tb00355.x

Willig, C. (1998). Constructions of sexual activity and their implications for sexual practice lessons for sex education. Journal of Health Psychology, 3(3), 383-392.

Willig, C. (2013). Foucauldian discourse analysis. In C. Willig (Ed.) Introducing qualitative research in psychology (3rd ed., pp. 129-142). New York, NY: McGraw-Hill Education.

Wong, G., Derthick, A. O., David, E. J. R., Saw, A., \& Okazaki, S. (2014). The what, the why, and the how: A review of racial microaggressions research in psychology. Race and Social Problems, 6, 181-200. http://doi.org/10.1007/s12552-013-9107-9 
Yosso, T. J., Smith, W. A, Ceja, M., \& Solórzando, D. G. (2009). Critical race theory, racial microaggressions, and campus racial climate for latina/o undergraduates. Harvard Educational Review, 79(4), 659-691. 


\section{APPENDICES}

\section{Appendix A: Extended Literature Review}

On November 2013, Jonathan Martin, an African American offensive lineman for the National Football League (NFL) team Miami Dolphins, left the team to seek mental health services after reportedly being harassed by his teammates (Wells, Karp, Birenboim, \& Brown, 2014). Upon investigation, Wells et al. (2014) found a pattern of harassment within the Dolphins organization against Martin as well as against some other players and staff. The harassment was primarily led by fellow offensive lineman Richie Incognito. Incognito's varied actions included racial and homophobic slurs, unwelcomed physical touch, threats of physical harm to victims and their family, and acts that belittled others based on their sexual orientation or race etc. Incognito frequently referred to Martin with the 'N-word' and kept a journal recording times he was able to "break J-Mart," a nickname for Jonathan Martin. Once the investigation was completed, Incognito was suspended for three months with pay (Breech, 2014) and Martin sat the rest of the season out.

Despite investigation results supporting Martin's claim of repeated harassment, the reactions to the Martin-Incognito case were varied and contradictory. Incognito's responses to the abuse were consistent: "it was all harmless fun, they willingly participated and joked back, and no one was offended" (Wells et al., 2014, p. 34). He adamantly denied the harassment allegations, claiming "Dear Jon Martin.... The truth is going to bury you and your entire "camp". You could have told the truth the entire time." (Lorenzo, 2014) and "I'm ready to move on with my life and career. I've been dragged through the mud for months by my "best friend". \#betrayed \#railroaded" (Lorenzo, 2014). Investigators also found that the coaching staff endorsed and took part in some of the actions that were called into question. For example, coaching staff reportedly asked players to toughen Martin up and participated in a gag gift that sent denigrating messages to gay athletes (Wells et al., 2014). When the 
incident was publicized, the offensive lineman coach, Jim Turner, even urged Martin via text message to "do the right thing" (Wells et al., 2014, p. 46) and clear Incognito from allegations. The Dolphin players also supported Incognito and questioned Martin's motives saying, "We joke with each other. You can't have thin skin around here.” (Mihoces, 2013). Numerous NFL players and staff also criticized Martin; one player said, "I think Jonathan Martin is a weak person. If Incognito did offend him racially, that's something you have to handle as a man!” (Phillips, 2013). Was Incognito a racist, homophobic bully or was Martin simply unable to take a joke and took things too seriously?

\section{Microaggressions in Everyday Life}

Although there are various ways to characterize what happened in the IncognitoMartin case (e.g., bullying, harassment, overt discrimination), a concept that helps one understand the mixed responses the case garnered is microaggressions. First in the 1970s (Pierce, Carew, Pierce-Gonzalez, \& Wills, 1977), racial microaggressions are defined as "brief, everyday exchanges that send denigrating messages to people of color because they belong to a racial minority group" (Sue et al., 2007, p. 273). Microaggressions are characterized by their subtlety, which result in the victim as well as the perpetrator being unaware of their occurrence at times. Microaggressions are also referred to as “microinequities" (Sue et al., 2007, p. 273) because, unlike overt acts of discrimination, they can be delivered unconsciously and unintentionally. The subtle or unconsciousness nature of some of Incognito's actions may be why he and others remain so adamant about his innocence.

\section{Taxonomy of Microaggressions}

Sue et al. (2007) described three types of microaggressions: (a) microassaults, (b) microinsults, and (c) microinvalidations. Microassaults are "explicit racial derogations characterized primarily by a violent verbal or nonverbal attack meant to hurt the intended 
victim through name-calling, avoidant behavior or purposeful discriminatory actions" (p. 278). Microassaults would be most comparable to overt forms of discrimination; for example, throwing a banana peel at a Black hockey player or calling them a monkey could be classified as a microassault. Microinsults are "behavioral/verbal remarks or comments that convey rudeness, insensitivity and demean a person's racial heritage or identity” (p. 278). Microinsults are subtler than microassaults and are often delivered subconsciously without consciously harmful intent. They may even appear neutral depending on the context, but often communicate hidden undertones of insulting messages. Attributing a Black athlete's athletic abilities to the fact that they are black could be characterized as a microinsult. Microinvalidations are also subtle and are "verbal comments or behaviors that exclude, negate, or nullify the psychological thoughts, feelings, or experiential reality of a person of color" (p. 278). Promoting colorblind ideology and claiming all athletes are the same and awarded based on merit, for example, invalidates the lived realities of racial minority athletes. These communicate the message that racial minorities and their perspectives are less worthy and inferior to their White counterparts.

\section{Microaggression Themes}

Sue et al. (2007) proposed that the types and themes one experiences vary depending on one's group membership. For example, Sue and colleagues (2007) suggested there were racial differences in the themes of microaggressions people of color encountered. In the following section, I will outline the microaggression sub-themes as outlined by Sue (2010).

Microinsults. Sue outlined four themes related to the microinsults commonly experienced by people of color. The first theme was attributing one's intelligence to one's race. For example, Asian Americans are often associated with high intelligence or being the stereotype of being nerdy (Yu, Nguyen, \& Petrie, 2016). Hearing comments such as "Of course you're good at math. You're Asian!" would be an example of a microinsult. 
Black/African Americans, on the other hand, are often associated with lower intelligence. Comments such as, "You talk so proper. You sound White" would serve as an example of a microinsult because it conveys the assumption that Black people should not be able to speak intelligently. Another theme is treating people of color as second-class citizens, which is when people of color are treated as lesser than their White counterparts. For example, researchers found that people of color are often mistaken as service people (Sue et al., 2007). When in positions of authority, people of color's authority is more likely to be challenged (Alabi, 2015; Delapp, 2015).

The third theme identified by Sue (2010) was "pathologizing cultural values/communication styles" (p. 29). These are microaggressions that are based on the taken for granted assumption that Whiteness and Eurocentric values are the norm (Ryba \& Schinke, 2009) and communicate that one's cultural or racial background that deviates from the White norm is abnormal. For example, Jordan (2011) found that Black student-athletes experienced numerous microaggressions in sport that conveyed that their communication style was inferior compared to their White teammates. The final theme Sue (2010) outlined was related to associating people of color, especially Black and Brown bodies with criminality. Researchers found that teachers are more likely to suspend Black males in school (Allen, Scott, \& Lewis, 2013; Murray, 2013). Black males were also perceived as more threatening on college campuses (McCabe, 2009; Solórzano et al., 2000). These various type and themes of microaggressions worked to maintain racial stereotypes and biases and subtly communicate that people of color are abnormal or inferior to their White counterparts.

Microinvalidations. Within Asian Americans and Lationa/os, one of the most common microaggressions themes were related to asking them their country of origin. Although asking "Where you are really from?" appears to be an innocent question, the fact that this question is primarily and repeatedly asked to people from certain racial backgrounds 
communicates that they are constant foreigners. Researchers found that Asians and Latina/os are consistently "other-ed" and exoticized, which communicates that they do not belong (McCabe, 2009). A common theme that is consistently perpetrated is the idea of colorblindness, which is denying that race acts as an important cultural identifier that influences one's experiences. The ideology of color-blindness was found in various settings such as the workplace (Offermann et al., 2014), sport (Burdsey, 2011; Jordan, 2010), and counseling (Banks, 2014), which invalidates the racialized experiences of people of color. A related theme to color-blindness is the belief in meritocracy, which, again, invalidates the racialized and discriminatory experiences of people of color. Statements such as, "We want the best person for the job" or "We do not see color" could be characterized as microinvalidations. A final microaggression theme is the "denial of individual racism" (p. 29), which upholds the belief that racism is upheld by individual acts of racism and invalidates the systematic and institutionalized reality of racism. Researchers found that there were racial differences in the types and themes experienced by people of color (Constantine \& Sue, 2007; Nadal, 2008; Nadal et al., 2015).

\section{Microaggression Process Model}

Sue (2010) outlined the microaggression process model to explain what happens to an individual once they have experienced a microaggression. He identified five phases that an individual goes through: (a) the incident phase, (b) the perception phase, (c) the reaction phase, (d) the interpretation phase, and (e) the consequence for the individual phase.

Phase one describes the occurrence of a microaggressive incident. The type and themes of microaggressions may vary depending on the perceived identity of the individual (Sue, 2010). Once the incident occurs, the next phase is the recipient's perception and questioning of the incident to determine whether the incident was a microaggression or not. Because microaggressions are often subtle and innocuous, the questioning of whether the 
incident was discriminatory or not is complex. "Many factors often go into the assessment process: relationship to the perpetrator (relative, friend, coworker, or stranger), the racial/cultural identity development of the recipient, the thematic content of the microaggression, and personal experiences of the target. All are factors in construing meaning to the event" (Sue, 2010, p. 72).

Recipients then react to their own initial perceptions of the microaggressive incident. Sue (2010) explains that the recipient often experiences "an inner struggle that evokes strong cognitive, behavioral, and emotional reactions" (p. 73). An example of a cognitive reaction could be paranoia. Some researchers have explained the paranoia of marginalized groups as "healthy paranoia or cultural mistrust" (Sue, 2010, p. 73) because that their suspicion is warranted as well as vital to their survival in the dominant culture. Sue explains that healthy paranoia serves multiple purposes such as acting as a resistance to accepting the offenders' perceptions of the incident, a resistance to constantly self-blaming or ruminating on the incident, and/or as validation of the victims' own lived experiences. Without this healthy paranoia, recipients may constantly feel invalidated to the point that they need to check their own sanity. Without validation, recipients may perceive their own reactions and paranoia to various incidents as self-imposed and unwarranted, resulting in them questioning their own sanity. This can further lead to victim blaming not only by others including the offender - but by the recipient themselves. Recipients can attribute their experiences to their own lack of strength and personal deficiencies.

Moreover, recipients may even rescue their offenders by considering the offenders' motivations and feelings before their own. Recipients of racial microaggressions have explained how they empathize with the offender as not knowing any better and because they are also a victim of white supremacy. The recipients of racial microaggressions, on the other hand, seldom receive the empathy and understanding of White offenders, but rather 
experience a constant state of victim blaming as being overly sensitive or petty. Although healthy paranoia is often essential for marginalized groups' survival, exercising caution and constantly discerning the true motives of others ("constant state of questioning," Sue, 2010, p. 73) can be emotionally exhausting.

After the initial assessment and reaction to microaggressions, recipients interpret the meaning behind the microaggressive incident. This phase may be most similar to Foucauldian discourse analysis as the recipient is examining the taken-for-granted assumptions to perceiving microaggressions. Some examples of microaggression interpretations can be "you do not belong, you are abnormal, you are intellectually inferior, you are not trustworthy, you are all the same" (Sue, 2010, pp. 77-79).

The final phase of the microaggression process model is the consequences and the impact that the recipients experience based on their interpretation of the microaggressive incident. Sue explains four main consequences of microaggressions: powerlessness, invisibility, forced compliance/loss of integrity, and pressure to represent one's group. Consequences of microaggressions can manifest cognitively, emotionally, and behaviorally, which can have short or lasting effects. The short and long-term consequences to the recipient as well as the surrounding environment will be outlined in the following section.

\section{Consequences of Microaggressions}

Some researchers found that microaggressions can lead to severe psychological consequences. In a review of literature on racial microaggressions in the field of psychology, researchers found that minorities reported lower health outcomes (Wong, Derthick, David, Saw, \& Okazaki, 2014) when they perceived discrimination. For example, victims of microaggressions reported experiencing more mood disorders such as depression or anxiety. Victims of microaggressions were also more likely to feel paranoid, frustrated, and isolated from their environment (Solórzano, Ceja, \& Yosso, 2000). Victims also doubted themselves 
more and perceived their self confidence and self-esteem to be lower (Donovan, Galban, Grace, Bennett, \& Felicie, 2013; Gomez, Khurshid, Freitag, \& Lachuk, 2011).

Microaggressions not only affect individuals, but can also influence the broader surrounding climate. For example, in a study of racial microaggressions on college campuses, racial minority students perceived that microaggressions contributed to a hostile racial campus climate (Solórzano et al., 2000). Students reported feeling unsafe, disrupted, and unwanted on their campus community, which impacted their academic performance as well as their overall wellbeing. Melendez (2008) also found that subtle forms of discrimination left Black football players playing on a predominantly white institution feeling oppressed and isolated from their environment. Black student-athletes reported feeling rejected and mistreated by their campus community as well as their team, which disrupted the team's cohesion and performance (Melendez, 2008). In the case of Jonathan Martin, after his initial departure from the team, the Miami Dolphins also experienced conflict within and outside of the team, as many players were divided in their own experiences of the bullying incident (Wine, 2013).

Sue et al. (2007) argued that microaggressions can be even more harmful than overt forms of discrimination because the harm is either invisible to the perpetrator. Due to the ambiguous nature of microaggressions, Sue (2010) described how victims of microaggressions are often faced with psychological dilemmas, which subsequently influence how they respond to microaggressions. Sue (2010) explained how the victim and perpetrator usually have a different assessment on what really happened when a microaggression occurs. "As long as microaggressions remain invisible to the aggressor, reactions to them by marginalized groups place them in an unenviable position: they are damned if they don't (not take action) and damned if they do (take action)!" (Sue, 2010, p. 58). Sue (2010) critiques that White people have had the power to define reality and recommends we should listen to 
the experiences of people of color to understand racism and oppression because "the most disempowered groups have a more accurate assessment of reality, especially relating to whether discriminatory behavior is bias-motivated (Hannah et al., 2000; Keltner \& Robinson, 1996, as cited in p. 47).

Nevertheless, due to the subtle and confusing nature of microaggressions, victims may not always be able to clearly understand or explain what happened. Ignoring microaggressions can lead to frustration and anger because one can feel denied of one's experience; However, responding to microaggressions can also result in negative consequences such as victim-blaming and being perceived as petty. Recipients of microaggressions can feel powerless, unsure, and/or invalidated to speak up as well as feel powerless that they can elicit any lasting change or understanding from the offender(s). Recipients may also fear of retaliation for speaking up about something petty and nonessential. This can lead to victims of microaggressions feeling that they have no one to blame but themselves for the harm they are experiencing. Not only perpetrators, but also victims of microaggressions have been found to repeat the rhetoric that they are being overly sensitive (Burdsey, 2010). As a result, many microaggression recipients choose not to do anything in response to a microaggression.

Although the microaggression process model and research on the short and long term cognitive, behavioral, and emotional consequences are useful illustrations on how one can experience a microaggression, Sue (2010) admits that the model is descriptive in nature and not meant to be exhaustive. The model attempts to explain "the internal psychological dynamics" (Sue, 2010, p. 83) of a recipient of microaggressions, but does not yet sufficiently explain how and why the recipients' perceptions and responses vary. Why there are inconsistencies in experiences with microaggressions, even among racial minority groups. Why do some people of color perceive microaggressions while others do not? Moreover, why 
do people of color trivialize or even perpetuate microaggressions and violence against each other (Pérez Huber \& Solorzano, 2015)? Are microaggressions still harmful if the victim does not recognize it as such?

Until now, microaggreesions have been examined from a critical humanist approach, such as critical race theory that gives primacy to human consciousness and a hierarchical power relationship. "Such an approach assumes an unproblematic distinction between an internal psychological self and external social influences (McGannon \& Mauws, 2000). Consequently, these studies have avoided "genuine psychological topics such as subjectivity - the subjective personal experiences and the meanings that human beings attribute to these experiences" (Theo, 2009, p. 37, emphasis in original, as cited in Crocket, 2014, p. 186). In other words, all these psychological dilemmas and consequence can be explained only when assuming that people of color consciously perceive microaggressions. Nevertheless, it is timely for researchers to consider a larger body of theory to understand the ambiguity and subconscious manifestation of racial microaggressions and the subject experience.

\section{Summary of Racial Microaggressions}

Researchers have examined microaggressions in various minority populations such as African-Americans (e.g., Robinson, 2012; Sue, Capodilupo, \& Holder, 2008), Latino/as (e.g., Palmer \& Maramba, 2015; Rivera, Forquer, \& Rangel, 2010), Asians (e.g., Huynh, 2012; Nadal, 2008), multiracial individuals (e.g., Johnston \& Nadal, 2010; Nadal et al., 2011), and LGBTQ individuals (e.g., Balsam, Molina, Beadnell, Simoni, \& Walters, 2011). Researchers also found the presence of microaggressions across various contexts such as in work settings (e.g., Sue, Lin, \& Rivera, 2009; Young, Anderson, \& Stewart, 2015), classroom settings (e.g., Offermann et al., 2014; Watkins, Labarrie, \& Appio, 2010), in graduate programs (e.g., Michael-Makri, 2010; Shah, 2008), in supervisory relations (e.g., Constantine \& Sue, 2007; Murphy-Shigematsu, 2009), and in therapeutic spaces (e.g., Morton, 2011; Owen, Tao, Imel, 
Wampold, \& Rodolfa, 2014). Although Sue et al.'s (2007) model of microaggressions have been mostly used and supported, some researchers found that the themes of microaggressions that were reported differed slightly depending on the population and the context (Wong et al., 2014).

Despite growing research on microaggressions, there have been limited studies examining microaggressions in sport; thus, it is unclear how microaggressions manifest and are experienced in sporting contexts. Although previous research findings on microaggressions allow us to infer that microaggressions would be present in sporting contexts as well, sport culture contains unique aspects that could affect how one conceptualizes, perceives, and responds to microaggressions. As microaggressions are fluid, contextual, and contradictory, it is important to situate the study of microaggressions within a social context.

\section{Race in Sport}

Despite the fact that the athletic population is often the most racially diverse population on college campuses in the U.S. (Parham, 2009), research on race in sport psychology has traditionally been limited (Kamphoff et al., 2010; Ram et al., 2004). In fact, sport is often considered a post-racial space that transcends issues of identity such as race. For example, Ronald Reagan (1990) described sport as:

When men and women compete on the athletics field, socioeconomic status disappears. Black or white, Christian or Jew, rich or poor... all that matters is that you're out there on the field giving your all. It's the same way in the stands, where corporate presidents sit next to janitors... and they high-five each other when their team scores... which makes me wonder if it [status] should matter at all. (cited in “Athletics a Great Equalizer,” 1990, p. 1, as cited in Eitzen, 1996, p. 98) 
Brown et al., (2003) found that athletes, regardless of their race, similarly reported that race and racial discrimination is no longer a problem in the United States and in sport. Recently, the high level of sport success among racial minorities has been used as an explanation for why some, including people of color, to believe racism is no longer relevant in sport (Burdsey, 2011).

Nonetheless, researchers argued that sport is a microcosm of society that reflects issues within society such as racism (Sage \& Eitzen, 2015). For example, researchers examined how structural factors such as sport media (van Sterkenburg \& Knoppers, 2004) and sport policy (van Sterkenburg \& Knoppers, 2012) contribute to upholding Whiteness as the norm in sport. Researchers also found that, for athletes-of-color, race continued to influence their level of engagement and overall satisfaction in sport (Cooper \& Dougherty, 2015). Moreover, researchers recognized sport as a powerful social institution that promotes “contemporary meanings and practices regarding race/ethnicity" (McDonald, 2012, p. 235).

Although one cannot deny the current racial realities that disenfranchise racial minorities at large (APA, 2000), there is a surprising lack of research on racial minorities in sport and exercise psychology (SEP) research. For example, Kamphoff et al. (2010) found that not only is there a lack of issues of diversity incorporated in applied research in SEP, but also the diversity topics that are addressed have primarily revolved around Caucasian women. Racial minority's experiences have been largely neglected, which increases the likelihood that the White experience becomes normative (Kamphoff et al., 2010) and perpetuates ethnocentric monoculturalism (Sue, 2004). Within sport psychology, cultural sport psychology researchers have also called upon researchers to examine cultural identities such as race in sport and the psychological implications to one's experience (McGannon \& Smith, 2015; Ronkainen, Kavoura, \& Ryba, 2016; Ryba, Schinke, \& Tenenbaum, 2010). It is timely to explore the experiences of student-athletes-of-color to allow traditionally marginalized 
voices that have been largely absent in SEP research to be presented. These voices will allow researchers to disrupt the Whiteness in SEP (Butryn, 2009) by understanding how studentathletes-of-color negotiate their experiences with microaggressions and sport participation while being subjected to dominant sport discourses and cultural stereotypes. Thus, examining how subtle forms of discrimination such as racial microaggressions manifest through athletes' interpersonal relations is timely.

\section{Subculture of U.S. Intercollegiate Sports}

Research on North American sport suggests that the culture of sport involves a bracketed morality, "a legitimated, temporary suspension of the usual moral obligation to equally consider the needs and desires of all persons" (Bredemeier \& Sheilds, 2001, pp. 257258). In other words, actions that would be perceived as transgressions in society are not only often accepted but also expected and, at times, and celebrated in the sporting context. For example, athletes displayed more egocentric behaviors in sport than they would in other social settings; they reported the perception that they put their own needs and interests over others in game situations to be legitimate (Bredemeier \& Shields, 1986). Athletes also engaged in more aggressive behaviors such as intentionally injuring an opponent. Studentathletes also normalized the use of trash talk as simply being part of the game, even though the content of trash talk ranged from belittling one's athletic ability to one's sexuality and masculinity (Rainey \& Granito, 2010). Athletes reported that such trash talk is allowed and sanctioned to gain a competitive edge, even though it goes against values of sportsmanship and NCAA rules (Rainey \& Granito, 2010). Research also suggests abuse by coaches or hazing within teams is also normalized to the point where parents will not intervene coaches that display abusive behavior (Schinke \& McGannon, 2015). These results suggest that transgressions may be expected, normalized, sanctioned in sport that would not otherwise be sanctioned in society. 
If sport operates under a unique set of norms, how does that influence the manifestation of and one's understanding of racial microaggressions in sport? Could microaggressions also be normalized as a part of sport to the point of being invisible to those involved? If so, what are the consequences of such behaviors being normalized, accepted, and even celebrated? This is why sport, especially sport culture in the U.S., could be a unique context to examine microaggressions. Researchers argued that behaviors that would be considered transgressions in society (e.g., violence, trash talk) are not only accepted, but expected and even celebrated in sport culture. If this is the case, do the normalized practices in U.S. sport culture allow subtle forms of discriminations such as racial microaggressions to be expressed more overtly? What are normalized practices in sport and how does that influence student-athletes-of-colors' experiences with race and racial microaggressions? If racial microaggressions do occur, are athletes-of-color more likely to brush it off as a part of the game since transgressions are 'normal' in sport, or are they similarly impacted by microaggressions, regardless of the context it occurred? Carrington (2004) stated that "sport has a particular corporeal resonance in making visible those aspects of social life that often remain submerged in other domains" (p. 2). Sport may provide a unique setting to examine subtle manifestations of racism as the invisible may be more likely to become visible in sport.

\section{Microaggressions in Sport}

Research exploring experiences with microaggressions in sport are scarce. The first study to explore athletes' experiences with racial microaggressions in sport was by Burdsey (2011). Burdsey examined the presence and consequences of racial microaggressions in sport, specifically with British Asian male professional cricket players. The athletes reported receiving negative comments from various sources including their teammates, their opponents, staff, and the spectators. A wide range of insults and slights were expressed about athletes' religious backgrounds (i.e., Islamophobia), ethnicity, and appearance. Moreover, 
some athletes reported receiving minimal support or regulation by the referees when the players or the crowd made negative comments on the field during matches. Despite recalling specific episodic accounts of experiencing microaggressions, however, Burdsey found that the athletes simultaneously had the tendency to downplay and trivialize the effects of microaggressions. Burdsey's findings were consistent with previous research where victims of microaggressions adopted the discourse of the perpetrators (i.e., color-blind ideology) and denied or minimized the severity of microaggressions and/or blamed themselves as overreacting. Burdsey asserted that "the hegemonic model of oppositional categories "racist" and "not racist" is inadequate" (p. 278), as it does not capture nor offer an effective way to combat contemporary racism. Burdsey, nevertheless, did not clearly explain why athletes adopted the discourses of the dominant group despite recalling specific instances of microaggressions, even when they perceived microaggressions as harmful.

In the U.S., Comeaux (2012) examined the occurrences of microaggressions amongst college student-athletes. Comeaux examined student-athletes' experiences with studentathlete microaggressions, slights from their professors or peers for being a student-athlete. An example of a student-athlete microaggression would be if your peers assumed you are unintelligent because you are an athlete. Out of the 122 NCAA Division I student-athletes that participated in a brief online survey, the majority of participants reported not experiencing any microaggressions simply from the fact that they were student-athletes. Nevertheless, the few who did perceive that professors or students were discriminatory against them reported that the microaggressions were related to verbal slights about intellectual abilities, academic motivation, and overall preferential treatment they allegedly received by the university. Although the study provides insight into student-athletes' experiences with microaggressions, it is unclear why some student-athletes perceived microaggressions and some did not. 
In an unpublished master's thesis, Jordan (2010) examined the impact of racial microaggressions on Black student-athletes. Jordan found that Black student-athletes experienced five out of the 12 microaggressions themes that were identified by Sue et al. (2007), such as ascription of intelligence, assumption of superiority of white cultural values, second-class citizen, denial of individual racism, and assumption of criminality. A unique theme that the athletes experienced was the exoticism of Black athletes; their athleticism was often attributed to the fact that they were Black. These microaggressions further reinforced Black stereotypes such as having inherent animal-like athletic abilities, aggressive tendencies, and hypersexuality that needs to be controlled and tamed (Ferber, 2007, as cited in Jordan, 2010, p. 53). The White beauty standards were another theme that emerged, which impacted Black student-athletes and required them to change their appearance or hair to participate in their sport. Participants reported emotional consequences and feelings of helplessness when experiencing microaggressions, which is consistent with previous research findings. Participants perceived this to contribute to a negative racial climate where Black students have to actively work towards disproving Black stereotypes rather than feeling free to be themselves. Jordan concluded that Black student-athletes experienced race-related stress in response to overt and subtle forms of racism even in settings such as university or sport, where circumstances are supposed to and claimed to be equal and meritocratic. Research on microaggressions in sport suggests that microaggressions are present in sporting contexts and are perceived as harmful. Nevertheless, researchers have not articulated why victims have mixed and/or inconsistent experiences with microaggressions.

As research on microaggressions increased, however, so have the criticisms against them. Researchers have argued against the authenticity and true impact of microaggressions because they are not only subtle and difficult to observe, but peoples' experiences with them are inconsistent and, at times, contradictory. It is not clear why people, even those from the 
same racial minority group, have different experiences with them. Moreover, researchers and columnists have argued that microaggressions promote a culture of victimhood that encourages individuals to be overly sensitive and weak (Friedersdorf, 2015; Harris, 2008). Thomas (2008) called microaggressions macrononsense, calling victims' responses to microaggressions as excessive. Recently, Campbell and Manning (2014) argued victimhood culture, contrary to honor cultures or dignity cultures, gives rise to microaggressions where people work to attract the sympathy and support from third parties rather than dealing with the indignities on their own. Previous research has been unable to answer why microaggression experiences are, at times, inconsistent and why we should take subtle and innocuous slights such as microaggressions seriously. In other words, microaggressions are in need of theoretical and conceptual refinement. Foucauldian poststructuralist theory offers a new lens to explain why people have mixed experiences with microaggressions and why subtle microaggressions are problematic. Moreover, sport provides an ideal setting to examine the complexities and contradictions of microaggressions as subtle microaggressions could become more overt in sport, which provides researchers with more direct access to microaggressions.

\section{Poststructuralist Research in Sport and Exercise Psychology}

Poststructrualist approaches have been increasingly integrated in sport and exercise psychology (SEP) literature in the past two decades (Ronkainen et al., 2016b; Ronkainen, Kavoura, \& Ryba, 2016a). Researchers have increasingly pointed to the potential of poststructuralist theory in integrating theory and practice within SEP to facilitate social change (Kavoura et al., 2015; McGannon \& Mauws, 2000; McGannon \& Schinke, 2013; McGannon \& Spence, 2010).

McGannon and Mauws (2000) were the first to apply a discursive approach to exercise psychology. Pointing out the limitations of the dominant theoretical approach to 
resolving exercise adherence issues, social cognitive theory, they proposed that researchers broaden their theoretical approach. Focusing on discourse as, "it is discourses that produce persons rather than persons who produce discourses" (p. 159), McGannon and Mauws suggest that researchers need to examine what discursive understandings the individual is drawing from to make sense of their experiences. Since this seminal article, Mcgannon has continued to apply a discursive psychological approach to examining exercise adherence among other sport and exercise psychology topics (e.g., McGannon \& Schinke, 2013; McGannon \& Spence, 2010).

One limitation of a discursive psychology perspective, however, is their lack of discussion and integration of the effects of power. Although discursive psychology and a Foucauldian poststructuralist approach stem from the same ontological assumption, their views on the power and the degree one can exercise human agency and power vary. Further elaboration on the differences in the theoretical approaches between discursive psychology and Foucauldian discourse analysis could provide researchers with a wider range of theoretical perspectives. A Foucauldian poststructuralist approach would also allow more discussions on power into the study of various phenomenon in SEP.

Roy and Ryba (2012) were the first in SEP to adopt Foucauldian poststructuralist perspective to theorize athletes' experiences with emotions. They examined how Malaysian women's emotional experiences in physical activity were constituted by the culturally situated discursive resources available to them. From a Foucauldian perspective, Roy and Ryba were able to examine the influences of power relations on the subjective emotional experiences of the participants. By critically examining the influences of cultural discourses on participants' subjectivities, the authors were able to theorize how dominant discourses subconsciously regulated women's experiences in sport, which (re)produced gender discrimination and stereotypes. 
Kavoura, Ryba and Ani (2015) were the first in SEP to research gendered athletic identities from a Foucauldian perspective. Kavoura and colleagues demonstrated how Greek female judokas constructed multiple subjectivities according to their discursive context. For example, they drew upon the biological conception of femininity to explain how they were exceptional women and not typical women to be competing in a sport like judo. The female athletes drew upon multiple and, at times, competing discourses to construct multiple identities. By applying Foucauldian poststructuralist theory, Kavoura and colleagues were uniquely able to theorize the contradictory experiences of Greek female judokas.

Although outside of SEP, most recently, Gearity and Metzger (2017) applied a Foucauldian poststructuralist perspective to theorizing intersectional microaggressions. They were among the first to apply a theory other than a critical humanist approach to theorizing racial microaggressions. Gearity and Metzger theorized microaggressions as a form of disciplinary power, which contributed to producing a particular type of athlete. By providing layered accounts of various types of microaggressions, the authors demonstrated how the various aspects of our identities (e.g., gender, race, religion) were normalized and corrected. Moreover, the authors also introduced the concept of microaffirmations as a way to counter and replace microaggressions. The authors called for additional research to examine, from a Foucauldian poststructuralist perspective, the impact of microaggressions to athletes' mental health and wellbeing.

In summary, poststructuralist theory can help explain the subjective experience that appears subconscious, irrational, and even contradictory. By focusing on language, researchers examine how participants'/clients' discursive understanding of themselves constitute their sport and exercise experiences. The goal of SEP research and practice, then, is to examine how we, as SEP professionals, can broaden participants'/clients' discursive 
resources and understandings. Additional research examining the discursive constructions and power relations within SEP are warranted. 


\section{Appendix B: Extended Theoretical Framework}

Racial microaggressions have emerged as a way to explain how racial discrimination manifests and is sustained in society (Sue et al., 2007). Although research on microaggressions has expanded exponentially in the past decade, microaggressions still remain poorly understood. In popular culture, microaggressions are often confused with misunderstandings (Friedersdorf, 2015a; Thomas, 2008). Recently, Campbell and Manning (2014) argued that microaggressions are promoting a culture of victimhood where individuals resolve their conflicts by claiming victim and garnering the support from third party observed rather than resolving conflicts on their own. Although this is a potential explanation for why microaggressions are emerging, Campbell and Manning do little to explain and resolve social injustices historically and currently observed within society. By explaining that victims claim victimhood, the authors ignore an alternative explanation that the reason victims claim to be victims is because victims are, in fact, actually victims of discrimination and oppression.

Although microaggressions as a popular term and an empirical construct is relatively new, contrary to Campbell and Manning's explanation, microaggressions are not ahistorical nor atheoretical. Microaggression research is an extension of a longstanding and rigorous body of critical scholarship. From a theoretical perspective, critical race theory has been the most common theoretical framework researchers have used to make sense of racial microaggressions (e.g., Burdsey, 2011; Solórzano et al., 2000; Yosso, Smith, Ceja, \& Solórzando, 2009). Through a critical race theory perspective, researchers explained racial microaggressions as everyday manifestations of racism that preserve white supremacy and white dominance over people of color and their bodies in place. Most recently, Pérez Huber and Solorzano (2015) developed a conceptual framework that situates "racial microaggressions as tool for critical race research" (p. 1). They explained that racial microaggressions cannot be understood as isolated interactions between individuals (e.g., an 
innocent joke). Microaggressions need to be understood in the context of societal oppression and institutional racism; "Where a racial microaggression occurs, institutional racism operates to enforce it" (p. 10). Pérez Huber and Solorzano further explained how racism and racial microaggressions are symptomatic of larger issues related to race. In other words, critical race theorists provided a lens to understand seemingly innocuous daily encounters as manifestations of racism.

Although critical race theory has been constructive in helping scholars understand microaggressions, there are limits to critical humanist approaches such as critical race theory. Markula and Silk (2011) outlined three major limitations of critical humanist approaches such as critical race theory: a "critique of universal metanarratives, critique of dualistic understanding of power relations and critique of the humanist self" (p. 46). These critiques of critical humanist approaches are applicable to microaggression research as well. For example, despite growing research on microaggressions, microaggressions are found to be contextual and situational (Sue et al., 2007), making it difficult to devise a clear and singular metanarrative of microaggression experiences. In a review of research on racial microaggressions in psychology, for example, Wong et al. (2014) concluded that what is and is not a microaggression is still unclear. Moreover, Pérez Huber and Solorzano (2015) pointed out that a critical race theory approach does not yet clearly theorize why people of color participate in their own subjugation, which suggests limits to a dualistic and hierarchical understanding of power relations. Furthermore, in a review of research on racial microaggressions in psychology, Wong et al. (2014) found that all but one study (i.e., Smith et al., 2011) published since Sue et al.'s (2007) seminal article on racial microaggressions incorporated Sue et al.'s racial microaggression taxonomy in their interpretation of microaggressions. Therefore, researchers that examine microaggressions as an empirical 
construct are called upon to open themselves up to a larger body of theory to help us understand racial microaggressions.

In this study, I propose Foucauldian poststructuralist theory as a way to theorize microaggressions. In the following sections, I will outline the main principles of Foucauldian poststructuralism and how it can help us understand why microaggressions are confusing, yet problematic. I will illustrate how Foucault's theorizing of discourse and power can be useful for us in understanding microaggressions.

\section{Principles of Foucauldian Poststructuralist Theory}

Language. Poststructuralism developed in response to structuralism, which sought to uncover universal theories of language because they believed language produces meaning and constitutes reality rather than reflecting it (Markula \& Silk, 2011). Poststructuralism extended Saussure's theory by demonstrating the arbitrariness of language (Weedon, 1997). For example, there is no inherent reason why a cat (i.e., signified) must be referred to by the word cat (i.e., signifier; Weedon, 1997). It could easily be called something else. Rather, language "acquire[s] meaning through the language chain and their difference within it from other signs" (Weedon, 1997, p. 23). In other words, poststructuralists explain that a cat is a cat because it is not a dog; signs are defined not by what they are, but by what they are not, which demonstrates the arbitrary relationship between and language and reality.

Although poststructuralists acknowledge a physical reality outside of language, they argued that it is only through language expression that this physical reality acquires any meaning (Weedon, 1997). For example, how many colors do you see when you look at a rainbow? If you grew up in the United States, you will most likely see six colors: red, orange, yellow, green, blue, and purple. If you grew up in another country such as South Korea, however, you will most likely see seven colors: red, orange, yellow, green, blue, indigo, and purple. This is because these are the colors that were most likely taught to you in schools. 
Although the colors of a rainbow are actually on a spectrum, which means that the number of colors are infinite, we most likely see the colors we know to see. Even if you could see an infinite number of colors in the rainbow, you would not necessarily have the language to describe each and every color. What would you call the $11^{\text {th }}$ shade you identified? As you can see from this example, we are restricted by the language and the meanings that are made available to us. Even though a physical reality of the rainbow exists, we perceive different realities and meanings because, consequently, we see what we know.

Moreover, poststructuralists argued that "language is not an abstract system... [but] always socially and historically located in discourses" (Weedon, 1997, p. 40), where meaning can be constantly contested and changed. How society understands gender differences, for example, is arbitrary (the signifier has no inherent link to the signified reality) but constitutes one's reality and becomes taken-for-granted notions of truth. Although the meaning we construct and communicate through language are arbitrary, they have social consequences and shape how we feel, think, and behave. The assumption that language constitutes meaning and reality, however, also suggests that discourses (ways of understanding) can change. Therefore, poststructuralists focused on language and discourse to understand people's experiences and to work towards social change.

Poststructuralist theorists presented three main arguments against humanist approaches: "critique of universal metanarratives, critique of dualistic understanding of power relations and critique of the humanist self" (Markula \& Silk, 2011, p. 46). The following sections will outline the three arguments of poststructuralism and their implications.

\section{Critique of universal metanarratives: Multiple, fractured realities.}

Poststructuralists argued against humanist beliefs of metanarratives such as progress or emancipation (Weedon, 1997). Rather, poststructuralists believed that the world is not unified 
and coherent, but fragmented, ever changing, unpredictable, irrational, and unrelated (Crotty, 1998). Foucault, influenced by 'Nietzsche's anti-humanist stance and his de-centering of the human subject" (Markula \& Pringle, 2006, p.12) also believed that "truth is not discovered but invented; and that power struggles are continually fought 'around truth"' (Markula \& Pringle, 2006, p. 12). Moreover, poststructuralists favored "cultural pluralism" (Markula \& Silk, 2011, p. 47) and to see the world as "organised in a series of fragmented presents (Jameson, 1983, as cited in Markula \& Silk, 2011, p. 47). Although both humanist and poststructuralists believed there can be multiple meanings, poststructuralists assumed that "the multiple interpretations of reality become valuable only when reflected against the social and historical context of the knowledge making (Markula, Grant, \& Dension, 2001, as cited in Markula \& Silk, 2011, p. 47).

Critique of dualist understanding of power. Although the critical humanist approach and poststructuralist approach both evolve around social critique, poststructuralists theorized that power is relational. This stands in contrast with humanist views of binary and hierarchical power relations between the privileged and the oppressed. Poststructuralists believed that everything falls within power relations that are fluid and that "can be modified under different cultural conditions" (Markula \& Silk, 2011, p. 51).

Nevertheless, this does not necessarily mean that everyone is equal in power, presently. Although poststructuralists assumed there are multiple truths and power is embedded within every relationship, this does not mean that the multiple truths are all equally influential. Some discourses have become so much more dominant and widely used than others that they become common sense and taken-for-granted notions of truth (Willig, 2013). As discourse, "ways of knowing" (Markula \& Silk, 2011, p. 49), constitutes the way one sees and understands the world, and has strong implications for power (Willig, 2013). Discourses are not inherently good or bad, but they do "legitimate and reinforce existing social and 
institutional structures, [while] these structures in turn also support and validate the discourses" (Willig, 2013, p. 130).

Foucault theorized "the linkages between discourse, knowledge and power... [and] politicized the workings of discourse to fundamentally ask 'whom does discourse serve?"' (Markula \& Pringle, 2006, p. 14). Taking a historical perspective, Foucault examined "the ways in which discourses have changed over time, and how this may have shaped historical subjectivities" (Willig, 2013, p. 130). He also argued that "instead of possessing power, dominant individuals or groups have arrived at their positions through the strategic use of discourses" (Markula \& Silk, 2011, p. 48). Thus, "power relations, for Foucault, are supported by knowledge" (Markula \& Silk, 2011, p. 46), not intrinsic superstructures that divide the privileged from the oppressed. Discourses, therefore, can always be countered because the structure is not inherent, as critical humanists believed. Poststructuralists argued that discourses should be interrogated and problematized to create new and broader meanings of concepts to stimulate social change (Markula \& Pringle, 2006).

The role of the individual: Critique of the humanist self. Rather than using the term identity, which suggests there are coherent and essential qualities to the self that are true and unchanging, poststructuralists constructed the term subjectivity instead to suggest that our ideas of self-identity are "constituted through the discourses to which the subject has access" (Weedon, 1997, p. 21). Depending on the discursive context, one will have different subject positions available to them, which is "a location for people in relation to dominant discourses, associated with specific rights, limitations and ways of feeling, thinking and behaving (Weedon, 1997, p. 3). These subject positions, then, constitute one's subjectivity, which is "the conscious and unconscious thoughts and emotions of the individual, her sense of herself and her ways of understanding her relation to the world" (Weedon, 1997. p. 32). Poststructuralists do not believe there is a 'true self' but rather an individual becomes "a 
subject within power relations and continually creates an understanding of a self or assumes an identity suitable to a specific social context" (Markula \& Silk, 2011, p. 48). "While the construction of the self can be dominated by discourses, the individuals, as part of power relations, can also actively construct selves that while still informed by the discourses, are less dependent on them" (Markula \& Silk, 2011, p. 49). By decentering the essence of self and "making our subjectivity the product of the society and culture within which we live" (Weedon, 1997, p. 32), the discourses that constituted, and historically constrained, certain individuals' subjectivity becomes changeable.

\section{Foucauldian Theorizing of Power}

Foucault (1977) posited in Discipline and Punish that power operates differently in modern times compared to how it operated in monarchal societies. He observed that modern societies certainly punish less, but punish more efficiently. Foucault articulated ways in which power has changed its form and still operates as prevalently as it did in the past, today. Before, in monarchal societies, the ruling class would use torture and executions to assert power and control over their subjects. The king is the authoritative figure and the purpose of punishment is revenge. The ruling class would stay in power due to fear of prosecution and violence.

Foucault observed that, in modern society, power operates in a different form. Although modern society appears more humane and democratic society because there are less visible physical forces such as public executions, Foucault observed that power did not disappear; it just changed forms. Power is pervasive and everywhere rather than centralized in one power figure (i.e., the king). Whereas the previous goal of punishment was revenge, the current goal of power was seen as rehabilitation. The goal of power, which Foucault called discursive power, was to reform society's deviants so they could return back into 
society. In place of torture and punishment, Foucault explained that discursive power operated in the form of disciplinary techniques.

Means of correct training. Foucault (1995) explained that disciplinary power makes individuals because disciplinary power is productive. Individuals are produced through three means of correct training: hierarchical observation, normalizing judgment, and a culminating examination. Hierarchical observation allows the body to be easily surveyed and, therefore, known. Through continuous surveillance, individuals are subject to a normalizing judgment. Normalizing judgment "imposes homogeneity; but it individualizes by making it possible to measure gaps, to determine levels, to fix specialties and to render the differences useful by fitting them one to another" (Foucault, 1995, p. 184). These two instruments then culminate into the third, a highly ritualized examination, which "helps constitute different individuals" (Markula \& Pringle, 2006, p. 41, emphasis in original) through the continuous collection of personal information. Through the employment of these three instruments, individuals become "objects of knowledge" (Heikkkala, 1993, p. 401, as cited in Markula \& Pringle, 2006, p. 41) that are disciplined more easily.

Panopticism. The constant surveillance of deviance eventually becomes internalized by the subject and takes on the form of self-surveillance, which leads to a disciplinary society. Foucault perceived Jeremy Bentham's architectural design of the Panopticon as representative of his theorization of disciplinary power and its subsequent production of docile individuals (Foucault, 1995). The Panopticon was Bentham's design for a prison system, which consisted of a central tower erected in the center of a circular building. From the central tower, a single guard could observe every single inmate, as the inmates were divided into individualized cells that aligned the walls of the circular building. The central tower would also be brightly lit, which allowed the guard to see all, but left the prisoners unsure of when they were being observed and by whom. This produced, within the inmates, 
the effect being exposed to a subtle, but pervasive and omnipresent gaze, "a state of permanent visibility" (Foucault, 1995, p. 200).

By being exposed to this panoptic gaze, power is exercised with a "problematic efficiency" (Markula \& Pringle, 2006, p. 43) as individuals would self-survey deviance and correct themselves, even in the absence of powerful others. In other words, individuals are "caught up in a power situation of which they are themselves the bearers" (Foucault, 1995, p. 201). Thus, the Panopticon is "a type of location of bodies in space, of distribution of individuals in relation to one another, of hierarchical organization, of disposition of centres and channels of power, of definition of the instruments and modes of intervention of power" (Foucault, 1990, p. 205), which leads to the automatic functioning of disciplinary power. This efficiency is secured "only if... it can be exercised continuously in the very foundations of society, in the subtlest possible way" (Foucualt, 1995, p. 207)

The Panopticon provided an answer to the question, why are socially constructed discourses so pervasive? Why do individuals, even in the absence of authoritative figures, still discipline themselves? For example, why do women continue to take on domestic roles when opportunities for upward social mobility are increasingly made available? The perpetual and omnipresent visibility, the panoptic gaze, leads individuals to internalize dominant discourses where "the fear of punishment had been exchanged for the fear of being abnormal" (Wilchins, 2004, p. 960, emphasis in original). The Panopticon produced normalized individuals who worked to achieve normality to avoid "the range of micropenalties associated with deviations from the "norm"” (Markula \& Pringle, 2006, p. 44). Therefore, disciplinary power in a disciplinary society is productive in that "difference would not need to be punished, but could actively be prevented, and not by authorities, but by individuals themselves, and not just intermittently when in public, but continuously, in private as well" (Wilchins, 2004, p. 994). 


\section{Application of Foucauldian Poststructuralism to Microaggressions}

In this section, the I apply Foucauldian poststructuralist theory to theorizing microaggressions. Foucauldian poststructuralists posit that discourse has inherent implications of power because "unlike interpretive research, however, the multiple interpretations of reality become valuable only when reflected against the social and historical context of the knowledge making" (Markula, Grant, \& Dension, 2001, as cited in Markula \& Silk, 2011, p. 47). Not all realities are considered equally valid; some discourse becomes legitimized through power relations and social institutions while others do not. Some discourses (ways of understanding) become so dominant that they are considered "common sense" (Willig, 2013, p. 130) and hard to challenge. I further theorize that microaggressions act as a panoptic gaze in daily life, leading individuals to internalize societal power structures. Therefore, by examining the discourse used to make sense of racial microaggressions, researchers can examine which culturally and historically specific discourses have become dominant and how they are informing individuals' understanding of microaggressions and themselves.

Critique of universal metanarratives: Multiple, fractured realities. There are two dominant discourses that surround microaggressions: (a) microaggressions as harmful or (b) microaggressions as jokes that are taken seriously by some, which leads to a culture of victimhood. Although some microaggressions appear to be clear in their intent as to whether they were overtly racist or innocent jokes (Wong et al., 2014), more instances fall in between the two on a continuum. The contradicting, confusing, paradoxical experience for the victim as well as the perpetrator is precisely one of the reasons why microaggressions are reported to be harmful (Sue, 2010). Critics of microaggressions have used the subconscious and contextual nature of microaggressions as proof of its nonexistence (Friedersdorf, 2015). By demanding for a true and a single reality of microaggressions that all evidence points to, it 
appears as if critics are arguing, "if you cannot adequately respond to all our points, then racial microaggression does not exist!" (Sue, Capodilupo, Nadal, \& Torino, 2008, p. 278).

However, from a poststructuralist perspective, the contradicting and confusing realities of microaggressions are expected. Poststructuralists assume that reality is multiple, fragmented, unstable, and ever-changing (Markula \& Silk, 2011). Therefore, asking "Which version of the microaggression experience is true?" would not make much sense from a Foucauldian poststructuralist perspective because there will always be multiple ways to experience microaggressions because microaggressions are a discursive construction. From a Foucauldian poststructuralist perspective, the more relevant question to ask becomes "What are the dominant discourses that inform one's reality?" Examining the taken-for-granted assumptions would give us access to why people experience microaggressions differently. Although poststructuralists believe in choice and human agency, they argued that one's "choices are limited by the discourses they adhere to when shaping their identity" (Waldron, 2015, p. 36). Therefore, poststructuralists work to identify the dominant discourses that inform an individual's interpretation of microaggressions.

Critique of dualist understanding of power. Poststructuralists' assumption that power is relational has several implications for the theorizing of microaggressions. First, relational power explains how one comes into a position of power. An individual's or a group's position power is not based on one's inherent identity such as gender or race, but rather through the strategic use of discourses that are socially and historically legitimated through social practices and institutions. For example, White people (sub)consciously become perpetrators of microaggressions not because they are White per se, but because the socially constructed characteristics and social realities of Whites have historically been considered more legitimate and true. "For too long they [people of color] have been told that their perceptions are incorrect, that there are other logical and rational reasons for the actions 
of others (especially on racial issues), and that their assertions have no empirical validity" (Sue et al., 2008, p. 277, emphasis in original). Willig (2008) explained that traditionally dominant groups hold power through the strategic use of discourse rather than their innate qualities of skin color or gender. As Sue et al., (2008) put it, dominant social groups (e.g., White people) have had the "power to define reality" (p. 277).

The power-discourse-knowledge relationship allows researchers' understanding of microaggressions to extend beyond identity-based microaggressions. Although social identity categories, as they are socially constructed, have real social consequences, researchers may focus on the discourses that shape one's experiences of microaggressions rather than to what social identity category one belongs. The question becomes 'how does power work?' rather than "Who has power?" This view allows researchers to avoid creating a hierarchy of suffering by arguing which identity group is most oppressed. Understanding microaggressions outside of fixed social identity categories also allows for fluidity in power relations, which can allow for the consideration of the multiple, fragmented, and contradicting discourses one is exposed to rather than attributing one's experience solely to discourses surrounding their race or gender. This provides an explanation for why other Black athletes on the Miami Dolphins did not perceive the same racial microaggressions as Jonathan Martin, even though some of Incognito's verbal harassments reportedly held racial undertones.

The increasing critiques against microaggressions, claiming they promote a culture of victimhood (Campbell \& Manning, 2014; Friedersdorf, 2015) of "weak, psychologically vulnerable people who are unable to respond effectively" (Thomas, 2008, p. 275) offer another example of how power manifests in microaggression research. With the discourse of "microaggressions as encouraging victimhood culture", researchers might ask, "Whom does 
discourse serve?" (Markula \& Pringle, 2006, p. 14) when microaggression experiences are trivialized?

The role of the individual: Critique of the humanist self. Poststructuralist researchers theorize that realities as well as our sense of self is discursively constructed (Markula \& Silk, 2011), which helps researchers understand why people of color and various marginalized groups minimize or even deny that discriminatory experiences exist. For example, Jonathan Martin described himself in the following way:

I figured out a major source of my anxiety. I'm a push over, a people pleaser. I avoid confrontation whenever I can, I always want everyone to like me... I mostly blame the soft schools [Harvard-Westlake High School \& Stanford] I went to, which fostered within me a feeling that I'm a huge pussy, as I never got into fights. (Healy, 2014)

The understanding of Martin as a push over is not a self-evident or universally agreed upon understanding. It is legitimized only when drawing upon the discourse of hegemonic masculinity where men are expected to be tough and emotionally detached (Waldron, 2015). Within the discourse of hegemonic masculinity, Martin is positioned to either brush off various forms of bullying including microaggressions to form his subjectivity as a "real" man. To admit to being bothered by a microaggression would mean he was somehow not a real man or athlete, which is what appears to have occurred in his case.

Because poststructuralist researchers assumed that we are products of society and discourse our understandings of ourselves are discursively constructed and can change. In fact, since discourses are multiple and the subject positions available within each discourse varies, poststructuralist theorists explained that we constantly (re)negotiate our subjectivities. Poststructuralist understandings of the self, then, appear compatible to extend beyond identity-based microaggressions to examining intersectional (Crenshaw, 1991) 
microaggressions, which acknowledges our multiple social identities as well as the interrelated nature of systems of oppression due to our multiple intersecting social identities.

Microaggressions as panoptic gaze. Using a Foucauldian poststructuralist perspective, I theorize that microaggressions act as a daily panoptic gaze, a normalizing presence that continuously reminds individuals that hold minority statuses in society of their abnormality. Racial microaggressions such as assuming criminality of Black individuals not only reflects the perceptions, but further produces the dominant discourse that Black individuals are violent and dangerous. Microaggressions, therefore, exemplify Foucault's theorization of disciplinary power in how it subtly penetrates the most minute avenues in society, even in the absence of an authoritative other. The panoptic gaze, subsequently, “automatizes and disindividualizes power" (Foucault, 1995, p. 202). Power lies in disciplinary techniques, not an individual, which allows any random individual to exercise disciplinary power (Foucault, 1995).

The effect of mircroaggresssions is productive, in the following sense. A Japanese saying captures the essence of the panoptic gaze and its productive disciplinary power; "The nail that sticks out will be hammered in" (Wilchins, 2004, p. 985, emphasis in original). Microaggressions identify who is sticking out. With the constant perpetration of microaggressions, individuals become "excruciatingly self-conscious of it [their own abnormality]" (Wilchins, 2004, p. 985) and act to hammer themselves back in by normalizing themselves. These normalizing practices, however, are attributed to one's innate qualities rather than a product of socially constructed power structures.

He who is subjected to a field of visibility, and who knows it, assumes responsibility for the constraints of power; he makes them play spontaneously upon himself; he inscribes in himself the power relation in which he simultaneously plays both roles; he becomes the principle of his own subjection. (Foucault, 1995, p. 202) 
With disciplinary power, society no longer has to exclude individuals; rather, society can prevent deviance, as long as abnormal individuals are willing to conform. "Its [Panopticon's] aim is to strengthen the social forces - to increase production, to develop the economy, spread education, raise the level of public morality; to increase and multiply" (Foucault, 1995, p. 207).

The microaggression as a daily panoptic gaze provides a better and more efficient way to exercise power. Disciplinary power permeates to "the very foundations of society, in the subtlest possible way" (Foucault, 1995, p. 207) by becoming an" internalized norm" (Wilchins, 2004, p. 960). The panoptic gaze, which is everywhere and nowhere produces docile individuals who self-survey and correct their own deviance from the norm. Markula and Pringle (2006) argued that "a complex challenge for contemporary researchers stemming from Foucault's concerns with panopticism is to identity the mechanisms of disciplinary power and the related modes of domination" (p. 45). Previous researchers in the field of sport and exercise have attempted to see "how sport and fitness practices act as technologies of domination that encourage individuals 'into a discursive web of normalizing practices' (Markula, 2003, p. 88, as cited in Markula \& Pringle, 2006, p. 45). Researchers also examined the various "agents of normalization" (Halas \& Hanson, 2001, p. 123, as cited in Markula \& Pringle, 2006, p. 45) such as coaches and sport researchers in sport and exercise that contribute to the production of docile individuals. In this study, I examine "the taken-forgranted words people use as they account for and talk about" (Waldron, 2015, p. 35) microaggressions. 


\section{Appendix C: Extended Methodology}

The following section outlines my underlying philosophical assumptions as the researcher. My philosophical assumptions about knowledge and reality inform my subsequent theoretical and methodological decisions for how to design and conduct this study. This section is intended to inform the reader on how to understand this study from the researcher's point of view and understand the rationale for the methodological decisions I made by understanding my worldview on epistemology, ontology, axiology, rhetoric, and methodology.

\section{Epistemology}

Epistemology refers to how one understands the pursuit and acquisition of knowledge (Crotty, 1998). In other words, epistemology is the study of the relationship between the knower and the known, asking, 'How do I know what I know?' Can knowledge be acquired and known independent of the knower or is knowledge something that the knower (e.g., researcher) co-creates or even creates all by themselves?

There are a wide variety of epistemologies (views on how we know what we know), which fall on a continuum. Those on one end of the continuum state that the knower and what-is-to-be-known are completely independent of each other. Traditional epistemologies such as objectivism view knowledge and meaning as solely lying within what-is-to-beknown. How we acquire meaning and knowledge, thus, is to remove ourselves (the knower) as much as possible so we can acquire meaning objectively and without interference. For example, a researcher studying microaggressions, while adhering to an objectivist epistemological view, would need to remove themselves as much as possible during data collection and analysis so as to not influence the process of acquiring knowledge. The underlying assumption in this case would be that meaning and knowledge lies within participants and microaggressions, not the researcher. 
On the other end of the spectrum is subjectivist epistemology that views meaning and knowledge as being created solely by the knower. They argue that there is no knowledge that is independent of the knower, but that there are, in fact, only interpretations of the knower. What-is-to-be-known has no inherent and intrinsic meaning; rather, meaning is imposed onto the known by the knower. This is not to say that meaning comes from nowhere - the knower's meaning must come from somewhere such as the knower's previous experience, dreams, unconscious etc. Nevertheless, it is to say that "meaning comes from anything but an interaction between the subject and the object to which it is ascribed" (Crotty, 1998, p. 9).

Constructionism may be seen as lying in between objectivism and subjectivism on the continuum of epistemologies. Constructionism also rejects the idea that meaning and knowledge lies solely within the what-is-to-be-known. Crotty (1998) explains "there is no meaning without a mind" (pp. 8-9), meaning that we acquire meaning and knowledge when the knower (consciousness) engages with the object (what-is-to-be-known). A material reality may exist independent of the knower, but meaning is always co-constructed by the knower and what-is-to-be-known. This is not to say, though, that everyone can arrive at their own independent meanings and interpretations or that all interpretations are considered and weighted equally (this would be subjectivism). Although meaning can be whatever the knower wants it to mean in the ideal (because the relationship between the knower and the known is arbitrary), in reality, social constructionists assume that meaning is not limitless, but always bound by the societal context, not because it has to be, but because it is. Crotty (1998) explains the hold culture has on us,

We are all born into a world of meaning. We enter a social milieu in which a 'system of intelligibility' prevails. We inherit a 'system of significant symbols'. For each of us, when we first see the world in meaningful fashion, we are inevitably viewing it through lenses bestowed upon us by our culture. 
Our culture brings into view for us and endows them with meaning and, by the same token, leads us to ignore other things. (p. 54)

In other words, the knower will see only what they know as well as know what they have the language to explain, which is shaped and produced by one's cultural context.

In this study, I adhere to an epistemology of social constructionism. My view of knowledge is that, even though a material reality can exist (e.g., we can literally see difference in skin pigment, chromosomes, and physical characteristics), what this material reality means (e.g., what it means to have darker skin) is dependent on the knower. The knower will then know and see, within the object (what-is-to-be-know), what they formally know; in other words, you only see what you know based on the cultural meanings and interpretations that are afforded to you. Thus, in my analysis of data, my goal was to examine the underlying discourse and taken-for-granted assumptions that allow individuals to see, think, feel the way they do as a way to examine the cultural hold on individuals, rather than focus and analyze what participants are saying in a literal sense (e.g., linguistic analysis). This approach is consistent with a critical line of thought that scrutinizes "particular sets of meanings [or culture], because they have come into being and out of the give-and-take of social existence, [and] exist to serve hegemonic interests" (Crotty, 1998, p. 59). This is the underlying philosophical assumption of a poststructuralist approach, which is the theoretical framework of this study.

\section{Ontology}

Ontology is the study of reality and being (Crotty, 1998). An ontological question asks, 'What is reality?' or 'What exists?' Because of the confluences of epistemological issues and ontological issues, Crotty (1998) clarifies that, when talking about reality, we are never suggesting there is no material reality at all, but that "the existence of a world without a mind is conceivable. Meaning without a mind is not" (pp. 10-11). As I noted in the 
epistemological section above, certainly there are realities that exist that are observable to us all (e.g., different physical features between genders, varying skin pigment). Nevertheless, it is when we discuss how we come to learn the meaning of what we observe that it becomes an issue of epistemology (what do we know and how do we know what we know?).

Realism is "an ontological notion asserting that realities exist outside the mind" (Crotty, 1998, p. 10). Realism views that there is one universal truth. There is one meaning to be derived, whether it be from discovering it, constructing it, or creating it. There is an inherent essence to the world, to phenomenon, and to meaning and understanding. For example, positivists adhere to a realist ontology and look for universal principles that explain phenomena, and may ask questions such as 'What is a microaggression?' 'What is the phenomenological essence to peoples' experiences with microaggressions?' or 'Does daily mindfulness practice reduce stress related to microaggressions or not?'

On the other hand, relativists view realties and meanings as multiple and that there is no single and universal essence to truth and to phenomena. The goal of research for relativists, then, is to find ranges of ways to make sense of phenomena rather than to find universal and generalizable truths. Foucauldian poststructuralists adhere to a relativist ontology that multiple truths exist; nevertheless, as discussed above, multiple realities are not considered and weighted equally. Some are considered and made more legitimate than others. Therefore, in this study, I adhered to a relativist ontological approach and aimed to examine the underlying power dynamics within participants' experiences by examining how some truths are legitimized over others (e.g., what has become a dominant way of understanding) and by examining the social consequences of legitimizing some truths and not others.

\section{Axiology}

Axiology is the study of the role of values in knowledge acquisition (Clark \& Creswell, 2008). There are two main schools of thought: the idea that knowledge is value 
neutral and the idea that knowledge is value-laden. Whereas traditional quantitative and positivistic research strives to conduct research that is free from the values of the researcher, others view knowledge as value-laden that cannot be free of or neutral to the impact of values (Clark \& Creswell, 2008). Axiological views are naturally connected to ontology and epistemology. If one views reality as being singular and universal and is in search of a universal meta-narrative and views knowledge as being independent of the knower, knowledge can be acquired value-free from the knower. However, if one adheres to a worldview that knowledge is always acquired through the eyes of the knower, knowledge can never be value-free from the knower.

Foucauldian poststructuralists acknowledge that all knowledge is, in fact, value-laden. Moreover, Foucault explained the relationship between knowledge and power as interconnected. There is no value-free and power-free knowledge; knowledge always has power implications. The implication for researchers is that the knowledge constructed by the researcher is always value-laden. It is shaped as well as limited by the researchers' lens. The researcher is always bound by cultural contexts; in other words, what the researcher sees and knows is bound by the cultural understanding of the researcher.

Therefore, for researcher validation, poststructuralist researchers do not strive to obtain value-free and neutral knowledge. Rather, poststructuralists aim to make their own cultural lens explicit. In this study, I, as the researcher, took reflexive notes to try to be explicit in my own cultural lens. As I adhere to a Foucauldian poststructuralist theoretical lens, I outlined the ways in which Foucault's theorization informed my understanding of participants' experiences. In addition, I contextualized as well as contested my own boundaries and socially constructed meanings through the analytic memos in an effort to offer multiple and layered constructed meanings. This adheres to crystallization, a research validation method for poststructuralist research. All of these poststructuralist validation 
measures, however, are to provide context to knowledge rather than freeing knowledge from its constructed nature.

\section{Rhetoric}

There are two common ways to communicate academic research: a first-person narrative and a third-person narrative (Ellingson, 2009). Researchers are encouraged to choose the style of reporting that best reflects their philosophical assumptions(Ellingson, 2008; Richardson, 2000). In positivist or post-positivist research, it is common or essential to write in third-person because (post)positivist researchers assume that what-is-to-be-known is separate from the knower (Clark \& Creswell, 2008). The third-person writing style reflects this assumption that the researcher is removed from the researcher-ed. In constructionist or critical research tradition, however, it is more common to write in first-person to reflect the epistemological assumptions that the knower and knower's lens cannot be removed from what-is-to-be-known (Ellingson, 2008; Richardson, 2000). A fundamental assumption of a Foucauldian poststructuralist perspective is that discourses constitute our reality; we see what we know. This assumption applies to researchers and the process of research as well. As a social constructionist, my assumption is that the researcher is always co-constructing meaning(s) in the moment that are multiple, partial, and limited (Ellingson, 2008). Rather than viewing co-construction as a limitation, I engage in a validation process of crystallization to "celebrate multiple points of view of a phenomenon across the methodological continuum" (Ellingson, 2008, p. 22).

Thus, in this study, I chose a first-person style of rhetoric to reflect this assumption that the knower and what-is-to-be-known cannot be separated from each other. "First-person voice usually provides the most concise and precise way of describing research processes, finding, and implications” (Ellingson, 2008, p. 159). Following Ellingson's (2008) suggestions for improving writing in social science, I write myself into my research and offer 
my standpoint to demonstrate how I am co-constructing the research process, data collection, analysis, and reporting. In fact, “interrogating my subjectivity through continual reflection on my role in data collection, analysis, and representation offers far more rigor than pretending my subjectivity does not exist or has been somehow eliminated from the process of my research (see Harding's 1993 discusion of “strong objectivity”)" (Ellingson, 2008, pp. 183184).

\section{Methodology}

Research methodology refers to the research design and strategy that shapes our subsequent choice of methods for data collection and analysis (Patton, 2014). The methodological approach for this study, as influenced by social constructionist epistemology and Foucauldian poststructuralist theoretical approach, is Foucauldian discourse analysis. Thus, in this study, I focused on discourse as a way to access meaning(s) and truth(s) that inform participants' experiences with microaggressions. Per my adherence to constructionist epistemology, I assumed that we see what we know, which is produced by cultural meanings and interpretations. Furthermore, adhering to a Foucauldian poststructuralist theoretical approach, I assumed that what we know is determined by discourse. Moreover, I used a Foucauldian approach to discourse analysis to examine how power operates within language and how that constitutes our reality. Thus, for the purposes of my study, I attempted to access participants' discourses related to microaggressions during data collection through two separate interviews; I examined the social consequences of drawing upon such discourses related to microaggressions in those interviews by asking focused and theoretically informed questions. I also provided a literature review to situate the study as a way to provide social and cultural context for making sense of the dominant discourses of participants, and in addition took detailed analytic memos as a way to contextualize my interpretations as the 
researcher (i.e., why do I see what I do based on what I know). The subsequent methods I chose were also aligned with my philosophical and theoretical assumptions.

\section{Researcher Positionality}

Poststructuralist researchers argued that a positionality statement contradicts the underlying assumption of poststructuralist research because it is a rhetorical tool used to establish a sense of objectivity within research. Nevertheless, poststructraulist researchers adhering to social constructionism assume that the entire research process is constituted by the researcher's lens, which is bound by societal discourses. The knower cannot be separated from what-is-to-be-known. Rather than seeking objectivity in research, poststructuralist researchers aim to achieve crystallized understandings of a phenomenon by examining it through multiple reflexive lenses. Thus, I construct the positional statement below, not as a form of "bracketing," but as a way to provide a reflexive lens through which the study can be crystallized through. I make no claims of objectivity or neutrality throughout the project.

Role of the researcher. I am an Asian female doctoral student who was born in the United States. I spent my early childhood in the U.S., in Texas, but moved to Seoul, South Korea in the $3^{\text {rd }}$ grade and lived there until I started graduate school in 2009. Growing up as a racial minority in a dominantly white neighborhood, I was very aware of my racial identity from an early age. Although I did not feel different, my interactions with other people made me realize that I was not the norm. I was different and I remember I was aware that being different was a bad thing. I remember hating being different. I disliked that I was Asian. I did not like that I had different phenotypes and that I did not like that we ate different food at my house. I was embarrassed to bring my White friends to my house. I hated having to "embrace" my Korean roots and wear traditional clothes for school fairs because this meant my difference was accentuated and it was embarrassing. Looking back, I learned about the discourses surrounding race, not through the overt discriminatory acts of others, but through 
subtle communications such as microaggressions. Microaggressions were heavily featured during my childhood in the United States.

In college, I had the opportunity to study abroad for my education in Finland. I enjoyed being there and seeing their appreciation for physical activity, which was different from what I encountered in Korea. In Korea, I perceived that society devalued physical activity and sport and did not perceive it as a rigorous academic discipline. I decided to go back to Finland to pursue my Master's degree in Sport and Exercise Psychology. I also had the chance to study in Germany for a semester; I was exposed to various colleagues and scholars from all over the world during these two years. This was an important turning point in my life because I was exposed to critical scholarship during this time that gave me a framework and language to make sense of some of my lived experiences of living in different countries.

Currently, I am pursuing my doctorate in the U.S. in a small rural town in WV. This past year, I moved to Ithaca, NY, for a predoctoral position. During my graduate training, I developed a strong interest in issues of social justice because I recognized from my personal experiences and my graduate training that cultural differences not only exist, but that these cultural differences are also stratified. Especially, being a foreigner in different countries has led to an acute awareness of my "otherness" (Connolly, 1985), my deviation from the norm. However, it was difficult to pinpoint why and how I felt this cultural stratification. Everyone was nice to me. Overt acts of discrimination were rare. In fact, most people I encountered expressed openness and acceptance of different cultures. So why did I still feel like an outsider? Was I being petty? This is when I encountered the academic concept of microaggressions. It was a "Eureka!" moment, as though I finally had a label to name my experiences and validate them as something real. It was not me! I learned that I was not making things up in my head, but that microaggressions were a real construct and 
phenomenon that many people from marginalized groups experienced. The term was extremely validating for me. It allowed me to continue sharing experiences with others because I finally had a name for the subtle discrimination I experienced daily through my entire life. Gradually, I started focusing my doctoral training on addressing cultural competence issues in the field and advocating for more culturally inclusive practices. I decided to explore the concept of microaggressions in sport to identify and demonstrate how discrimination is prevalent and permeates our daily lives, whether we are aware of it or not.

My personal and professional interests influence the research process. Social constructionists consider the researcher's influence as inevitable. Nevertheless, it is ethical and practical to report the process of the data collection and analysis process in great detail in an effort to demonstrate how the researcher co-constructed the study. One way this is achieved is through reflexive practice (Mcgannon \& Busanich, 2010; Ryba et al., 2013). Thus, "Self-reflexive forms of writing and record keeping are adopted throughout data collection and analysis phases (e.g., reflexive journal to focus on researcher responses, thoughts and feelings toward participants, thoughts about emergent categories and the implications)" (McGannon \& Smith, 2015, p. 82). Based on this self-reflexive journal of the research process, I plan to write additional research articles of how I interacted with and influenced the research process from the researcher's point of view as a way to engage in the research crystallization process, which shows the multiple perspectives and nuance of the phenomenon of racial microaggressions in sport (Ellingson, 2009). 


\section{Appendix D: Focus Group Interview Script}

\section{Interview Script for Focus Group}

Hi everyone, I'm Sammy. Thank you again for taking the time to participate in my research on student-athletes' experiences as a racial minority in sport. Before we begin, I would like to go over some reminders for your participation. This information has also been outlined in the informed consent form I emailed you. You also have a copy in front of you here.

First of all, the most important thing for you to remember is that there are no right or wrong answers. I am interested in each individual's unique experience. Because I want to ask specifically about how YOU experience things, I may ask several follow up questions and ask you to explain in detail to make sure I am following YOUR point of view. Because I don't want to assume anything or put words in your mouth. If, at one point, I do summarize your ideas inaccurately, please feel free to jump in and correct me.

Your participation will be kept as confidential as legally possible. However, there are limits to confidentiality since this is a focus group. The person beside you obviously knows who you are and what you have discussed. If you feel uncomfortable or unwilling to share, you may choose to remain silent during the focus group. Regardless of your level of participation, this focus group interview will be helpful for your second interview. However, the more you participate, the more helpful it will be for your follow up interview. I do ask that you will respect the privacy of each other today, and keep whatever was discussed amongst us here confidential and do not discuss what the other person said to someone else, without their permission.

If you feel uncomfortable with any question, you may choose to skip it. I am trained as a master's level counselor so if you are, by any chance, feeling distress with any of the topics raised today, we can stop the interview. Your wellbeing is the most important and I 
will help you process your distress. I can also connect you to additional resources if you need them.

This interview is being audio recorded. However, the recording will also be kept confidential. Even for the recording, I will remove names. So we can refer to you as A. And you can refer to yourself as B. So if I have to refer to you, I will say, "thank you for sharing that, A". Do you have any questions? If not, you can sign the consent form. You will sign two forms and you may take a copy. 


\section{Appendix E: Focus Group Interview Protocol}

\section{Introduction Phase}

1. I would like you to introduce yourself freely, using your own words. You can choose to share whatever you think is important for us to know who you are.

2. Tell me about the most salient parts of your identity. Complete the following sentence, "I am..."

3. Using your own words, can you describe what it is like to be a student-athlete?

4. Using your own words, can you describe what it is like to be a student-athlete of color?

\section{Photo Phase}

B What are your reactions (thoughts, feelings) to these photos?

C What do you think they are thinking?

D What do you think they are feeling?

E How do you think they could react to these comments surrounding them?

F How do you think they should react to these comments surrounding them?

\section{Discussion Phase}

1. Have you had similar experiences as those mentioned in these photos?

2. Have you witnessed experiences similar TO those mentioned in these photos?

3. Can you share your example(s) using details?

a. How did you feel in response to that incident?

b. What were your thoughts in response to that incident?

c. How did you respond to that incident?

d. Looking back, would you respond differently? If so, how? If not, why not?

e. How do you cope with incidents like that?

\section{SPORT}

4. Have you had similar experiences as those in sport? 
5. Have you witnessed similar experiences in sport?

6. Can you share your example(s) using details?

a. How did you feel in response to that incident?

b. What were your thoughts in response to that incident?

c. How did you respond to that incident?

d. Looking back, would you respond differently? If so, how? If not, why not?

e. How do you cope with incidents like that?

7. Do you have any other experiences similar to those in the photos you'd like to share?

8. Where do these incidents occur?

9. When do these incidents occur?

10. Who makes comments like this?

\section{Closing Phase}

1. What is it like to talk about your experiences now in this interview?

2. Is there anything else you would like to add or share?

\section{General open-ended questions for probing}

- Can you tell me more?

- Is there anything else?

- Are there any other details you would like to add that could help me understand [your example/statement/comment/etc.]? 


\section{Appendix F: Individual Interview Protocol}

\section{Microaggressions}

a. Would you like to add to anything you said/did not say in our last focus group interview?

b. Can you recall experiences in your life in sport that you would be characterized as microaggressions?

\section{A. If participant can think of many examples}

1. Think about one microaggression example in sport that has impacted/stuck with you the most. Can you share your example using details?

2. What about this example has made it stick with you the most?

a. How did you feel in response to the microaggression?

b. How did the microaggression affect you?

c. How did you respond to the microaggression?

d. Looking back, would you respond differently? If so, how? If not, why not?

e. How do you cope with microaggressions?

f. Do you have any prologues to your example that would be helpful for me to know? In other words, is there information that happened before the incident that would be useful for me to know to understand your example?

g. Now tell me about the epilogue. Can you tell me what happened after the incident?

3. Think about one microaggression example in sport that you would consider to be typical. Can you share your example using details?

a. What about this example makes you consider it typical?

b. How did you feel in response to the microaggression?

c. How did the microaggression affect you?

d. How did you respond to the microaggression? 
e. Looking back, would you respond differently? If so, how? If not, why not?

f. Do you have any prologues that would be helpful for me to know? Is there information that happened before the incident that would be helpful for me to understand your example?

g. Now tell me about the epilogue. Can you tell me what happened after the incident?

h. How do you cope with microaggressions?

4. What was it like to participate in the focus group interview?

5. What is it like to share your experiences now in this interview?

\section{B. If participant cannot think of many or any examples}

1. Can you recall your experiences that you witnessed in sport that would be characterized as microaggressions? Can you share your example using details?

a. What was it like to witness the microaggression? How did it impact you?

b. Do you have any prologues to your example that would be helpful for me to know? In other words, is there information that happened before the incident that would be useful for me to know to understand your example?

c. Now tell me about the epilogue. Can you tell me what happened after the incident?

2. Can you think of a time(s) when you felt you were judged or did not fit in while you were participating in your sport? Can you share your example using details?

a. How did you feel in response to the(se) experiences?

b. How did the(se) experiences affect you?

c. How did you respond to the(se) experiences?

d. Looking back, would you respond differently? If so, how? If not, why not? 
e. Do you have any prologues to your example that would be helpful for me to know? In other words, is there information that happened before the incident that would be useful for me to know to understand your example?

f. Now tell me about the epilogue. Can you tell me what happened after the incident?

3. What was it like to participate in the focus group interview?

4. What is it like to talk about your experiences now in this interview? 


\section{Appendix G: Questions for Foucauldian Discourse Analysis}

Key questions driving Foucauldian discourse analysis (adopted from Vingoe, 2008, as cited in Willig, 2013, p. 141)

\begin{tabular}{|c|c|}
\hline Key questions & Corresponding analytic stage \\
\hline $\begin{array}{l}\text { - How is the discursive object constructed } \\
\text { through language? } \\
\text { - What type of object is being } \\
\text { constructed? }\end{array}$ & Stage 1: Discursive constructions \\
\hline $\begin{array}{l}\text { - What discourses are drawn upon? } \\
\text { - What is their relationship to one } \\
\text { another? }\end{array}$ & Stage 2: Discourses \\
\hline $\begin{array}{l}\text { - What do the constructions achieve? } \\
\text { - What is gained from deploying them } \\
\text { here? } \\
\text { - What are their functions? } \\
\text { - What is the author doing here? }\end{array}$ & Stage 3: Action orientation \\
\hline $\begin{array}{l}\text { What subject positions are made } \\
\text { available by these constructions? }\end{array}$ & Stage 4: Positionings \\
\hline $\begin{array}{l}\text { - What possibilities for action are mapped } \\
\text { out by these constructions? } \\
\text { - What can be said and done from within } \\
\text { these subject positions? } \\
\text { What can be said and done from within } \\
\text { these subject positions? }\end{array}$ & Stage 5: Practice \\
\hline $\begin{array}{l}\text { - What can potentially be felt, thought and } \\
\text { experienced from the available subject } \\
\text { positions? }\end{array}$ & Stage 6: Subjectivity \\
\hline
\end{tabular}




\section{Appendix H: Participant Recruitment Email - Student-Athlete}

\section{WestVirginiaUniversity.}

\section{Dear Participant,}

Hello. MY name is Sae-Mi Lee and I am a doctoral candidate at West Virginia University (WVU) in the Sport and Exercise Pyychology program. This letter is a request for you to take part in my dissertation research project to learn about the experiences of student-athletes who identify as a racial minority. This study is under the supervision of Dr. Edward Etzel, a prolessor in the College of Physical Activity and Sport sciences at Wvu (Edward.etzelemail.wwuedu). You are invited to participate in two separate interviews: a locus group interview followed by an individual interview 1-2 weeks later. Each interview will take approximately 60 minutes.

To participate in this study, you must be 18 years of age or older, identity as a racial minority, and have been a NCAA Divsion I athlete lor a minimum of one academic semester. Your involvement in this project will be kept as confidential as legally possible. The interviews will be audio recorded; the recordings will be securely stored and disposed of once the study is completed. All data will be reported in aggregate with all identifying information removed. I will not ask any information that should lead back to your identity as a participant. Your participation is completely woluntary. You may skip any question that you do not wish to answer and you may discontinue at any time. Your class or team standing will not be affected if you decide either not to participate or to withdraw. If you complete both interviews that are apart of this study you will receive a \$25 Amazon gift card. WVu's Institutional Review Board has reviewed and approwed this study (Protocol t1603052293).

To participate in this study, please email Sae-Mi at smlee Pmix. wru.edu. I hope that you will participate in this research project, as it could be beneficial to gain a deeper understanding of the experiences of student-athletes-of-color. My intended outcome is to find ways to improve student-athletes' experiences by developing and promoting inclusive sporting practices. Thank you very much for your time and willingness to participate in this study. Should you have any questions about this letter or the research project, please feel free to contact Sae-Mi or Dr. Edward Etwel.

Thank you for your time and help with this project.

Sincerely.

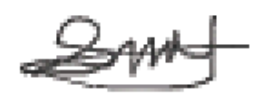

Sae-Mi Lee, M.S, M.A.

Fhent: 904-2919-70h Fas: 304-2015000 hatp/Woricinabanthwwitd.
Chesth-4 Midpe Restach B.Idhe

albs Chestin-t Fidpe Roud

Fo Bow 6ajs.

Margantown, wV 26sob-645 


\section{Appendix I: Participant Recruitment Email - Student-Athlete Development Staff}

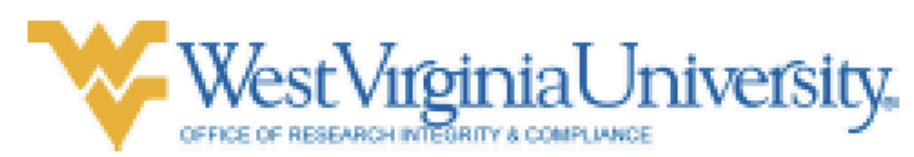

Dear Student-Athlete Development Staff,

Hello. MY name is Sae-Mi Lee and I am a doctoral candidate at West Virginia University (WVU) in the Sport and Exercise Pyychology program. This letter is a request for your help in recruiting studentathletes-ol-color to take part in my dissertation project to leam about the experiences of studentathletes who identily as a racial minority. This study is under the supervision of Dr. Edward Etzel, a professor in the College of Physical Activity and Sport Sciences at WvU (Edward.etzelemail.wwuedu). The student-athletes are invited to participate in two separate interviews a focus group interview followed by an individual interview 1-2 weeks later. Each interview will take approximately 60 minutes.

To participate in this study, participants must be 18 years of age or older, identity as a racial minority. and have been a NCAA Division I athlete for a minimum of one academic semester. The studentathletes' involvement in this project will be kept as confidential as legally possible. The interviews will be audio recorded; the recordings will be securely stored and disposed of once the shudy is completed. All data will be reported in aggregate with all identilying information removed. I will not ask any information that should lead back to their identity as a participant. Their participation is completely voluntary and they may skip any question that they do not wish to answer and they may discontinue at any time. The student-athlete's class or team standing will not be affected if they decide either not to participate or to withdraw. If they complete both interviews that are apart of this study, they will receive a $\$ 25$ Amazon gitt card. WVu's Institutional Review Board has reviewed and approved this study (Protocol tri603052293).

To participate in this study, please instruct your student-athletes to email Sse-Mi at smlee@mix.wvi.edu. I hope that wou will encourage your student-athiletes to participate in this research project, as it could be beneficial to gain a deeper understanding of the experiences of student-athletesof-color. My intended outcome is to find ways to improve student-athletes" experiences by developing and promoting inclusive sporting practices. Thank you very much for your time and willingness to encourage student-athletes-of-color to participate in this study. Should you have any questions about this letter or the research project, please feel free to contoct Sse-Mi or Dr. Edward Etzel.

Thank you for your time and help with this project.

Sincerelv.

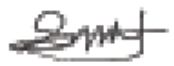

Sae-Mi Lee, M.S, M.A.

\begin{tabular}{|c|c|}
\hline Mathe sot. & 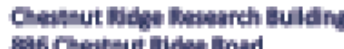 \\
\hline Mn: 364-294-5064 & po bar bists \\
\hline 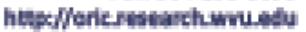 & Morpintow, wN 20506-68s \\
\hline
\end{tabular}




\section{Appendix J: Participant Recruitment Email - Coaching Staff}

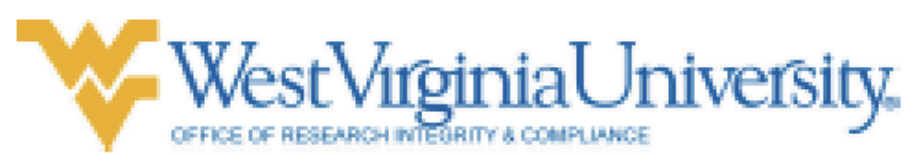

Dear Coaching Staff,

Hello. MV name is Sae-Mi Lee and I am a doctoral candidate at West Virginia University (WVU) in the Sport and Exercise Pyychology program. This letter is a request for your help in recruiting studentathletes-of-color to take part in my dissertation project to leam about the experiences of studentathletes who identify as a racial minority. This study is under the supervision of Dr. Edward Ekzel, a professor in the College of Physical Activity and Sport Sciences at WvU (Edward.etzellemail.wvuedu). The student-athletes are invited to participate in two separate interviews: a focus group interview followed by an individual interview 1-2 weeks later. Each interview will take approximately 60 minutes.

To participate in this study, participants must be 18 years of age or older, identity as a racial minority. and have been a NCAA Division I athlete for a minimum of one academic semester. The studentathletes' involvement in this project will be kept as confidential as legally possible. The interviews will be audio recorded; the recordings will be securely stored and disposed of once the study is completed. Al data will be reported in aggregate with all identifying information removed. I will not ask any information that should lead back to their identity as a participant. Their participation is completely voluntary and they may skip any question that they do not wish to answer and they may discontinue at any time. The student-athlete's class or team standing will not be affected if they decide either not to participate or to withdraw. If they complete both interviews that are apart of this study, they will receive a \$25 Amazon gitt card. Wvu's Institutional Review Board has reviewed and approved this study (Protocol t1603052293).

To participate in this study, please instruct your student-athletes to email Sae-Mi at smleedmix.wvu.du. I hope that wou will encourage your student-athiletes to participate in this research project, as it could be beneficial to gain a deeper understanding of the experiences of shudent-athletesof-color. My intended outcome is to find ways to improve student-athletes' experiences by developing and promoting inclusive sporting practices. Thank you very much for your time and willingness to encourage student-athletes-of-color to participate in this study. Should you have any questions about this letter or the research project, please feel free to contact Ste-Mi or Dr. Edward Etzel.

Thank you for your time and help with this project.

Sincerely,

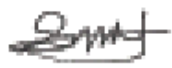

Sae-Mi Lee, M.S., M.A. 


\section{Appendix K: Informed Consent Form}

Human Research Protocol Only Minimal Risk Consent Form Without HIPAA

\section{W-WestVirginiaUniversity.}

\section{Only Minimal Risk \\ Consent Information Form (without HIPAA)}

Principal Investigator

Department

Protocol Number

Study Title

Co-Investigator(s)

\author{
Dr. Edward Etzel
}

College of Physical Activity and Sport Sciences

1603052293

Student-athletes' Experiences with Microaggressions

Sae-Mi Lee

\section{Contact Persons}

In the event you experience any side elfects or injury related to this research, you should contact Dr. Edward Etzel at (304) 293-7062 or Edward.etzel@mail.wvu.edu. If you have any questions, concerns, or complaints about this research, you can contact Sae-Mi Lee at smleee mix.wvu.edu or Dr. Edward Etzel.

For information regarding your rights as a research subject, to discuss problems, concerns, or suggestions related to the research, to obtain information or offer input about the research, contact the office of Research Integrity and Compliance at (304) 293-7073.

In addition if you would like to discuss problems, concerns, have suggestions related to research, or would like to offer input about the research, contact the Office of Research Integrity and Compliance at 304-293-7073.

\section{Introduction}

You, have been asked to participate in this research study, which has been explained to you by Sae-Mi Lee, PhD candidate in Sport and Exercise Psychology. This study is being conducted by Sae-Mi Lee under the supervision of Dr. Edward Etzel in the Department of Sport Sciences at West Virginia University.

\section{Purpose(s) of the Study}

The purpose of this study is to better understand the experiences of student-athletes-of-color. You are invited to participate in this study to share your ideas and feelings about your experiences in sport as a racial minority. The intended outcome of this study is to find ways to improve student-athletes' experiences by developing and promoting inclusive sporting practices.

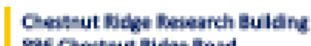

$$
\begin{aligned}
& \text { sab Chuit-ut indge liond } \\
& \text { po Ber } 6 \text { bas }
\end{aligned}
$$




\section{W. WestVirginiaUniversity.}

\section{Description of Procedures}

This study inwolves two separate interviews: a focus group followed by an individual interview 1 to 2 weeks later. Each interview will take approximately 60 minutes for you to complete. The most important thing for you to remember while participating in this study is that there are no right or wrong answers to the questions that the researcher asks.

\section{Discomforts}

The risks for participating in this study are minimal. You may experience discomfort with some topics raised in the interview. Questions about forms of discrimination can cause participants to feel anger, confusion, or resentment. In such cases, the researcher will provide you with additional resources to help you process your discomfort.

\section{Benefits}

The benefit of participating in this study is that you may learn some new things about yourself. You may also enjoy sharing your experiences as a NCAA Division I student-athlete. In addition, your participation in this study may help the researcher and others develop and promote more inclusive sport practices that could improve the experiences of student-athletes.

\section{Financial Considerations}

There are no special fees for participating in this study. If you complete the two interviews that are apart of this study. you will receive a \$25 Amazon gift card. If you withdraw before the end of the study, no payments will be made.

\section{Confidentiality}

Any information about you that is obtained as a result of your participation in this research will be kept as conlidential as legally possible. The researcher and the 3 to 4 other focus group participants will be the only people who know that you are participating in this study. You can choose to remain silent throughout the focus group if you feel uncomlortable or unwilling to share your experiences with other tocus group members. However, the focus group, regardless of your level of participation, will help you with your follow up individual interview.

Your research records, just like hospital records, may be subpoenaed by court order or may be inspected by federal regulatory authorities (including the FDA if applicable) without your additional consent. In addition, there are certain instances where the researcher is legally required to give information to the appropriate authorities. These would include mandatory reporting of infectious diseases, mandatory reporting of information about behavior that is imminently dangerous to your child or to others, such as suicide, child abuse, etc.

All the interviews will be audiotaped. Audiotape recordings of your interviews will be kept locked up and will be destroyed as soon as possible after the research is finished. In any publications that result from this research, neither your name nor any inlormation from which you might be identilied will be published without your consent.

\begin{tabular}{|c|c|}
\hline 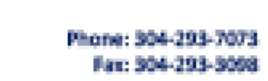 & 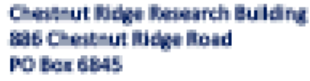 \\
\hline 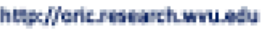 & Morgantowe, wV 20506-6Bes, \\
\hline
\end{tabular}

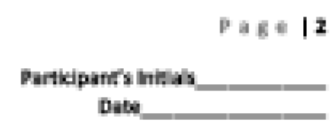


Human Research Protocol Only Minimal Risk Consent Form Without HIPAA

WestVirginiaUniversity.

\section{Voluntary Participation}

Participation in this study is woluntary. You are free to withdraw your consent to participate in this study at any time.

Refusal to participate or withdrawal will not affect your class standing or your team standing and will irvolve no penalty to you. Refusal to participate or withdrawal will not affect your future care, or your employee status at West Virginia University.

In the event new information becomes available that may affect your willingness to participate in this study, this information will be given to you so that you can make an inlormed decision about whether or not to continue your participation.

You have been given the opportunity to ask questions about the research, and you have received answers concerning areas you did not understand.

Upon signing this form, you will receive a copy-

I willingly consent to participate in this research.

\section{Signatures}

Signature of Participant

Printed Name Date Time

The participant has had the opportunity to have questions addressed. The participant willingly agrees to be in the study.

Signature of Investigator or Co-Investigator

Printed Name Date Time

\begin{tabular}{|c|c|c|c|}
\hline 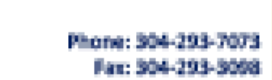 & 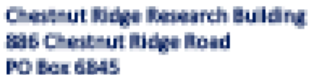 & & $P=5+13$ \\
\hline hespoleric-sestarch wouledu & Mor inntow, WV 26506-66es & Date & \\
\hline
\end{tabular}




\title{
Appendix L: Resources for Participants
}

\author{
West Virginia University Carruth Center for Psychological and Psychiatric Services \\ 304-293-4431 \\ http://well.wvu.edu/ccpps
}

COMMUNITY COUNSELING PROVIDERS

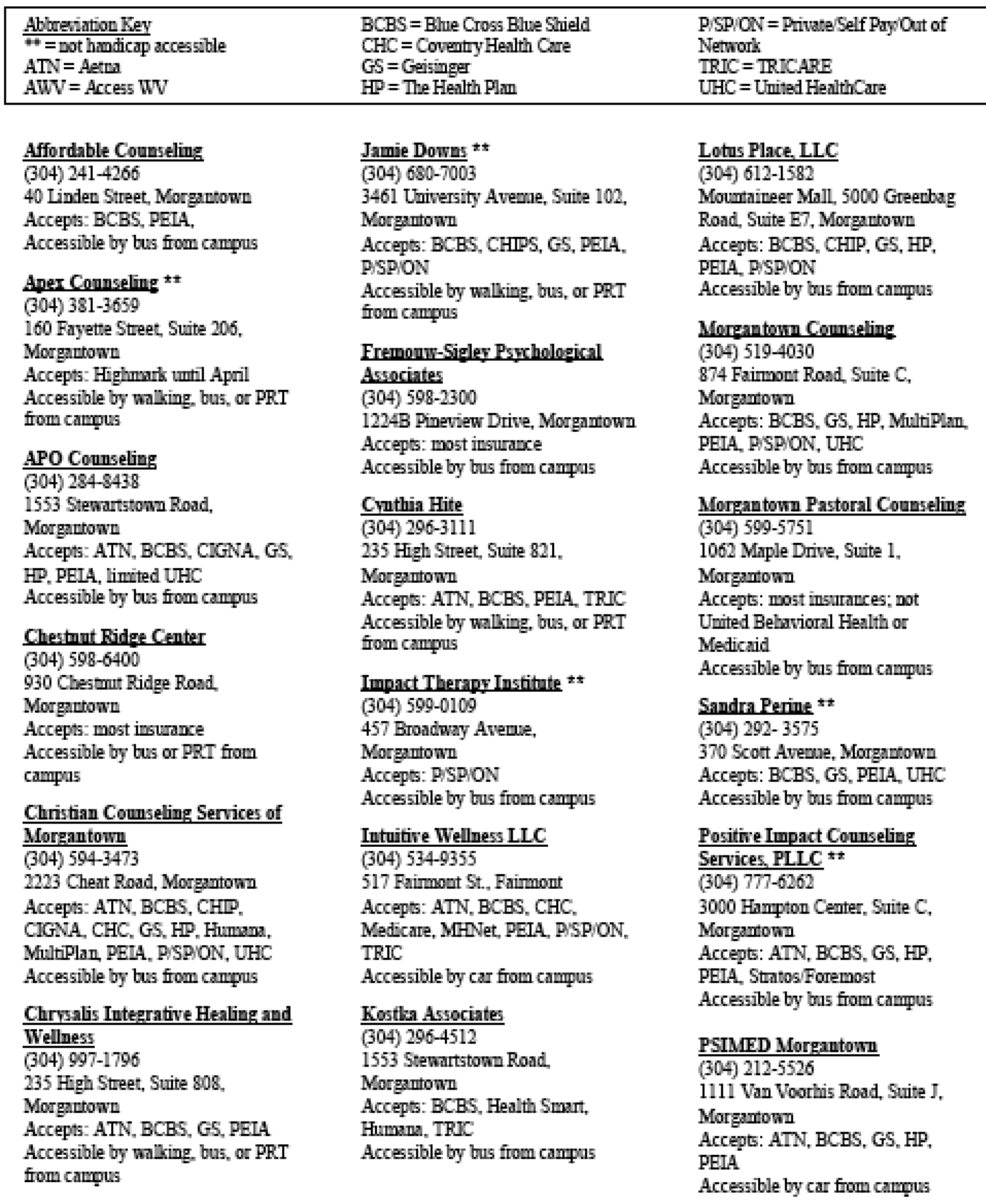




\section{COMMUNITY COUNSELING PROVIDERS}

Pswchology Associates, PLLC (304) $381-4168$

1286 Suncrest Towne Center, West

Entrance, $2^{\text {al }}$ Floor, Norgantown

Accepts: BCBS, PEIA

Accessible by car from campas

\section{Pswhotherapy Services of \\ Morgantown, PLIC \\ (304) 685-4631 \\ 1286 Suncrest Town Center Drive, \\ West Entrance, 2al Floor, \\ Morgantown \\ Accepts: BCBS, GS, Humana, \\ Medicare, MaltiPlan, PEIA, \\ PISPON, TRC \\ Accessible by car from campas}

\section{Quantum Change counseling and}

Mental Health

(304) $907-2673$

235 High Street, \#603 (Mon

Building), Morgantown

Accepts: AWV, BCBS, CHIP, HP.

Humana, PEIA

Accessible by walking, bus, or PRT

from campus

\section{Roots \& Harmony \\ (304) 460-5123 \\ 1005 White Willow Way. \\ Morgantown}

Accepts: ATN, BCBS, CHC, Cigpa, GS, HP, Meticare part B, PEIA,

TRIC. Workers Comp, some others Accessible by car from campas

\section{Valerie Stansberry *t}

(304) 290-0333 or (304) 291-9491

709 Beechurst Avemae, Suite 14-B,

Morgantown

Accepts: ATN, BCBS, CIGNA, GS, PELA, UHC

Accessible by walking, bus, or PRT from campus

\section{Holly Thomas, PLC}

(304) 362-6647

235 High Street, Suite 701,

Morgantown

Accepts: BCBS, GS, PEIA

Accessible by walking, bus, or PRT from campus
TIMKo Counseling Services,

LLC $^{ \pm \pm}$

(304) $841-0108$

517 Fairmout Avewe, Suite 2,

Fairmout

Accepts: BCBS, ComPsych GS,

Optum Health, PEIA, P/SP/ON,

UHC,

Accessible by car from campus

United Summit Center

(304) 241- 1708

40 Commerce Drive, Suite B,

Westover

Accepts: AARP, ATN, BCBS,

Champus, CHP, CIGNA, CHC, GS,

HP, Humana, Mental Health

Network, Mutual of Omahn, PEIA,

Stratos/Foremost, TRIC, UHC,

Value Options, WV Medicaid

Accessible by bus from campas

\section{Valley HealthCare System}

(304) 296-1731

301 Scott Aveme, Morgantown

Accepts: Nost insurance

Accessible by bus from campas

Shannon Waliser (2 locations, same phone mumber)

(304) $363-4265$

Accepts: BCBS, CHIP, PEIA,

P/SPION

- 235 High Street, Suite 223 ,

Morgantown

Accessible by walking bas, or

PRT from campus

- 207 Faimont Avemoe, Stuite 3,

Fairmont +*

Accessible by car from campus

Wedgewood Family Practice

(304) 599-1975

613 Buroughs Street, Norgantown

Accepts: BCBS, CHI, ComPsych,

GS, PEIA, P/SPION, THP, UHC

Accessible by bus or PRT from

campus

\section{West Virginia Fumily Grief}

Center

(304) 282-4935

361 Scott Aveme, Morgantown

Free ino cost

Accessible by bus from campus
WV Therapy \& Wellness Center

(304) 413-0426

235 High St. Suite 720 (euter in

Suite 719)

Morgantown, WV 26505

Accepts: BCBS, PEIA, UHC

Accessible by walking, bus, or PRT

from campas

\section{WVU Beharioral Medicine}

Healthy Minds

(304) 598-4433

6 Caryon Rd, Morgantown

Accepts: Most commercial insurance

Accessibly by car

Theresa Williams

(304) 216-1160

816 Somerser Street, Morgantown

Accept: ATN, BCBS, GS, HP,

PEIA,

Accessible by bus from campus

Women in Balance, Counseling \& Life Coaching

(304) 241-1097

3000 Coombs Farm Drive, Suite

102, Morgnitown

Accept: ATN, BCBS, CTGNA, GS, HP, Health Smart, PELA, P/SP/ON, TRIC UHC, some UNR. Health Accessible by bas from cammus 


\section{Appendix M: Extended References}

Abreu, J. M., Chung, R. H. G., \& Atkinson, D. R. (2000). Multicultural counseling training past, present, and future directions. The Counseling Psychologist, 28(5), 641-656. https://doi.org/10.1177/0011000000285003

Alabi, J. (2015). Racial microaggressions in academic libraries: Results of a survey of minority and non-minority librarians. Journal of Academic Librarianship, 41(1), 4753. https://doi.org/10.1016/j.acalib.2014.10.008

Allen, Q. (2010). Racial microaggressions: The schooling experiences of Black middle-class males in Arizona's secondary schools. Journal of African American Males in Education, 1(2), 125-143. Retrieved from http://digitalcommons.chapman.edu/education_articles/24/?utm_source=digitalcomm ons.chapman.edu\%2Feducation_articles\%2F24\&utm_medium=PDF\&utm_campaign $=$ PDFCoverPages

Allen, A., Scott, L. M., \& Lewis, C. W. (2013). Racial microaggressions and African American and Hispanic students in urban schools: A call for culturally affirming education. Interdisciplinary Journal of Teaching and Learning, 3(2), 117-129.

American Psychological Association (2000). Racial and Ethnic Health Disparities. Retrieved from http://www.apa.org/about/gr/issues/minority/disparity.aspx

Avner, Z. (2014). What can Foucault tell us about fun in sport? A Foucauldian critical examination of the discursive production and deployment of fun within varsity coaching contexts. (Doctoral dissertation, University of Alberta, Alberta, Canada). Retrieved from https://era.library.ualberta.ca/files/rb68xc09k/Avner_Zoe_201407_PhD.pdf

Balsam, K. F., Molina, Y., Beadnell, B., Simoni, J., \& Walters, K. (2011). Measuring multiple minority stress: The LGBT people of color microaggressions scale. Cultural 
Diversity and Ethnic Minority Psychology, 17(2), 163-174.

https://doi.org/10.1037/a0023244

Banks, K. H. (2014). "Perceived" discrimination as an example of color-blind racial ideology's influence on psychology. American Psychologist, 69(3), 311-313. https://doi.org/10.1037/a0035734

Bimper, A. Y. (2015). Lifting the veil: Exploring colorblind racism in black student athlete experiences. Journal of Sport and Social Issues, 39(3), 225-243. doi: $10.1177 / 0193723513520013$

Bonilla-Silva, E. (2006). Racism without racists: Color-blind racism and the persistence of racial inequality in the United States (2nd ed.). Lanham, MD: Rowman \& Littlefield Publishers.

Bredemeier, B. J., \& Shields, D. L. (1986). Game reasoning and interactional morality. The Journal of Genetic Psychology: Research and Theory on Human Development, 147(2), 257-275. https://doi.org/10.1080/00221325.1986.9914499

Brown, T. N., Jackson, J. S., Brown, K. T., Sellers, R. M., Keiper, S., \& Manuel, W. J. (2003). "There's no race on the playing field" Perceptions of racial discrimination among White and Black athletes. Journal of Sport \& Social Issues, 27(2), 162-183. doi: $10.1177 / 0193732502250715$

Burdsey, D. (2011). That joke isn't funny anymore: Racial microaggressions, color-blind ideology and the mitigation of racism in English men's first-class cricket. Sociology of Sport Journal, 28(3), 261-283. Retrieved from http://web.b.ebscohost.com/ehost/detail/detail?sid=46fa0661-95d3-46de-93cfa175f7e5e4b6\%40sessionmgr101\&vid=0\&hid=123\&bdata=JnNpdGU9ZWhvc3QtbG 12ZSZzY29wZT1zaXRl\#db=s3h\&AN=66736158 
Butryn, T. M. (2002). Critically examining white racial identity and privilege in sport psychology consulting. The Sport Psychologist, 16(3), 316-336. Retrieved from http://www.fitnessforlife.org/AcuCustom/Sitename/Documents/DocumentItem/2790. pdf

Butryn, T. M. (2009). (Re)examining whiteness in sport psychology through autonarrative excavation. International Journal of Sport and Exercise Psychology, 7(3), 323-341. Retrieved from https://www.researchgate.net/profile/Ted_Butryn/publication/254300977_Reexamini ng_whiteness_in_sport_psychology_through_autonarrative_excavation/links/573ce24 408aea45ee841a1fc.pdf

Campbell, B., \& Manning, J. (2014). Microaggression and moral cultures. Comparative Sociology, 13(6), 692-726. https://doi.org/10.1163/15691330-12341332

Clark, V. L. P., \& Creswell, J. W. (Eds.). (2008). The mixed methods reader. Thousand Oaks, CA: SAGE Publications.

Comeaux, E. (2012). Unmasking athlete microaggressions: Division I student-athletes' engagement with members of the campus community. Journal of Intercollegiate Sport, 5(2), 189-198. http://dx.doi.org/10.1123/jis.5.2.189

Connolly, W. E. (1985). I. Taylor, Foucault, and otherness. Political Theory, 13(3), 365-376.

Constantine, M. G., \& Sue, D. W. (2007). Perceptions of racial microaggressions among black supervisees in cross-racial dyads. Journal of Counseling Psychology, 54(2), 142-153. doi: 10.1037/0022-0167.54.2.142

Cooper, J. N. (2015). The value of qualitative approaches in the examination of Black male student athletes. Qualitative Research in Sport, Exercise and Health, 7(3), 361-376. https://doi.org/10.1080/2159676X.2014.888586 
Cooper, J. N., \& Dougherty, S. (2015). Does race still matter?: A post bowl championship series (BCS) era examination of student athletes' experiences at a division I historically Black college/university (HBCU) and predominantly White institution (PWI). Journal of Issues in Intercollegiate Athletics, 8, 74-101.

Crenshaw, K. (1991). Mapping the margins: Intersectionality, identity politics, and violence against women of color. Stanford Law Review, 43(6), 1241. https://doi.org/10.2307/1229039

Crocket, H. (2017). Problematizing Foucauldian ethics: A review of technologies of the self in sociology of sport since 2003. Journal of Sport and Social Issues, 41(1), 21-41. https://doi.org/10.1177/0193723516677617

Crotty, M. J. (1998). The foundations of social research: Meaning and perspective in the research process. Thousand Oaks, CA: SAGE Publications.

Delapp, R., C. T. (2015). Professional challenges facing African American psychologists: The presence and impact of racial microaggressions. The Behavior Therapist, 38(4), $101-105$.

Donovan, R. A., Galban, D. J., Grace, R. K., Bennett, J. K., \& Felicie, S. Z. (2013). Impact of racial macro- and microaggressions in Black Women's Lives: A preliminary analysis. Journal of Black Psychology, 39(2), 185-196. https://doi.org/10.1177/0095798412443259

Dortants, M., \& Knoppers, A. (2013). Regulation of diversity through discipline: Practices of inclusion and exclusion in boxing. International Review for the Sociology of Sport, $48(5), 535-549$.

Dovidio, J. F., \& Gaertner, S. L. (2000). Aversive racism and selection decisions: 1989 and 1999. Psychological Science, 11(4), 315-319. https://doi.org/10.1111/14679280.00262 
Eitzen, D. S. (1996). Classism in sport: The powerless bear the burden. Journal of Sport and Social Issues, 20(1), 95-105. https://doi.org/10.1177/019372396020001008

Ellingson, L. L. (2008). Engaging crystallization in qualitative research: An introduction. Thousand Oaks, CA: SAGE Publications.

Fisher, L. A., Butryn, T. M., \& Roper, E. A. (2003). Diversifying (and politicizing) sport psychology through cultural studies: A promising perspective. The Sport Psychologist, 17(4), 391-405.

Foucault, M. (1990). The history of sexuality, Vol. 1: An introduction. New York, NY: Vintage.

Foucault, M. (1995). Discipline and punish: The birth of the prison (2 ed.). New York, NY: Vintage Books.

Friedersdorf, C. (2015a, September 11). The rise of victimhood culture. The Atlantic. Retrieved from http://www.theatlantic.com/politics/archive/2015/09/the-rise-ofvictimhood-culture/404794/

Friedersdorf, C. (2015b, September 14). Why critics of the "microaggressions" framework are skeptical. The Atlantic. Retrieved from http://www.theatlantic.com/politics/archive/2015/09/why-critics-of-themicroaggressions-framework-are-skeptical/405106/

Gearity, B. T., \& Mills, J. P. (2012). Discipline and punishment in the weight room. Sport Coahing Review, 1(2), 124-134. https://doi.org/http://dx.doi.org/10.1080/21640629.2012.746049

Gearity, B. T., \& Metzger, L. H. (2017). Intersectionality, microaggressions, and microaffirmations: Towards a cultural praxis of sport coaching. Sociology of Sport Journal, Advance online publication. 1-41. http://dx.doi.org/10.1123/ssj.2016-0113 
Gill, D. L. (2001). Feminist sport psychology: A guide for our journey. The Sport Psychologist, 15(4), 363-372.

Gomez, M. L., Khurshid, A., Freitag, M. B., \& Lachuk, A. J. (2011). Microaggressions in graduate students' lives: How they are encountered and their consequences. Teaching and Teacher Education, 27(8), 1189-1199. https://doi.org/10.1016/j.tate.2011.06.003

Grier-Reed, T. L. (2010). The African American student network: Creating sanctuaries and counterspaces for coping with racial microaggressions in higher education settings. The Journal of Humanistic Counseling, Education and Development, 49(2), 181-188. https://doi.org/10.1002/j.2161-1939.2010.tb00096.x

Gutting, G. (2005). Foucault: A very short introduction. Oxford, UK: Oxford University Press.

Hackett, C. D. (2013). Constructing an understanding of Black student athletes' achievement concerns at a private Hispanic serving institution. Journal of African American Males in Education, 4(1), 62-77.

Harris, R. S. (2009). Racial microaggression? How do you know?-Revisited. American Psychologist, 64(3), 220-220. https://doi.org/10.1037/a0014749

Harris, R. S. J. (2008). Racial microaggression? How do you know? American Psychologist, 63(4), 275-276. https://doi.org/10.1037/0003-066X.63.4.275

Healy, J. (2014). Messages between Jonathan Martin and parents detail issues former Dolphin faced. NY Daily News. Retrieved from http://www.nydailynews.com/sports/football/text-martin-parents-struggle-depressionarticle-1.1614955

Huynh, V. W. (2012). Ethnic microaggressions and the depressive and somatic symptoms of Latino and Asian American adolescents. Journal of Youth and Adolescence, 41, 831846. https://doi.org/10.1007/s10964-012-9756-9 
Johnston, M. P., \& Nadal, K. L. (2010). Multiracial microaggressions: Exposing monoracism in everyday life and clinical practice. In D. W. Sue (Ed.), Microaggressions and marginality: Manifestation, dynamics, and impact (pp. 123-144). Retrieved from http://works.bepress.com/marc_johnston/3/

Jones, L., \& Toner, J. (2016). Surveillance technologies as instruments of discipline in the elite sports coaching context: A cautionary post-structural commentary. Sensoria: A Journal of Mind, Brain \& Culture, 12(2), 13-21. Retrieved from http://sensoria.swinburne.edu.au/index.php/sensoria/article/view/439

Jordan, T. A. (2010). The impact of racial microaggressions on Black athletes: Implications for counseling and sport psychology (Master's thesis, Georgia Southern University). Retrieved from http://digitalcommons.georgiasouthern.edu/cgi/viewcontent.cgi?article=1110\&context $=$ etd

Kamphoff, C. S., Gill, D. L., Araki, K., \& Hammond, C. C. (2010). A content analysis of cultural diversity in the Association for Applied Sport Psychology's conference programs. Journal of Applied Sport Psychology, 22(2), 231-245.

Kavoura, A., Ryba, T. V., \& Chroni, S. (2015). Negotiating female judoka identities in Greece: A Foucauldian discourse analysis. Psychology of Sport and Exercise, 17, 8898. https://doi.org/10.1016/j.psychsport.2014.09.011

Krane, V., \& Barber, H. (2005). Identity tensions in lesbian intercollegiate coaches. Research Quarterly for Exercise and Sport, 76(1), 67-81. https://doi.org/10.1080/02701367.2005.10599263

Lee, S. (2015). Cultural competence development in sport and exercise psychology graduate programs. Athletic Insight, 7(3), 269-289. 
Liamputtong, P. (2006). Researching the vulnerable: A guide to sensitive research methods. Thousand Oaks, CA: SAGE Publications.

Lilienfeld, S. O. (2017). Microaggressions: Strong claims, inadequate evidence. Perspectives on Psychological Science, 12(1), 138-169.

Lorenzo, S. (2014, February 12). Richie Incognito rants on Twitter about Jonathan Martin, says Dolphins teammate was suicidal. NY Daily News. Retrieved from http://www.nydailynews.com/sports/football/incognito-blasts-martin-teammatesuicidal-article-1.1611901

Madriz, E. (2000). Focus groups in feminist research. In N. K. Denzin \& Y. S. Lincoln (Eds.), The handbook of qualitative research ( $2^{\text {nd }}$ ed., pp. 835-850). Thousand Oaks, CA: SAGE Publications.

Markula, P. (2003). The technologies of the self: Sport, feminism, and Foucault. Sociology of Sport Journal, 20(2), 87-107.

Markula, P., \& Silk, M. (2011). Qualitative research for physical culture. London, UK: Palgrave Macmillan. doi: 10.1057/9780230305632

Markula, P., \& Pringle, R. (2006). Foucault, sport and exercise: Power, knowledge and transforming the self. New York, NY: Routledge.

McCabe, J. (2009). Racial and gender microaggressions on a predominantly-White campus: Experiences of Black, Latina/o and White undergraduates. Race, Gender \& Class, 16(1/2), 133-151. Retrieved from http://s3.amazonaws.com/academia.edu.documents/31149058/racial_and_gender_mic ro.pdf?AWSAccessKeyId=AKIAIWOWYYGZ2Y53UL3A\&Expires=1492745250\& Signature=KWBPvePSegapn2fepPLEvT1JolI\%3D\&response-contentdisposition=inline $\% 3 \mathrm{~B} \% 20$ filename\%3DRacial_and_Gender_Microaggressions_on_ a.pdf 
McDonald, M. G. (2012). Thinking through sport, analyzing whiteness. Journal of Multicultural Discourses, 7(3), 235-241. https://doi.org/10.1080/17447143.2012.699530

Mcgannon, K. R., \& Busanich, R. (2010). Rethinking subjectivity in sport and exercise psychology: A feminist post-structuralist perspective on women's embodied physical activity. In T. V. Ryba, R. J. Schinke, \& G. Tenenbaum (Eds.), The cultural turn in sport psychology (pp. 203-229). Morgantown, WV: Fitness Information Technology. Retrieved from https://www.researchgate.net/publication/257959295_Rethinking_subjectivity_in_spo rt_and_exercise_psychology_A_feminist_poststructuralist_perspective_on_women's_embodied_physical_activity

McGannon, K. R., \& Mauws, M. K. (2000). Discursive psychology: An alternative approach for studying adherence to exercise and physical activity. Quest, 52(2), 148-165.

McGannon, K. R., \& Schinke, R. J. (2013). "My first choice is to work out at work; then i don't feel bad about my kids": A discursive psychological analysis of motherhood and physical activity participation. Psychology of Sport and Exercise, 14(2), 179-188. https://doi.org/10.1016/j.psychsport.2012.10.001

McGannon, K. R., \& Smith, B. (2015). Centralizing culture in cultural sport psychology research: The potential of narrative inquiry and discursive psychology. Psychology of Sport and Exercise, 17(0), 79-87.

McGannon, K. R., \& Spence, J. C. (2010). Speaking of the self and understanding physical activity participation: What discursive psychology can tell us about an old problem. Qualitative Research in Sport and Exercise, 2(1), 17-38. https://doi.org/10.1080/19398440903510145 
Melendez, M. C. (2008). Black football players on a predominantly White college campus: Psychosocial and emotional realities of the Black college athlete experience. Journal of Black Psychology, 34(4), 423-451. https://doi.org/10.1177/0095798408319874

Mihoces, G. (2013, November 6). Dolphins players defend Incognito, question Martin in bullying case. USA TODAY. Retrieved from http://www.usatoday.com/story/sports/nfl/dolphins/2013/11/06/miami-dolphinsjonathan-martin-richie-incognito-locker-room/3458891/

Mills, J. P. (2014). Soldiers, animals and machines: A Foucauldian analysis of the making of the contemporary endurance running body. (Doctoral dissertation, University of Alberta, Alberta, Canada). Retrieved from https://era.library.ualberta.ca/downloads/d791sg391

Murray, K. (2013). Microaggression as Foucaultian subjectivism: A critical race analysis of the classroom dynamic. Journal of Philosophy \& History of Education, 63(1), 59-68.

Nadal, K. L. (2008). Ethnic group membership, phenotype, and perceptions of racial discrimination for Filipino and Chinese Americans: Implications for mental health (Doctoral dissertation, Columbia University). Retrieved from http://eaop.ucsd.edu/198/groupidentity/Ethnic\%20group\%20membership,\%20phenotype,\%20and\%20perceptions \%2 0of $\% 20$ racial $\%$ 20discrimination $\% 20$ for $\% 20$ Filipino $\% 20$ and $\% 20$ Chinese $\% 20$ Americ ans.pdf

Nadal, K. L., Wong, Y., Sriken, J., Griffin, K., \& Fujii-Doe, W. (2015). Racial microaggressions and Asian Americans: An exploratory study on within-group differences and mental health. Asian American Journal of Psychology, 6(2), 136-144. https://doi.org/10.1037/a0038058 
Offermann, L. R., Basford, T. E., Graebner, R., Jaffer, S., De Graaf, S. B., \& Kaminsky, S. E. (2014). See no evil: Color blindness and perceptions of subtle racial discrimination in the workplace. Cultural Diversity \& Ethnic Minority Psychology, 20(4), 499-507. https://doi.org/10.1037/a0037237

Parham, W. D. (2009). African-descendent collegiate athletes: An invitation to respond to their visibility. In E. F. Etzel (Ed.), Counseling and psychological services for college student-athletes (pp. 215-237). Morgantown, WV: Fitness Information Technology.

Patton, M. Q. (2014). Qualitative research \& evaluation methods: Integrating theory and practice (4 ed.). Thousand Oaks, CA: SAGE Publications.

Pérez Huber, L., \& Solorzano, D. G. (2015). Racial microaggressions as a tool for critical race research. Race Ethnicity and Education, 18(3), 297-320. https://doi.org/10.1080/13613324.2014.994173

Phillips, B. (2013, November 7). Man up. Grantland. Retrieved from http://grantland.com/features/richie-incognito-jonathan-martin-miami-dolphinsbullying-scandal/

Pierce, C. M., Carew, J. V., Pierce-Gonzalez, D., \& Wills, D. (1977). An experiment in racism TV commercials. Education and Urban Society, 10(1), 61-87.

Rainey, D. W. (2012). Sport's officials' reports of hearing trash talk and their responses to trash talk. Journal of Sport Behavior, 35(1), 78-93.

Rainey, D. W., \& Granito, V. (2010). Normative rules for trash talk among college athletes: An exploratory study. Journal of Sport Behavior, 33(3), 276-294.

Ram, N., Starek, J., \& Johnson, J. (2004). Race, ethnicity, and sexual orientation: Still a void in sport and exercise psychology? Journal of Sport and Exercise Psychology, 26(2), 250-268. https://doi.org/10.1123/jsep.26.2.250 
Richardson, L. (2000). Writing: A method of inquiry. In N. K. Denzin \& Y. S. Lincoln (Eds.), The handbook of qualitative research ( ${ }^{\text {nd }}$ ed., pp. 923-948). Thousand Oaks, CA: SAGE Publications.

Ronkainen, N. J., Kavoura, A., \& Ryba, T. V. (2016a). A meta-study of athletic identity research in sport psychology: Current status and future directions. International Review of Sport and Exercise Psychology, 9(1), 45-64.

Ronkainen, N. J., Kavoura, A., \& Ryba, T. V. (2016b). Narrative and discursive perspectives on athletic identity: Past, present, and future. Psychology of Sport and Exercise, 27, 128-137. https://doi.org/10.1016/j.psychsport.2016.08.010

Roy, A., \& Ryba, T. V. (2012). Curb your enthusiasm: A case of young Malaysian women's emotional embodiment. Women in Sport \& Physical Activity Journal, 21(1), 50-60.

Ryba, T., Schinke, R. J., \& Tenenbaum, G. (Eds.). (2010). The cultural turn in sport psychology. Morgantown, WV: Fitness Information Technology.

Ryba, T. V., \& Schinke, R. J. (2009). Methodology as a ritualized eurocentrism: Introduction to the special issue. International Journal of Sport \& Exercise Psychology, 7(3), 263274.

Ryba, T. V., Stambulova, N. B., Si, G., \& Schinke, R. J. (2013). ISSP position stand: Culturally competent research and practice in sport and exercise psychology. International Journal of Sport and Exercise Psychology, 11(2), 123-142.

Sage, G. H., \& Eitzen, D. S. (2015). Sociology of North American sport (10 ed.). New York, NY: Oxford University Press.

Salvatore, J., \& Shelton, J. N. (2007). Cognitive costs of exposure to racial prejudice. Psychological Science, 18(9), 810-815.

Solórzano, D., Ceja, M., \& Yosso, T. (2000). Critical race theory, racial microaggressions, and campus racial climate: The experiences of African American college students. 
The Journal of Negro Education, 69(1), 60-73.

https://doi.org/10.1080/095183998236926

Sue, D. W., Bucceri, J., Lin, A. I., Nadal, K. L., \& Torino, G. C. (2007a). Racial microaggressions and the Asian American experience. Cultural Diversity and Ethnic Minority Psychology, 13(1), 72-81. https://doi.org/10.1037/1099-9809.13.1.72

Sue, D. W., Capodilupo, C. M., Torino, G. C., Bucceri, J. M., Holder, A. M. B., Nadal, K. L., \& Esquilin, M. (2007b). Racial microaggressions in everyday life: Implications for clinical practice. American Psychologist, 62(4), 271-286.

https://doi.org/10.1037/0003-066X.62.4.271

Sue, D. W. (2010). Microaggressions in everyday life: Race, gender, and sexual orientation. Hoboken, N.J: Wiley.

Thomas, K. R. (2008). Macrononsense in multiculturalism. American Psychologist, 63(4), 274-275. https://doi.org/10.1037/0003-066X.63.4.274

van Sterkenburg, J., \& Knoppers, A. (2004). Dominant discourses about race/ethnicity and gender in sport practice and performance. International Review for the Sociology of Sport, 39(3), 301-321. https://doi.org/10.1177/1012690204045598

van Sterkenburg, J., \& Knoppers, A. (2012). Sport as a contested racial/ethnic discourse:

Processes of racialization in Dutch sport media and sport policy. Journal of Multicultural Discourses, 7(2), 119-136.

https://doi.org/10.1080/17447143.2012.687001

Weedon, C. (1997). Feminist practice and poststructuralist theory (2 ed.). Hoboken, N.J: Wiley-Blackwell.

Wells, T. V., Karp, B. S., Birenboim, B., \& Brown, D. W. (2014, February 14). Report to the National Football League concerning issues of workplace conduct at the Miami 
Dolphins. Retrieved from http://63bba9dfdf9675bf3f10-

68be460ce43dd2a60dd64ca5eca4ae1d.r37.cf1.rackcdn.com/PaulWeissReport.pdf

Whaley, D. E., \& Krane, V. (2012). Resilient excellence: Challenges faced by trailblazing women in U.S. sport psychology. Research Quarterly for Exercise and Sport, 83(1), 65-76. https://doi.org/10.1080/02701367.2012.10599826

Wilchins, R. (2004). Queer theory, gender theory: An instant primer. Bronx, NY: Magnus Books.

Wilkinson, S. (1999). Focus groups: A feminist method. Psychology of Women Quarterly, 23(2), 221-244. https://doi.org/10.1111/j.1471-6402.1999.tb00355.x

Willig, C. (1998). Constructions of sexual activity and their implications for sexual practice lessons for sex education. Journal of Health Psychology, 3(3), 383-392.

Willig, C. (2013). Foucauldian discourse analysis. In C. Willig (Ed.) Introducing qualitative research in psychology (3rd ed., pp. 129-142). New York, NY: McGraw-Hill Education.

Wong, G., Derthick, A. O., David, E. J. R., Saw, A., \& Okazaki, S. (2014). The what, the why, and the how: A review of racial microaggressions research in psychology. Race and Social Problems, 6, 181-200. http://doi.org/10.1007/s12552-013-9107-9

Yosso, T. J., Smith, W. a, Ceja, M., \& Solórzando, D. G. (2009). Critical race theory, racial microaggressions, and campus racial climate for latina/o undergraduates. Harvard Educational Review, 79(4), 659-691.

Yu, A. B., Nguyen, T., \& Petrie, T. (2016). The Jeremy Lin effect: Being an Asian sport psychology consultant in a Black and White world. Journal of Clinical Sport Psychology, 10(4), 289-308. https://doi.org/10.1123/jcsp.2016-0006 